\title{
NON-LINEAR ANALYSIS \\ IN \\ LIGHT WATER REACTOR \\ DESIGN
}

MASTER

Prepared For

SANDIA LABORATORIES

Albuquerque, New Mexico

\section{ANATECH INTERNATIONAL CORP.}

La Jolla, California 



\section{DISCLAIMER}

This report was prepared as an account of work sponsored by an agency of the United States Government. Neither the United States Government nor any agency Thereof, nor any of their employees, makes any warranty, express or implied, or assumes any legal liability or responsibility for the accuracy, completeness, or usefulness of any information, apparatus, product, or process disclosed, or represents that its use would not infringe privately owned rights. Reference herein to any specific commercial product, process, or service by trade name, trademark, manufacturer, or otherwise does not necessarily constitute or imply its endorsement, recommendation, or favoring by the United States Government or any agency thereof. The views and opinions of authors expressed herein do not necessarily state or reflect those of the United States Government or any agency thereof. 


\section{DISCLAIMER}

Portions of this document may be illegible in electronic image products. Images are produced from the best available original document. 
ALO-64

ANA 79-3

\section{NON-LINEAR ANALYSIS \\ IN \\ LIGHT WATER REACTOR \\ DESIGN}

\author{
$Y$. R. Rashid \\ M. N. Sharabi \\ R. E. Nickell \\ E. P. Esztergar \\ J. W. Jones
}

Prepared by

ANATECH International Corp. La Jolla, California

\section{Prepared for}

U. S. Department of Energy

Light Water Reactor Safety Technology Management Center

Sandia National Laboratories

Albuquerque, New Mexico 87185

\section{Sponsored by}

U. S. Department of Energy

Division of Nuclear Power Development Washington, D.C. 20545

Work performed under Sandia Contract No. 42-0648

Printed: March 1980 
$\bullet$

. 
SUMMARY. . . . . . . . . . . . . . . . . . 1

INTRUIDUCTION ................... 3

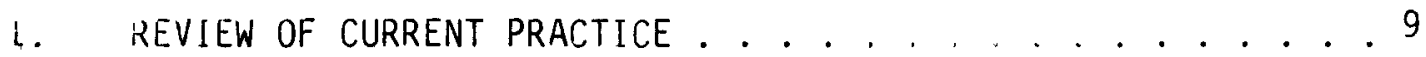

l. 1 BASIS FOR CURRENT PRACTICE. . . , , . . 9

1.2 REVIEW OF CODE STRESS BASES IN LWR DESIGN PRACTICF. . . 13

1.2.1 Primary Stress Limits. . . . . . . . . . 15

1.2.2 Secondary Stress Limits. . . . . . . . . . 16

1.2.3 Peak Strass Limits............ . . 16

1.3 REVIEW OF DEVELOPMENT OF DESIGN SPECIFICATIONS AND

LOADING CONDITIONS. . . . . . . . . . . . . . 17

1.4 FRACTURE MECHANICS APPLICATIONS . . . . . . 28

1.5 SUMMARY OF THE APPLICABILITY AND EXPECTED

BENEFITS OF NON-LINEAR ANALYSIS METHODS IN SAFETY

ANALYSIS OF LWR COMPONENTS. . . . . . . . . . . . 32

1.5.1 Economics. . . . . . . . . . . . 32

1.5.2 Resolution of Outstanding Safety Issues. . . . 34

1.5.3 Functional Requirements of Mechanical Components.............. 37

2. NON-LINEAR ANALYSIS. . . . . . . . . . . . . . 39

2.1 MATERIAL MODELS FOR LWR ELASTIC-PLASTIC ANALYSIS. . . . 41

2.2 SOIL MODELING FOR NON-LINEAR SOIL-STRUCTURE

INTERACTION SEISMIC ANALYSIS. . . . . . . . . . . . 47

2.3 GEOMETRIC NON-LINEARITIES . . . . . . . . . . . . 50

$\therefore 4$ GEOMETRIC FEATURES AND COST LONSIDERATIONS. . . . . . 53

2.5 ANALYSIS EXAMPLES . . . . . . . . . . 55

2.5.1 Snakedown Analysis............ . 56

2.5.2 Containment Buckling Analysis. . . . . . . 63 


\section{Page}

\subsubsection{Effects of Soil Non-Linearity on}

Seismic Response........... 73

2.6 NON-LINEAR FRACTURE MECHANICS . . . . . . . . . 81

2.7 SUMMARY OF NON-LINEAR APPLICATIONS IN LWR DESIGN. . . 86 ATTACHMENT I . . . . . . . . . . . 89 ATTACHMENT II. . . . . . . . . . . . . . . 92 REFERENCES ...................... . 98 


\section{LIST OF FIGURES}

Fijure Page.

1 Sample Load Taple. . . . . . . . . . . . . 22

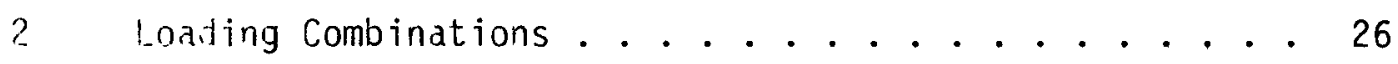

3 Stress-Strain and Yield Surface, . . . . 44

4 Sherr Modulus of Derse Sands ........... . 48

; Arificial Earthquake Acceleration . . . . . . . . 51

; inite Element Idealization. . . . . . . . 57

7 Erfective Plastic Strains. . . . . . . . . 60

i3 Effective Stress-Strain Curve. . . . . . . . . 61

9 Hoop Stress-Strain Curve . . . . . . . . . . 62

10 Buckling Load vs Initial Imperfection. . . . . . 66

11 Geometry and Sign Convention for Spherical Cap . . . . 72

12. Dynamic Model and Soil Properties. ......... 76

13 Dynamic Response Curves. . . . . . . . . . . 80

If Surface Response Spectrum. . . . . . . . . 82 
1 Sumnary and Ratings of Expected Benerits of Non-i inear Analysis. ............... 38

2 Comparison of Linear and Non-Linear Responses, . . . 79

3 Comparison of Surface Accelerations for Shake and Stealth Analyses............. . . 79

4 Summary of Non-Linear Analysis Application . . . . . 88 


\section{PREFACE}

This report summarizes the results obtained from a scoping study sponsored by the U. S. Department of Energy (DOE) under the Light Water Reactor (LWR) Safety Technology Program at Sandia National Laboratories. Basically, this project calls for the examination of the hypothesis that the use of nonlinear analysis methods in the design of LWR systems and components will lead to potential economic and safety benefits. LWR systems and components of interest include such items as: the reactor vessel, vessel internals, nozzles and penetrations, component support structures, and containment structures. Piping systems are excluded because they are being addressed by a separate study.

In order to get a broad perspective, three contracts were placed with industrial organizations with expertise in this particular problem area. The three contractors were: ANATECH International Corporation, O'Donnell Associates, Inc., and Teledyne Engineering Services. A time period of approximately three and one-half months was allowed for each contract.

Essentially, the findings were that nonlinear analysis methods are beneficial to LWR design from a technical point of view. However, the costs needed to implement these methods are the roadblock to readily adopting them. In this sense, a costbenefit type of analysis must be made on the various topics identified by these studies and priorities must be established. The bulk of the three reports addressed this point in detail. This document is the complete report by ANATECH International Corporation: Comments are welcome and should be addressed to the DOE LWR Safety Technology Program, Technical Management Center, Sandia National Laboratories, Division 4443, Albuquerque, New Mexico 87185 . 
우 


\section{SUMMARY}

The purpose of this report is to provide a preliminary evaluation of the role of non-linear analysis in light water reactors design to identify areas where present practices can be improved by the use of non-linear analysis methods. These improvements would lead to the following changes from current practices:

a) More accurate evaluation of the calculated stress and strain quantities traditionally regarded (by the ASME Code) as defining structural response in terms of shakedown, collapse or limit load definitions;

b) More accurate evaluation of the simplifying assumptions concerning the boundary conditions that affect the loading levels such as treatment of soil-structure interaction in defining seismic loads;

c) Introduction of the capability to calculate other (or newer) quantities that can quantify damage progression and failure conditions by application of non-linear fracture mechanics;

d) Make better use of the Code rules with the aid of more accurate analysis to develop improved design economy and safety;

e) Development of more reliable bases for load combination procedure to replace pseudo-elastic techniques currently in use.

The report is presented in two parts. Part I contains a review of current practices (discussed in terms of the Standard Review Plan), load level identification and load envelops, and the description of the underlying assumptions in current practice as they are influenced by design-by-analysis methodology and failure mode definitions. Fron these discussions, the targets for possible improvements by application of non-linear analyses are 
identified and representative analysis tasks are selected. Part II deals with the demonstration of the utility of non-linear analys is in LWR applications. The state of the art is briefly examined and material models and geometric features that could constitute practical targets for non-linear analysis are discussed. Numerical analyses to demonstrate the application of non-linear methods to LWR's are presented. 
The design analysis process of nuclear power plants of ten folows a lengthy path before it reaches the final stage of comparing calculated stresses with ASME Code allowables. At each step in the process, the analyst introduces a series of conservative assumptions which, when combined with linear analysis, can produce large conservatisms in the final design. It is interesting to note, however, that despite the precise analyses performed the true final safety margin is in many instances only qualitatively known. This is because true safety margins can on ly be determined through detailed non-linear analyses, which are not ordinarily part of the design process of LWR power plants. Conservatisms, and consequently safety margins, depend also on the assumptions made in load definitions which in many cases are done through analyses such as, for example, seismic loads on reactor internals, blowdown loads on the primary loop and containment, etc. Therefore loadings that are not directly determined by physical data, but by structural and hydrodynamic analyses, are always subject to re-evaluation. Consequently, any improvements in the analysis through the use of appropriate non-linear modeling result in a more accurate load definition and, hence, improved final design.

The design use of non-linear analyses in LWR Systems beyond the admissible range of the ASME Code, has traditionally been reserved for two main applications: Firstly, in the interpretation of field failures when they unexpectedly occur, and secondly, in a posteriori demonstration of design adequacy under new loads not previously considered. Non-linear analysis, properly utilized, can play a greater role in nuclear components design, such as, for example, to develop stronger licensing positions or to better quantify safety margins for critical components requiring design modifications.

A broader, but perhaps longer range, utility of non-linear analysis is to legislate it into the usual design process. However, the resolution of ensuing problems would be time consuming. For example, the highly specialized nature of these analyses, the material data requirements, the associated 
engineering and computer cost, the non-unique and diverse modeling approaches, etc., are some of the problems for which general consensus in the technical community would be difficult to achieve. Perhaps a more achievable goal would be to use non-linear analys is to produce more realistic Design Standards, particularly for faulted and transient conditions. Irrespective of their target uses, however, non-linear analys is methods, to be generally feasible, must conform to certain acceptance standards. These might be:

a) Qualified state of the art methods

b) Generally available and relatively economical numerical procedures

c) Reasonably valid constitutive models and material data

The basic framework of LWR analysis methods can be divided into two areas: ASME Code related analyses and supplementary evaluations of the requirements of Regulatory Guides. The ASME Code criteria are based on "failure mode" concepts and a system of implicit safety factors that result from the overlaping allowable stress and distortion limits. The Code design rules link the failure modes to analytical requirements by the stress categories of primary, secondary, and peak stresses.

Primary stresses are those which can cause tensile instability or buckling. The analysis requires equilibrium consideration.

Secondary stresses can result in ratchetting and incremental plastic collapse. The analys is rules require compatibility considerations and demonstration of shakedown.

Peak stresses govern the initiation of fatigue cracks. The analys is methods provide an estimate of the elastic-plastic-strain range in terins of pseudo-elastic stress intensities and corresponding fatigue limits.

The primary stress limits for very ductile materials (e.g., austenitic stainless steels) are adjusted by strain limiting factors which are strongly linked to the type of non-linear analysis performed, 
particularly for level C and D (faulted) loading conditions. Large economic benefits are expected from accurate non-linear-analys is-based load combination rules and limit-condition definition for these off-normal conditions.

Linear analysis is used in the evaluation of secondary stresses because the secondary stress limits are currently based on a shakedown criterion of twice the yield stress derived from first-cycle shakedown limit for non-strain-hardening materials. This limit, however, is very restrictive for austenitic materials which have low yield strength but exhibit strong work hardening capacity. Non-linear-analysis-based shakedown limits can replace the current requirements.

The limits on peak stresses are aimed at controlling fatigue crack initiation that is directly related to stresses. Because of the linearizing assumption underlying the primary and secondary stress limits, the magnitude of the peak stresses are only remotely (even though conservatively) related to the plastic strains controlling the fatigue damage mechanisms. Non-linear analysis can supply directly the physically meaningful fatigue damage accumulation parameters.

For level $C$ and $D$ loading conditions, the safety considerations require crack propagation evaluation in addition to the fatigue analysis. The current linear peak stress limits are either irrelevant or excessively conservative for a strain history dependent crack growth evaluation procedure. Significant economic and procedural benefits are expected from non-linear-strain analys is and life evaluation criteria.

This brief discussion shows that the prevention of structural failure of any piece of equipment involves much more than just the choice of a safe value for design stress. The rules of the ASME Code for example, are intended to prevent failure by the following mechanisms [1].

(1) Excessive elastic deformation including elastic instability

(2) Excessive plastic deformation

(3) Brittle fracture 
(4) Stress rupture/creep deformation (inelastic)

(5) Plastic instability incremental collapse

(6) High strain-low cycle fatigue

(7) Stress corrosion

(8) Corrosion fatigue

In every category except the latter two, the stress limits imposed are based upon elastically calculated stresses. Clearly, it is unreasonable to expect that a uniform safety factor for all types of failure can be obtained by imposing limits on elastically calculated stresses.

It can be stated, on the bas is of the above discussion, that the current state of design and analys is practice for LWR systems are governed by, firstly, strict adherence to the ASME Code, and, secondly, conforming to the NRC Regulatory Guides which, though not mandatory, are taking on de facto mandatory status. This state of the practice is reviewed in this report for LWR components other than piping. The ASME Boiler and Pressure Vessel Code, Section III, design and analysis procedures, plus the supplementary requirements imposed in the form of regulatory guides and other documents are reviewed and sumarized as they pertain to LWR systems and components. Such systems and components include reactor vessels and internals, nozzles and penetrations, component support structures, and containment structures. Also, assumptions made in developing the current design practices are reviewed and described. Typical assumptions are those related to primary and secondary stress categories, and the self-limiting nature of some of these stresses. Another assumption relates to the use of either average or minimum material properties, depending upon the particular failure mode being designed against.

There are many LWR systems and components in which significant design improvements could be made by the use of inelastic analys is. The report discusses some of these including design of reinforcement for penetrations, areas of discontinuities, reactor contaminents and soilstructure interaction. 
As is well known, non-linear analysis can be time consuming and costly. More importantiy, however, the state of the art of non-linear analysis has not yet matured to a level where it can be applied routinely. Constitutive and material modeling, for example, differ considerably from one computer code to another. In many instances, it is the programing and numerical simplicity rather than the true phenomenological material behavior that govern the computer analysis. Earlier in this decade, when inelastic analyses were made part of RDT standard for LMFBR high temperature design, inelastic material behavior was brute-forced numerically into existing finite element computer codes. Since then significant progress and sophistication have been made, but many areas still remain in the domain of the "experts". In some instances, even the computer output requires appropriate interpretation before design judgements can be made. It is therefore, important to maintain an attitude of realism with regard to the use of non-linear analysis in LWR components design. The work described in this report deals with this general area from three aspects: Geometric features that are amenable to non-linear analysis, realistic material modeling, and the assessment of potential benefits of non-linear analyses.

Geometric features and structural characteristics which are within acceptable state-of-the-art non-linear analys is are identified. These include, nozzles, flawed sections, imperfection-sensitive components, and inherently non-linear structural systems such as soil structure interaction and plastic crack growth.

Material data requirements for non-linear analyses can be easily satisfied by currently available stress-strain data which provide the needed parameters for finite element elastic-plastic analyses. Bounding analyses, however, may necessitate the use of simplified forms of this data such as, for example, linear, stain hardening elastic-perfectly-plastic stress-strain curves and isotropic hardening. Realistic material and/or mathematical models that bound non-linear behavior are constructed and presented. 
The demonstration of the benefits of non-linear analysis is carried out for three problems, utilizing the material models discussed above: pressure vessel nozzle, containment buckling and soil-structure interaction. In addition to evaluating their impact on the design of LWR components, these analyses are particularly selected to demonstrate the level of maturity of non-linear analyses and to identify areas of high potential benefits but lack adequate analysis tools. 


\section{REVIEW OF CURRENT PRACTICE}

\subsection{BASIS FOR CURRENT PRACTICE}

The current state of practice in LWR design and licensing is for the most part governed by the ASME Code and the Regulatory Guides. In serving this state of practice, design-by-analys is played the essential role. However, in the early years of civilian nuclear power, a great deal of emphasis was placed upon the development of design criteria, following the general philosophy described in the background document to the ASME Boiler and Pressure Vessel Code, Section III and Section VIII, Division 2. This philosophy is characterized by design against specific modes of failure and by the requirement of analytical demonstration of design margin, as an alternative to the "design by rule" philosophy that forms the basis of Section I (Power Boilers) and Section VIII, Division I (Unfired Pressure Vessels), of the code.

The applicants and the regulators of nuclear power plant licenses adopted the framework of the Code as the basis for not only "design", but also for the presentation of safety analysis results. Basically, there were two reasons for this: (1) the Code is explicitly constructed as a safety code, with the force of law in almost every state in the country; and (2) Section III is based upon design by analysis principles; consequently it is adaptable to specific plant conditions and component configurations. However, the inherent flexibility of design by analysis also involves judgment factors which evolved through a process of iteration between the preliminary safety analysis report (PSAR) and the final safety analysis report (FSAR). Thus rather than provide rules, the Code assigns the responsibility for meeting safety regulations to the owner and the designer.

The reliance on proper judgment is justified and supported in the Code by the requirement that the Owner or the Owner's designee provides a Design Specification. The Design Specification is related to the safety analysis report in two important respects: First, in the safety classification of various plant components according to their function in the safe 
operation of the plant; and secondly in the appropriate designation of the Design and Service Loadings. According to Subsection NA-2110 (C) of Section II I :

\author{
"The definition... and... significance (of Design \\ or Service Loadings).... are beyond the scope of \\ this Section... Appropriate guidance for the selection \\ of plant or system operating conditions, which may \\ be determined to be of significance in the selection \\ of component or support Design or Service \\ Loadings, the combinations thereof, and the \\ corresponding acceptable limits, may be derived \\ from systems safety criteria documents for specific \\ types of nuclear power systems and may be found \\ in the requirements of regulatory authorities \\ having jurisdiction at the site."
}

Similarly, Subsection NA-2142 (a) states:

"In the design Specification, the owner or his designee shall identify the loadings and designate the appropriate Design and Service Limits for each component or support. The Design or Service Loadings shall be established considering all plant or system operating conditions anticipated or postulated to occur during the intended service life of the component or support."

Thus, the Code distinguished between design and service limits. However, it provides explicit rules only for the "design" conditions (design pressure, temperature and mechanical loadings), while it places the responsibility of defining the actual service conditions directly with the owner and the regulator. Once these are specified, the Code provides limits for the so-established service load conditions. For Service Levels A and B, detailed rules and procedures are given, but for Level $C$ (requiring inspection and posssible repair before being returned to service) and Level D (possibly requiring removal from service), the procedures are generally non-mandatory, their application to be reviewed by the owner in terms of compatibility with established systems safety criteria. 
This is the area where a great deal of thermo-hydrautic and dynamic analyses are performed to define the system behavior as part of the preliminary design. Once this task is accomplished and load levels are defined, possibly through several iterations of increasingly complex analyses, then the sequences of expected and hypothetical off-normal events are defined, followed by the safety classification of individual components. Thus, after the load levels and load combinations have been defined for various service conditions ( $A, B, C, D)$, and the components are assigned safety classes (1, 2 , 3), the Design Specifications are assembled and the Code rules applied.

Even after the Code rules are satisfied, there are areas of functional capability that are either explicitly excluded or not covered by the code limits. The demonstration of component operability and functional adequacy may require deformation or distortion limits and appropriate treatment of environmental effects which are not included in the code but can cause in-service deterioration of material and structural strength. Therefore, while the Code provides design criteria based upon design against specific modes of failure, it does not provide information to three important steps in the safety evaluation: 1) Guidance in assigning safety classifications to components; 2) Determination of the load combinations to be used in the safety analysis; 3) Evaluation criteria in the regulatory review of the safety analysis methods and results. These areas are left for supplementary coverage by the Regulatory Guides.

To assist the applicants in the tasks of safety classification and load specification, the U.S. Nuclear Regulatory Commission (and its predecessor, the AEC), began to provide guidance in 1971, with the adoption of the "General Design Criteria for Nuclear Power Plants" as Appendix A to Title 10, part 50, of the Code of Federal Regulations (10 CFR 50).

Although Appendix A of 10 CFR 50 provided some fairly specific guidance to the owner, in terms of the Design Specification, safety classification of components and load definitions, numerical values and specific procedures were not included. The Commission began to introduce safety guides (now called Regulatory Guides) to supplement Appendix A with 
specifics. These are not mandatory regulations, since they merely describe acceptable methodology; but they define current technical positions, and in some areas have gradually taken on de facto regulatory status.

Perhaps the most important of these safety guides is Regulatory Guide 1.70; Standard Format and Content of Safety Analys is Reports. This document, which is under continuing review and revision, provides the owner with guidance on the required information in the SAR. An original version of this document was issued in 1962 and in the process of revision, the guidance has become sufficiently detailed and specific to provide explicit assistance to industry and regulatory staff.

In some cases, the Regulatory Guides merely represent an endorsement of the ASME Code or other national standards (e.g., Regulatory Guides 1.85, 1.86, and 1.87). In other cases, they represent an established position with regard to a particular safety issue or may be derived as the result of extensive confirmatory research.

The current practice with respect to component safety classification and operational load definition can thus be sumarized as follows:

1. The ASME Code, Section III, requires a Design Specification to be developed by the owner or the owner's designee, using guidance from systems safety criteria (i.e., Appendix A, 10 CFR 50) and other information from the regulatory authorities (e.g., Regulatory Guides, staff positions). The Design Specification must include the component safety classification and the classification of operational transients and other loading conditions.

2. Owners use the Regulatory Guides and previous SAR's in order to develop much of the Design Specification, especially as they pertain to Class 1 equipment and Level D Service Limits.

3. The Code (Subsection NA-2150) stipulates that the description of load combinations and design transients and their categorization (Level A, B, C, or D), is beyond the scope of the 
Code; the owner is to be guided by systems safety criteria, engineering standards, and requirements of regulatory authorities.

In summary, the Code is used as an instrument of proof in the safety analysis but the main building blocks of SAR's are covered in the Regulatory Guides. Since the combination of loadings and the identification of limits defining operability is beyond the scope of the Code, the proof of functional adequacy of operating and safety systems are the primary tasks in the development of design specifications. Non-linear analys is is expected to improve the understanding of the interrelationship between system and component behavior in terms of stress allowables (for design, operating, off-normal service conditions), operability and functional adequacy. The underlying assumptions and analysis methods associated with the stress allowables in the code will be discussed in the next section.

\subsection{REVIEW OF CODE STRESS BASES IN LWR DESIGN PRACTICE}

The ASME Code Section III provides specific design and service stress limits to assure "structural integrity". In this respect the Code is regarded as an instrument of proof of technical correctness as a minimum requirement. Application of the Code to nuclear reactors began some 25 years ago with early development work on pressure vessel design criteria for light water reactors in naval propulsion systems. The subsequent commercial application of these types of reactors necessitated the development of a set of rules that evolved into Section III of the ASME Boiler and Pressure Vessel Code. In order to make use of the long, successful experience in application of the Code to fired and unfired pressure vessels (covered by Sections I and VIII, respectively), the average hoop stress limits which are used to set wall thickness are retained in Section III for the nominal design conditions. The actual operating and postulated off-normal conditions are treated by additional rules that require the detailed evaluation of local stress and strain conditions. The limits were set by developing the inter-relationship between calculated quantities and failure modes which lead to the definitions of stress categories and required design margins (loosely called "safety factors"). The criteria document [2] discusses the background and rationale 
of the rules of Section III and lists a number of failure modes to be considered by the designer:

(1) Excessive Elastic Deformation, including Elastic Instability

(2) Excessive Plastic Deformation

(3) Brittle Fracture

(4) Stress Rupture/Creep Deformation (inelastic)

(5) Plastic Instability-Incrementa 1 Collapse

(6) High Strain-Low Cycle Fatigue

(7) Stress Corrosion

(8) Corrosion Fatigue

The last two failure modes which are designated as "environmental effects" (including radiation embrittlement causing inservice deterioration) are explicitly excluded from coverage in the Code. The protection against such effects is made the "responsibility of the designers". Thus, the Code treats and is aimed at the prevention of essentially three failure modes: (1) instantaneous bursting or buckling; (2) incremental collapse, and (3) failure due to plastic strain fatigue. The rules begin with the identification of these different failure modes and then establish the corresponding elastic stress categories. These categories are: primary stresses, which can cause instantaneous failure (by bursting or buckling), secondary stresses which cause no instantaneous failure, but still could lead to incremental plastic collapse, and the peak stresses, which are present at strain concentrations or notch conditions, that control fatigue crack initiation and propagation. These limits will be further discussed in the following sections.

The limit state of these failure modes is associated with strains well above the proportional limit (except for elastic buckling). Thus, one may ask the question: "How can elastic calculations be utilized in the design analysis of basically inelastic phenomena?" The answer is that the seemingly elastic philosophy embodied in the Code is the result of a sequence of "conservative" assumptions introduced to develop simplified rules for the admittedly complex, non-linear material and structural behavior. This 
simplification was achieved by the application of limit load and shakedown concepts and by the development of a pseudo-elastic analys is method for the calculation of plastic strain quantities for fatigue analysis.

As a result, the present design rules require no detailed analys is (or knowledge) of the actual elasto-plastic behavior of the component. By exploiting these non-elastic concepts, the developers of the Code provided the means for inelastic strain analysis by utilizing traditional techniques of elastic stress analysis without actually requiring a drastic reorientation in the analyst's and designer's thinking.

\subsubsection{Primary Stress Limits}

Primary stresses are limited to a safe function of the plastic limit load of the structure by basing the primary stress on the yield strength of the material. To illustrate this, consider the simplest geometry and material, namely, a straight cylindrical vessel and ideal plastic behavior. The limit load for a cylinder is defined by the average hoop stress reaching the yield strength of the material. Therefore when $S_{m}$ is defined as $2 / 3$ of yield, and the average hoop stress is limited to $S_{m}$, the primary stress allowable, in effect, ensures a safety factor of $3 / 2$ against plastic yielding.

Plastic failure of structures is governed by the progressive change in shape and stiffness (post yielding) characteristics of the material. The primary stress limits, however, are based on linear, small deformation limit analysis of simple rectangular beam, using rigid plastic or elastic-ideally plastic material behavior under monotonic loading. The ideal plastic assumption closely approximates the monotonic stress-strain curve of ferritic material which exhibit negligible strain hardening in the vicinity of the yield strength value (defined as the stress at $0.2 \%$ offset.) Austenitic materials, however, exhibit strong strain hardening capacity, which has been taken into account in the Code by setting the $S_{m}$ limit equal to $0.9 \mathrm{~S}_{y}$ where $S_{y}$ is the stress that corresponds to $0.2 \%$ offiset. 


\subsubsection{Secondary Stress Limits:}

The limit of $3 \mathrm{~S}_{\mathrm{m}}$ on primary plus secondary stresses is intended to prevent plastic strain accumulation by assisting shakedown to elastic action after a few load cycles. Although the $3 S_{m}$ or $\left(2 S_{y}\right)$ value is intended to be a conservative limit on the range of the secondary stresses added to the primary stresses calculated elastically, certain situations can develop where satisfying the $3 S_{m}$ limit does not necessarily guarantee shakedown. An example of this is cited by Gerdeen in a PVRC report [3], who showed for pure bending of a beam that while the $3 \mathrm{~S}_{\mathrm{m}}$ limit was satisfied, there was no shakedown in case of pure reversed bending of $1.5 M_{y}$ (where $M_{y}$ is the first yield moment). Also analys is and experiments of pipe bends under internal pressure and cyclic bending with stresses not exceeding the $3 \mathrm{~S}_{\mathrm{m}}$ limit have demonstrated incremental plastic hoop strain accumulation in the elbow [4].

Other recent examples of violation of the $3 \mathrm{~S}_{\mathrm{m}}$ rule can be cited from the open literature, primarily originating from England, Leckie and Penny [5,6], Procter and Strong [7], Lewis and Price [ 8], and Procter and Flanders [9] have investigated nozzles and cylinder intersections while Save' and Massonnet [10] discussed beams, plates and shells. Therefore the evaluation of shakedown appears to be a natural candidate for non-linear analysis. It is therefore, reasonable to expect that non-linear (elasticplastic) analysis could eventually replace linear analys is as a mandatory requirement for demonstrating shakedown when the $3 \mathrm{~S}_{\mathrm{m}}$ limit is violated.

\subsubsection{Peak Stress Limits}

The limits on peak stresses is built on the primary and secondary stress allowables, under the postulate of ideal conditions. As was mentioned earlier the primary stress limits prevent gross plastic action, and when combined with the secondary stress limits the cross section should remain free from incremental strain accumulation. Therefore, the structure as a whole behaves elastically under all normal and upset conditions designated as levels A and B. Plastic strains, if any, occur only at local areas of stress concentration under complete restraint by the surrounding elastic bulk of the section. In these circumstances the distribution of the local plastic strain 
is a purely geometric function and the peak strain magnitude can be scaled by the elastic stresses. The geometric functions are given for many configurations (noles, notches, etc.,) by stress concentration factors, (or can be determined by experimental techniques) which, when multiplied with the nominal elastic stresses, provide the amplitude of the pseudo-elastic stress. Allowable fatigue endurances are given in the form of $\mathrm{S}-\mathrm{N}$ data generated from strain controlled fatigue data by converting the strains into pseudo-elastic stress ranges. This way the calculated stresses and allowable limits form a consistent total-strain-controlled fatigue evlauation procedure, thus circumventing the need for complex plastic strain analysis.

The final step in the peak stress evaluation process is the cummulative fatigue damage calculation by a Miner's rule type linear damage summation method:

$$
\Sigma n_{j} / N_{f i} \leq 1
$$

where $n_{j}$ includes all operating cycles $N_{f i}$ is less than the endurance limit defined as $N_{f}=10^{\circ}$ cycles. Non-linear damage evaluation and damage summation methods are clearly promising targets for non-linear analysis application, but these are large topics all by themselves and they fall outside the scope of the present review.

The pseudo-elastic strain analysis, however expedient, represents the true strains only at the expense of enforcing the severe restriction on the secondary stress represented by the $3 \mathrm{~S}_{\mathrm{m}}$ limit. Deviation from this limit is permitted by (NB3228.3) only with a proportional increase in the nominal elastic stress concentration factor.

\subsection{REVIEW OF DEVELOPMENT OF DESIGN SPECIFICATIONS AND LOADING CONDITIONS}

The ASME Code requires that a Design Specification be prepared for each Class 1 component in the nuclear steam supply system. This design specification then becomes the sole criteria document which the equipment supplier must meet. The design specification has legal status by virtue of the adoption of the ASME Code by governmental bodies, and must, therefore, be 
certified by a registered professional engineer. When the component is designed and shown to meet all requirements of the Design Specification, the final design report is reviewed and certified by one or more registered professional engineeers who are "competent in the applicable field of design and related nuclear power plant requirements." The ASME Code does not, however, define the magnitude or specific loading combinations for which the component shall be designed. The owner, in preparing the design specification, must develop this information for each component, usually from methodology supplied in the Regulatory Guidelines and including consideration of the results of analyses performed for previous plants of a similar design.

It is worth noting at this juncture, that the quality assurance for Class 2 and $\mathrm{Cl}$ ass 3 components need not involve a formal stress report, which may be one of the underlying reasons for some of the current steam generator feedwater nozzle cracking problems.

In developing component loading specifications, there are four categories of loadings for which the detailed loads and load combinations must be developed. These are defined in Appendix B of Section III, Division 1 of the ASME Code. The categories are designated A through D and may briefly be summarized as follows: Category A loads, formerly referred to as "normal loads", and Category B loads, formerly known as "upset loads", are provided in order to evaluate the effect of system operating loads on the fatigue life of a component. The variation, with respect to time of pressure, temperature, etc., as well as the number of times these changes occur in the life of the component is needed.

Category C loads, formerly known as "emergency conditions", are provided in order to evaluate the effect of plant operating loads on the structural integrity of a component for situations which are not anticipated to occur for a sufficient number of times to affect fatigue life, and for which large deformations in areas of structural discontinuities are not objectionable. Occurrence of the events considered under Category $\mathrm{C}$ will require inspection of the component and possible removal or repair. 
Category D events, formerly known as "faulted conditions", are provided in order to evaluate the effect of plant operating loads on the structural integrity of a component for situations in which gross general deformations, loss of dimensional stability, and damage requiring repair, excluding loss of pressure retaining function, are not objectionable. Occurrence of Category $D$ events will require inspection and possible repair or replacement of the component.

It is important to note for Category $C$ and $D$ events that the Code states that "Since the occurrence of stress associated with this 'Limit' may result in removal of the component from service for inspection or repairs, the Owner should review this limit for compatibility with established system safety criteria." Specific reference is made to the Regulatory Guides in Section B-2300, "Regulatory Requirements," which states:
"In the process of preparing a Design
Specification, it is important to refer to, and rely on, the requirements contained in SAR (Safety Analys is Report) documents, since they provide the basis for complying with existing regulatory requirements. Conflicts between a Design Specification and the SAR could lead to construction of items not in compliance with the license requirements. A reference list of regulatory documents is provided in B-11000, which may be used in determing the applicable requirements to be included in the Design Spec if ication."

This list includes applicable sections of Title 10 of the Code of Federal Regulations and applicable Regulatory Guides.

Having established the formal procedure used to develop loads and load combinations, it is instructive to examine specific cases. Appendix $A$ of 10 CFR 50, entitled "General Design Criteria for Nuclear Power Plants," provides guidance to the owner in that general requirements for developing the Design Specification are given. However, the criteria are given in rather general terms, and no explicit loadings are given. The flavor of this document is illustrated by Criteria 2, 14, and 15, which refer specifically to the design of components. 
Criterion 2: Design Bases For Protection Against Natural

Phenomena. Structures, systems, and components important to safety shall be designed to withstand the effects of natural phenomena such as earthquakes, tornadoes, hurricances, floods, tsunami and seiches without loss of capability to perform their safety functions. The design bases for these structures, systems, and components shall reflect: (1) Appropriate consideration of the most severe of the natural phenomena that have been historically reported for the site and surrounding area, with sufficient margin for the limited accuracy, quantity, and period of time in which the historical data have been accumulated;

Criterion 14: Reactor Coolant Pressure Boundary. The reactor coolant pressure boundary shall be designed, fabricated, erected, and tested so as to have an extremely low probability of abnormal leakage, of rapidly propagating failure, and of gross rupture.

Criterion 15: Reactor Coolant System Design. The reactor coolant system and associated auxiliary, control, and protection systems shall be designed with sufficient margin to assure that the design conditions of the reactor coolant pressure boundary are not exceeded during any condition of normal operating, including anticipated operational occurrences.

The next logical step in developing the content of the Design Specification is to meet the requirements of the Safety Analys is Reports (SAR's). Regulatory Guide 1.70, entitled "Standard Format and Contents of Safety Analysis Reports for Nuclear Power Plants", provides a detailed outline for the contents of the Safety Analysis Reports. The SAR's must contain a complete description of the loads that are considered, as well as loading combinations. Definition of these values is not specifically covered in Regulatory Guide 1.70. In practice, the Design Specification is developed concurrently with the Preliminary Safety Analysis Report. Design and operating loads for the individual components are developed during the course of the overall plant design. For example, the thermal-hydraulic analysis of the plant will produce flow and fluid temperature time histories for the components. These parameters are necessary to evaluate piping thermal expansion loads on the components. A seismic analys is of the overali plant 
is necessary to develop design spectra for the components. The process is multi-stage, of course, and an overstress condition may lead to redesign of the component or a change in a design transient, etc., thus, the SAR may have many iterations before the Final Safety Analys is Report is issued. In some cases, this process results in situations in which elastic analys is methods are not adequate to show the required safety margin, and neither the plant configuration nor the loading conditions can be modified. Non-linear analysis methods must then be used to evaluate the component.

As an example of this process, consider the Load Tables for Reactor Collant Systems, Fig. 1, taken from the FSAR of Units 2 and 3 of the San Onofre nuclear plant. The seismic classification of components w 17.1 be mad:in accordance with Regulatory Guide 1.29, Seismic Design Classification. A11 components in the primary system would, of course, be designated as seismic class and thus require a detailed analysis. This analysis must consider the interaction between the piping system and each component, using the response spectra developed for the plant. Response spectra are usually ${ }^{\star}$ developed as outlined in Regulatory Guide 1.60, Design Response Spectra for Seisinic Design of Nuclear Power Plants. Damping values used in the analys is are based upon Regulatory Guide 1.61, Damping Values for Seismic Design of Nuclear Power Plants. Further guidance is given in Regulatory Guide 1.122 , Development of Floor Design Response Spectra for Seismic Design of Floor Supported Equipment or Components. This document provides guidance in development of response spectra for components located at other than ground level and, therefore subject to amplification of the seismic occurrence.

Seismic analysis for Class 1 components must be a dynamic analysis. Either direct time integration or modal superposition tecnniques may be used, the latter being more common because of the nominally greater

\footnotetext{
* It should be reiterated that compliance with the procedures and methods outlined in the Regulatory Guide is not required. It is stated on each Guide that "methods and solutions different from those set out in the guides will be acceptable, provided they present a basis for the findings requisite to the issuance or continuance of a permit or license by the Commission." In practice, however, few exceptions are made for reasons of expediency.
} 
Table 3.7-23

LOAD TABLES FOR REACTOR COOLANT SYSTEM

\begin{tabular}{|c|c|c|c|c|}
\hline \multirow[b]{2}{*}{$\begin{array}{c}\text { Seismic } \\
\text { Excitation }\end{array}$} & \multirow[b]{2}{*}{ System Location } & \multicolumn{3}{|c|}{ Seismic Load $(a)$} \\
\hline & & $\begin{array}{c}\text { Component } \\
\text { of } \\
\text { Reactions }\end{array}$ & $\begin{array}{c}\text { Calculated } \\
\text { Maximum }\end{array}$ & $\begin{array}{l}\text { Specified } \\
\text { for Design }\end{array}$ \\
\hline $\begin{array}{l}\text { Combined } \\
\text { North- } \\
\text { South and } \\
\text { Vertical }\end{array}$ & $\begin{array}{l}\text { Reactor inlet } \\
\text { nozzle } \\
\text { Reactor inlet } \\
\text { nozzle }\end{array}$ & $\begin{array}{l}F x \\
F y \\
F z \\
M x \\
M y \\
M z \\
F x \\
F y \\
F z \\
M x \\
M y \\
M z\end{array}$ & $\begin{array}{r}364 \\
35 \\
226 \\
1,473 \\
3,814 \\
1,917 \\
490 \\
110 \\
4 \\
155 \\
115 \\
7,020\end{array}$ & $\begin{array}{r}370 \\
40 \\
230 \\
1,480 \\
3,820 \\
2,080 \\
\\
500 \\
110 \\
35 \\
1,630 \\
1,130 \\
7,025\end{array}$ \\
\hline $\begin{array}{l}\text { Combined } \\
\text { East-West } \\
\text { and } \\
\text { Vertical } \\
\text { (OBE) }\end{array}$ & $\begin{array}{l}\text { Reactor inlet } \\
\text { nozzle } \\
\text { Reactor outlet } \\
\text { nozzle }\end{array}$ & $\begin{array}{l}F x \\
F y \\
F z \\
M x \\
M y \\
M z \\
\\
F x \\
F y \\
F z \\
M x \\
M y \\
M z\end{array}$ & $\begin{array}{r}126 \\
35 \\
152 \\
1,343 \\
2,494 \\
2,070 \\
\\
127 \\
9 \\
33 \\
1,623 \\
1,126 \\
1,079\end{array}$ & $\begin{array}{r}370 \\
40 \\
230 \\
1,480 \\
3,820 \\
2,080 \\
\\
500 \\
110 \\
35 \\
1,630 \\
1,130 \\
7,025\end{array}$ \\
\hline $\begin{array}{l}\text { Combined } \\
\text { North- } \\
\text { South and } \\
\text { Vertical } \\
\text { (OBE) }\end{array}$ & $\begin{array}{l}\text { Steam generator } \\
\text { inlet nozzle } \\
\text { Steam generator } \\
\text { outlet nozzle }\end{array}$ & $\begin{array}{l}\mathrm{Fx} \\
\mathrm{Fb} \\
\mathrm{Mx} \\
\mathrm{Mb} \\
\mathrm{Fx} \\
\mathrm{Fb} \\
\mathrm{Mx} \\
\mathrm{Mb}\end{array}$ & $\begin{array}{r}427 \\
245 \\
254 \\
4,906 \\
\\
42 \\
59 \\
1,090 \\
2,397\end{array}$ & $\begin{array}{r}430 \\
250 \\
1,255 \\
4,910 \\
\\
45 \\
65 \\
1,140 \\
2,990\end{array}$ \\
\hline
\end{tabular}

Figure 1. Sample Load Table from San Onofre Units 2 \& 3 FSAR 
expense of a direct time integration analysis. ${ }^{\star \star}$ Having performed the seismic analysis, the loads on the individual components may be determined, using one of the procedures in Regulatory Guide 1.92, Combining Modal Responses and Spatial Components in Seismic Response Analys is. Figure 1 indicates the results of combining the north-south and vertical components of the OBE (Operating Basis Earthquake), and the east-west and vertical OBE for the reactor inlet and outlet nozzles for San Onofre Units 2 and 3 . The maximum calculated reaction must, of course, be less than the value specified for desigll. It is also evident from the large disparity between design to maximum margins that certain design values may have been revised as a result of the detailed analyses during the course of the project. The specification of design loads is initially based upon the results of analyses of similar designs or preliminary seismic analyses. As the plant design nears completion and more exacting analyses are performed, the design values are revised accordingly, when necessary. This example illustrates the feedback loop which exists during the design stage of the plant. In some casps, th? design requirement may change during the course of the design of the plant. For example, additional seismic data may become available, which would increase the magnitude of the SSE (Safe Snutdown Earthquake) for the plant site. The design loads which were previously issued in the Design Specification for various components would increase. In some cases, these components are completed or are in some stage of manufacture.

Inelastic analysis can often show that these components will still serve their intended function. A particular example can be cited to demonstrate this point. The main steamline check valve for the Duquesne Light Beaver Valley plant has been designed (by $S \& K$ Valve Manufacturing) to meet the faulted conditions prescribed by Stone and Webster (the architectural engineers for this plant), and based upon the initial plant design. A more refined analysis of the final plant configuration, performed for the FSAR, ravealed that the back pressure on the valve was much greater than previously specified in the design specification for the valve. Since the valve had already been installed in the plant, the redesign and replacement of the valve posed a severe economic problem, in addition to the delay in ** The assumption is made here that some type of rank reduction (e.g., static condensation) will be performed on the multi-degree-of-freedom model, so that only a relatively few modes will be analyzed. 
plant operation. A detailed dynamic inelastic analysis of the check valve was performed, which indicated that the component met the faulted limits of the ASME Code.

Although the Regulatory Guides do not specify load magnitudes, they are quite specific as to how the loadings shall be combined. Regulatory Guide 1.48, Design Limits and Loading Combinations for Se ismic Category Fluid Systems Components and 1.57, Design Limits and Loading Combinations for Metal Primary Reactor Containment System Components both delineate acceptable design limits and appropriate combinations of loading associated with normal operation, postulated accidents, and specified seismic events for the design of seismic category fluid system components. (Component supports are covered by additional Regulatory Guides, 1.124 for linear-type supports and 1.130 for plate and shell-type supports.)

Application of the Regulatory Guides can best be demonstrated by considering the FSAR for a particular plant. The San Onofre Units 2 and 3 will be used again to illustrate how loads are specified and loading combinations are developed. There are three types of loads specified for the plant: pressures, temperatures, and seismic loads. Individual component loads are then derived from the results of overall plant analyses. Attachment I is excerpted from the FSAR for San Onofre, specifically, Section 3.9.1.1, "Design Transients". This section provides the bas is for selecting the pressure and temperature fluctuations for the plant and the number of cycles of each transient. Discussion is included that describes which events were included, i.e., start-up, shut-down, etc., the sequence of events, and now the service conditions are enveloped conservatively. Table 3.9-1 indicates the transients used in the analysis of class 1 components.

The number of cycles pertaining to the $O B E$ is given in paragraph 3.7.3.2, which is Attachment II. This paragraph is also taken from the San Onofre FSAR. It is included to indicate how the number of cycles is calculated for use in a fatigue analys is of various system components. It is noted that Section 3.7.3.2.2 specifically addresses the Nuclear Steam Supply System (NSSS) and specified 200 full load cycles about a mean value of zero 
with an amplitude equal to the maximum response produced during the entire OBE event. (The current terminology only defines SSE as a seismic event. One-half the amplitude of the SSE is used for operating conditions, i.e., the Operating Bas is Earthquake).

The loading combinations for ASME Class 1 components (other than valves) and piping for the San Onofre Units 2 and 3 are shown in Fig. 2, Table 3.9-8 taken from the FSAR. Stress limits for each condition are given on Table 3.9-9. The design conditions are always specified in the Design Specification and envelop the worst case combination of pressure, temperature, and mechanical loading, to which the component will be subjected during operation. The design pressure usually exceeds the maximum expected operating pressure. The normal conditions must include the operating pressure and dead-weight loading. Other loads, such as may be caused by thermal transients, must be added when the analys is is performed. Cyclic stresses resulting from these loads must be included in the fatigue evaluation of the component.

The upset load combinations must include operating pressure, dead weight, and $1 / 2$ of the SSE, as well as other loading conditions which may be associated with the upset conditions. These will include thermal transients and pressure fluctuations which may be caused by upset condition events. The cyclic stresses calculated must be included in the fatigue evaluation of the component.

The emergency condition load combinations must include operating pressure and dead-weight stresses plus any dynamic loading caused by emergency conditions. The Safe Shutdown Earthquake (SSE) is considered an emergency condition. Stress limits for the emergency condition are higher than for the previous conditions for each category of stresses. Primary stresses up to the yield stress of the material at temperature are allowed. The Code prescribes no limits on secondary or peak stresses and no fatigue evaluation is required. The code does, however, require that deformations be limited, if prescribed in the Design Specification. It is recognized that occurrence of the events specified under Category $C$ will require inspection 
Table 3.9-8

LOADING COMBINATIONS ASME CODE CLASS 1 NSSS COMPONENTS

\begin{tabular}{|l|c|}
\hline Condition & Design Loading Combination (a) \\
\hline Design(b) & PD \\
Normal(b) & $P 0+D W$ \\
Upset & PO+DW+OBE \\
Emergency & $P O+D W+D E$ \\
Faulted & PO+DW+DBE+DF \\
& \\
\hline
\end{tabular}

a. Legend:

$$
\begin{aligned}
P D= & \text { design pressure } \\
P O= & \text { operating pressure } \\
D W= & \text { dead weight } \\
O B E= & \text { operating basis earthquake } \\
D B E= & \text { design basis earthquake } \\
D E= & \text { Dynamic system loadings associated with the } \\
& \text { emergency condition } \\
D F= & \text { Dynamic system loadings associated with a } \\
& \text { postulated pipe rupture (LOCA) }
\end{aligned}
$$

b. As required by ASME Code Section III, Division 1, other loads such as thermal transient, thermal gradient, and anchor point displacement portions of the $\mathrm{OBE}$ require consideration in addition to the primary stress producing loads listed.

Table 3.9-9

STRESS LIMITS FOR ASME CODE CLASS 1

NSSS COMPONENTS AND PIPING

\begin{tabular}{|l|l|}
\hline Condition & Stress Limits \\
\hline Normal and upset & NB 3223 and NB 3654 \\
Emergency & NB 3224 and NB 3655 \\
Faulted & NB 3225 and NB 3656 \\
\hline
\end{tabular}

a. As specified in ASME Section III, 1971 and applicable addenda.

Figure 2. Loading Combinations and Stress Limits for Class 1 NSSS Components \& Piping 
of the components and possible removal or repair. Since permanent deformations may occur during an emergency event, it is extremely important to determine if these deformations could cause a loss of ability to function for a component. Components which may have moving parts with small clearances, such as control-rod drive mechanisms and valves, may not function properly as a result of emergency events. The use of inelastic analys is to determine the extent of the deformation is highly desirable, and often mandatory. This is especially critical for components for which excessive deformation could prevent a safe shutdown of the plant.

Loads included in the faulted conditions per Table 3.9-8 of Fig. 2 include operating pressure, dead weight, SSE and loads due to a postulated pipe rupture (LOCA). The purpose of performing an analysis of the faulted condition is basically to show that there is no loss of the pressure retaining function of the components. There is currently some contruversy concerning whether the SSE 1) ads sinould be combined with pipe rupture loads.

This controversy provides an example of the interplay between nonlinear analysis and load combinations and is typified by the current discussion within the Advisory Committee on Reactor Safeguards (ACRS) on the generic safety issue of combined loads per Regulatory Guide 1.48, Regulatory Position $1(C)$. This section states that:

"The design limits specified in NB-3225 and NB-3656 of the ASME Code for vassels and piping, respectively, should not be exceeded when the component is subjected to concurrent loadings associated with the normal plant condition, the vibratory motion of the SSE, and the dynamic system loadings associated with the faulted plant condition."

This position, although non-mandatory, is considered to be an unnecessary requirement by many nuclear steam supply vendors, because the concurrency of the safe-shutdown earthquake and loss-of-collant-accident loadings implies that the earthquake is the initiator of the LOCA. Such a 
postulate is disputed by the vendors, who claim to be able to demonstrate, through the use of elastic-plastic fracture mechanics concepts, that permissible flaws will not propagate as the result of these cyclic earthquake loads to the point that a double-ended pipe rupture would occur. Extensive work by both industry and regulatory researchers appears to support this contention, with the ACRS now willing to entertain an NRC staff argument that Regulatory Guide 1.48 be revised to reflect non-concurrent SSE/LOCA loadings.

The non-linear stress analyses required to demonstrate that a SSE will not initiate a LOCA are quite sophisticated, ranging from a tnreedimensional, quasi-elastic shakedown analysis to a stress-intensity, crackgrowth analysis of flawed structures under cyclic loading. This subject will be addressed in greater detail elsewhere in this report.

\subsection{FRACTURE MECHANICS APPLICATIONS}

The Code design criteria using the principles of failure mode analys is eliminate, for all practical purposes, elastic buckling and structural failures of either the ductile type (bursting, gross yielding and buckling distortion), or the brittle (low-energy fracture) type. Using limit loads and bounding techniques, the failure modes involving plasticity over a significant area of the structure (of the order of the wall thickness) have also been eliminated. Therefore, if the Code rules are sdisifizid, failure from a single application of the load is virtualiy impossible early in the plant life. Since failures still occur occasionally, usually after a period of successful operation, protection against delayed failure modes is less reliable.

These failure modes are of three types:

1. Operating history-dependent (fatigue, incremental plastic collapse, ratchet)

2. Time-dependent (corrosion, embrittlement)

3. Interactive (corrosion assisted fatigue) 
These failure modes (or strength reduction effects) are all characterized by a slow growth of cracks that can possibly breach the pressure boundary or reach a critical size for the onset of unstable crack extension failure. Generally, the process of crack growth under cyclic loading initiates either from a highly stressed area or from a defect left after fabrication. Cracks can also initiate and propagate under constant or sustained load by stress corrosion in sensitized materials. Thus combinations of the various environmental, temperature and loading conditions can result in accelerated crack propagation; (e.g., cyclic loading in aggressive environment can lead to corrosion fatigue failure).

The propagation of cracks and defects is the domain of fracture mechanics. The beginnings of the crack growth studies go back to the inception of linear elastic fracture mechanics which originally emcompassed only the restricted field of brittle fracture (defined as failure at stress levels below the yield strength). To characterize fracture behavior, a new material property, fracture toughness, was identified. The quantitative measure of toughness is $K_{c}$, the critical stress intensity factor. Stress intensity factor $K$ is dependent on the crack or defect size, component geometry, and stress distribution. Much of the theoretical and experimental work in fracture mechanics was devoted to analyse and measure $k$ and $k_{c}$ values for various geometries and materials respectively. It can be said that the accumulated body of analytical results and material information is quite adequate to guard against crack propagation below the yield strength of structural materials, (i.e., to guard against the brittle mode of failure).

The fundamental concept of fracture mechanics, relating strain energy release of crack extension to changes in the stress intensity, was found to be applicable also to fatigue where the concern is not the size of the critical crack but the determination of the crack growth rate, which in turn determines the useful life of the component. Based on theoretical and empirical corrections for the stress field in the vicinity of the crack tip, linear elastic fracture mechanics can describe, in the sub-creep temperature range, the fatigue crack propagation process by expressions in the form: 


$$
\frac{d a}{d N}=C \Delta K^{n}
$$

where $\frac{d a}{d N}$ is the crack growth rate per cycle, $\Delta K$ is the stress intensity factor range, and $C$ and $n$ are material constants.

Information of this type are used in design evaluation by defining the critical size, either in terms of $K_{c}$, or by limiting the permissible crack extension to a fraction of the component thickness or by some other geometric definition of safe design.

All metallurgical evidence shows that fatigue cracks initiate on crystallographic planes where local stresses due to slip at the grain boundaries are intensified by dislocation pileups. Slip processes are controlled by the magnitude of the shear strain and occur preferentially on the place of maximum shear. This is defined as the Stage I crack initiation and micro-crack propagation mode. When the crack length reaches a critical value (dependent on the material grain size) at which the crack alters the stress distribution in the vicinity of the crack tip to the point of developing a plastic bulb extending over a large number of grains, the crack becomes a macrocrack which propagates by decohesion at the crack tip and void formation or cleavage just ahead of the tip. This is Stage II, crack propagation, governed by the principal tensile strains across the maximum shear plane. The relative magnitude of the strains and their orientation, with respect to the free surface, determine the direction of Stage II crack growth. The strain orientation and magnitude depends on the biaxiality of the stress field. The uniaxial test specimen represent special cases of strain biaxiality. The biaxiality ratio is negative in many thermal transient conditions when compressive thermal stresses at the hot fluid side are superimposed on mechanical loads (e.g., axial tensile stress due to pipe reaction). In this case Stage I crack initiates and Stage II crack propagates mainly along the surface because the maximum and minimum strains are equa1. This results in equal crack propagation rates in two directions thus producing the characteristics semi-circular crack front. Under pure tension loading the crack propagates as shallow surface cracks. Other special case 
is the equibiaxial loading (e.g., thermal restraint), that promotes crack tunneling through the thickness. The crack shape (length to depth ratio) and orientation depend also on the stress gradients. For example, the thermal stress in a cylinder subjected to a radial temperature gradient changes from tensile to compressive such that cracks initiated in the tensile region growing in the radial direction decelerate as they approach the compressive stress region and may either arrest or start to propagate in the circumferential direction.

Even from this cursory description and the few examples described, it can be clearly seen that the prediction of the rate and the direction of crack growth cannot be made a priori. An accurate strain analys is is needed to determine the direction of the maximum shear strains and the value of the strain normal to the maximum shear plane throughout the loading history. The shape of the crack front depends on the strain ratio which governs whether the crack grows longitudinally or circumferentially, whether it propagates mainly along the surface or primarily though the thickness or, simply stated, whether a pressure boundary leaks before it breaks.

In pressure vessel nozzles and piping system bends and supports, the stress orientation and biaxiality changes from point to point and can rotate through the loading history. Therefore, a variety of crack propagation rates and directions need to be evaluated, since many crack growth orientations are possible even for identical amplitudes of stress components. Simplifying assumptions of ten eliminate precisely this type of information when the actual three dimensional stress field is reduced to a "representative" or "conservative" one dimensional model.

It may be mentioned also that even if these considerations are disregarded, meaningful LEFM-based safety analys is cannot be made for many component geometries because of the lack of appropriate stress intensity factors. For straight cylinders, stress intensity factors have been calculated for a few initial crack configurations (thru-wall cracks under axial tension, internal pressure, and axial bending). For bends, elbows or tee joints, $k$ factors are not available for any kind of surface crack or thru-wall crack, let alone for the combination of in-plane, out-of-plane, 
pressure and thermal loading variations. The approximations and simplifications required at the present neglect the effects of negative curvature and stress ratios. Therefore, the available $K$ solutions are not capable of predicting the direction of crack propagation in an elbow or T-joint even for materials satisfying LEFM conditions.

In summary, it can be stated that despite its shortcomings, LEFM serves the designers' needs for load level A, B and C. However, for a certain class of Level D Safety issues, extension of the state of the art of plastic frarture and companion analys is methods is needed. This particular area is under discussion in the design community at present and is further discussed in Part 2 of this report.

1.5 SiJMMARY OF THE APPLICABILITY AND EXPECTED BENEFITS OF NON-LINEAR ANALYSIS METHODS IN SAFETY ANALYSIS OF LWR COMPONENTS

In this section the target areas are identified where non-linear analysis is expected to produce improvements in the current practice of assembling Safety Analysis Reports. The evaluation of the presently used procedures described in the preceding sections suggests three categories of potential improvements: 1) Economic benefits, 2) Resolution of outstanding safety issues, and 3) Verification of Functional Requirements.

\subsubsection{Economic Benefits}

Great economic benefits can be realized by reduced design analysis and SAR documentation, easier fabrication resulting from reduced thickness (and welding) requirements, and less frequent replacement of deteriorated components by more accurate life prediction methods.

\subsubsection{Design Analys is and SAR Documentation}

The first step and minimum requirement in the assembly of a SAR is the satisfaction of the ASME Code. While the Code rules, in general, produce a well balanced design (that is, the satisfaction of primary stress limits approximately ensures the satisfaction of the higher stress conditions) there are geometry and loading conditions, particularly in nozzles, where the 
secondary and/or peak stress limits require interactions on geometry changes or alterations of system operating conditions (operating temperatures, transient rates, etc.). When such changes become necessary late in the design process, the cost of redesign can be very high. In many such cases the elimination of the extra conservatism embodied in the code (due to the use of linear elastic and pseudo-elastic approximations of the actual inelastic structural response) provides the needed relief. Inelastic analysis of all but one stress limit (primary membrane stress under nominal design loads) are permitted by the Code via the provisions for the application of plastic analys is in NB-3228. The design acceptable in shakedown is demonstrated and the lower bound collapse load marg in of $3 / 2$ for a primary membrane plus primary bending stress is satisfied. The evaluation of these limits by non-linear analysis is a costly process which is to be attempted only if there is a reasonable expectation of providing the needed relief. Simplified rules can be developed from inelastic analyses of various geometry and material combinations to provide an estimate of the available margins and justify the cost of inelastic analysis.

\subsubsection{Fabrication Cost Improvement by Reducing Thickness}

The results of systematic inelastic analys is of common structural configuation of nozzles would provide a valuable aid in the utilization of the plastic analysis provisions of the Code at the preliminary design phase as we 11 as assist in the development of alternate rules for the present area-rep lacement-based reinforcement requirements, particularly when thermal stresses dominate the stress limits in the nozzle region. Reduction of nozzle thickness in such conditions improves the safety margins against fatigue failure due to reduction in thermal gradient, reduces nozzle forging cost and improves the weldment quality, inspection, etc.

\subsubsection{Life Prediction Method Improvement}

One of the most costly failure modes in current plant operational experience is the steam generator tube leak problem. This poses little or no safety risk when affecting Class 2 and 3 equipment, but necessitates periodic 
retubing or steam generator replacement. The crack initiation and extension is by corrosion and corrosion assisted fatigue which involves the interaction of time dependent (intergranular) and cyclic shear strain dependent (transgranular) micro-crack phenomena. For intergranular crack extension or internittent crack mode shift conditions, the LEFM based crack growth evaluation methods, which deal essentially with stress singularities are of little use. Non-linear analysis of void nucleation, coalescence controlled by volumetric, time dependent normal stress and plastic deformation in the grain controlled by shear strain (deviatoric stress) can provide a damage model that would be a useful tool to guide multiaxial materiai besting. The successful formulation of such a damage model could form the basis 'or design rule and improved life prediction development.

\subsubsection{Resolution of Outstanding Safety Issues}

Safety issues have been identified from the evaluation of LWR plant operating experience and by designating hypothetical events as having sufficiently high probability of occurance to require inclusion in the SAR. For some of these safety issues there is a lack of adequate verification standard, generally accepted analytical techniques and uniform evaluation criteria. These safety issues include structural problems that are generally outside the intended scope and coverage of the ASME Code. We have selerted d number of structural safety issues that can potentially be resolved by non-linear analysis. These are: 1) Buckling of metal containment shells, 2) Load combinations for Level $D$ service limits, 3) Definition of load levels for dynamic events, 4) Crack growth under significani: plasticity across the thickness.

\subsubsection{Buck ling of Metal Containment Shell}

A generic safety issue has been identified with respect to the possible structural instability of a steel containment shell as the result of LOCA-induced, unsymmetrical dynamic loading. Berause these containment shells are thin, in comparison to characteristic diametral dimensions, the imperfection sensitivity of their buckling loading has led to a re-avalid: : if the ASME Code design criteria and reguldrory acceptance criteria. Rece1: 
studies have postulated a "knock-down" factor approach to buckling analys is that would continue to permit elastic analysis methods to be used to neet these criteria [39]. Such a knockdown factor approach entails substantial increase in load factors above the theoretical buckling loads to account for uncertainties in imperfection sensitivities.

The industry has taken the general position that such an approach would unnecessarily penalize most designs, since it might reduce the "design" buckling limits to extremely low levels for most structures in an effort to remain conservative for truly imperfection-sensitive structures. That this is a problem can be recognized from studies which show that the imperfection lead to greater reductions in buckling load.

An alternative is non-linear analysis of the buckling problem, as described in Section 2.5.2. Here, some knowledge of the imperfection shape and amplitude would be required, but no penalty would accrue to well-designed structures. The industry objects to this type of non-linear analysis on two grounds: first, non-linear analys is is inherently expensive; second, the required knowledge of the imperfection shape and amplitude would lead them in the direction of a more exacting quality assurance program for manufacture and operation than presently exists.

It is our opinion that the controversy can be resolved by extensive non-linear analysis program aimed at the characterization of geometric parameters and loading types based on imperfection sensitivity. This could lead to:

1) Alternate tolerance requirements or modification of the present ASME Code limits on deviation from ideal shape.

2) Development of simplified design rules capturing the nonlinear analysis results.

3) Rationally established Quality Control requirement that would not penalize imperfection-insensitive structures. 


\subsubsection{Definition of Load Levels for Dynamic Loading}

Non-linear analysis can improve the present practice at two levels. First, in the process of developing the Design Specification, the structural loading parameters can be established, by taking into account the soilstructure interaction using realistically derived inelastic soil properties and damping values. Second, non-linear analysis greatly. enhances the analyst's ability to introduce more accurate geometric and material response characteristics than can be presently achieved with secondary response spectrum applications.

\subsubsection{Load Combination For Level D Service Limits And Crack Growth Under Significant Plasticity Across The Thickness}

Current regulatory systems safety criteria and regulatory positions require that the Level D operating conditions for Safety Class 1 components of nuclear power plants include the simultaneous effects of the Safe Shutdown Earthquake (SSE) and a loss of coolant event (LOCE). Probably no other single regulatory requirement has had the economic impact on plant design as this load simulataneity stipulation. Efforts have been underway for many years, by both reactor steam system suppliers and by regulatory consultants, in an attempt to mitigate this load combination requirement, and the role of non-linear stress analysis in general and non-linear fracture mechanics in particular, is central to these efforts.

The Advisory Committee on Reactor Safeguards has indicated to the USNRC staff the willingness to entertain arguments for decoupling the loadings from the SSE and the LOCE, as a prelude to modification of regulatory Guide 1.48; however, the ACRS has cautioned USNRC staff that these arguments, dependent as they are upon non-linear fracture mechanics concepts, should be complete and convincing. For example, some reasonable evidence should be produced that justifies the position that while the SSE cannot promote rapid crack propagation sufficient to initiate a LOCE, considerably lower cyclic loads are able to cause significant failures in $\mathrm{Cl}$ ass 2 equipment. Measurable crack growth during a sufficiently intense seismic event, such as a safe shutdown earthquake is the crux of the load combination 
controversy now before the ACRS. The arguments separating SSE loads from LOCE loads rest on the available techniques for ductile crack growth that requires non-linear analysis for the development of a viable criteria.

\subsubsection{Functional Requirements of Mechanical Components}

Operabilty and functional adequacy of components such as pumps and values is required by the Code to be established by the Owner. The explicit definition of loading and evaluation criteria are left in current practice to negotiation between the owner and regulatory authorities. Unlike pressure vessel components such as shells, nozzles, etc., no systematic failure mode analys is has been available to establish realistic requirements and criteria for such mechanicaliy discontinuous components. Therefore the deformation, strain, and stress limits currently specified are essentially borrowed from components that are of different structural behavior. Much of the valve seating, shaft loading, etc., conditions require analys is of local non-linear effects (Hertzian stresses at contact areas, etc.). Seizure of the pump shaft on one extreme and excessive vibration on the other can be the result of inadequate tolerance and deformation limits. These areas require further definition but are natural candidates for non-linear analys is for design specification, design evaluation and criteria development.

Table 1 contains merit ratings of the potential benefits of nonlinear analyses for the various target areas presented above. These ratings consider two design measures: the first utilizes the current design criteria, ASME, Reg. Guide, accepted practice, etc. The second is based on improved criteria such as, for example, new Reg. Guides for LOCA-SSE combination, new nozzle reinforcement rule (not based on area replacement), new shakedown limits, plastic fracture criteria, etc., In sumary: 
TABLE 1 SUMMARY AND RATING OF EXPECTED BENEFITS OF NON-LINEAR ANALYSIS

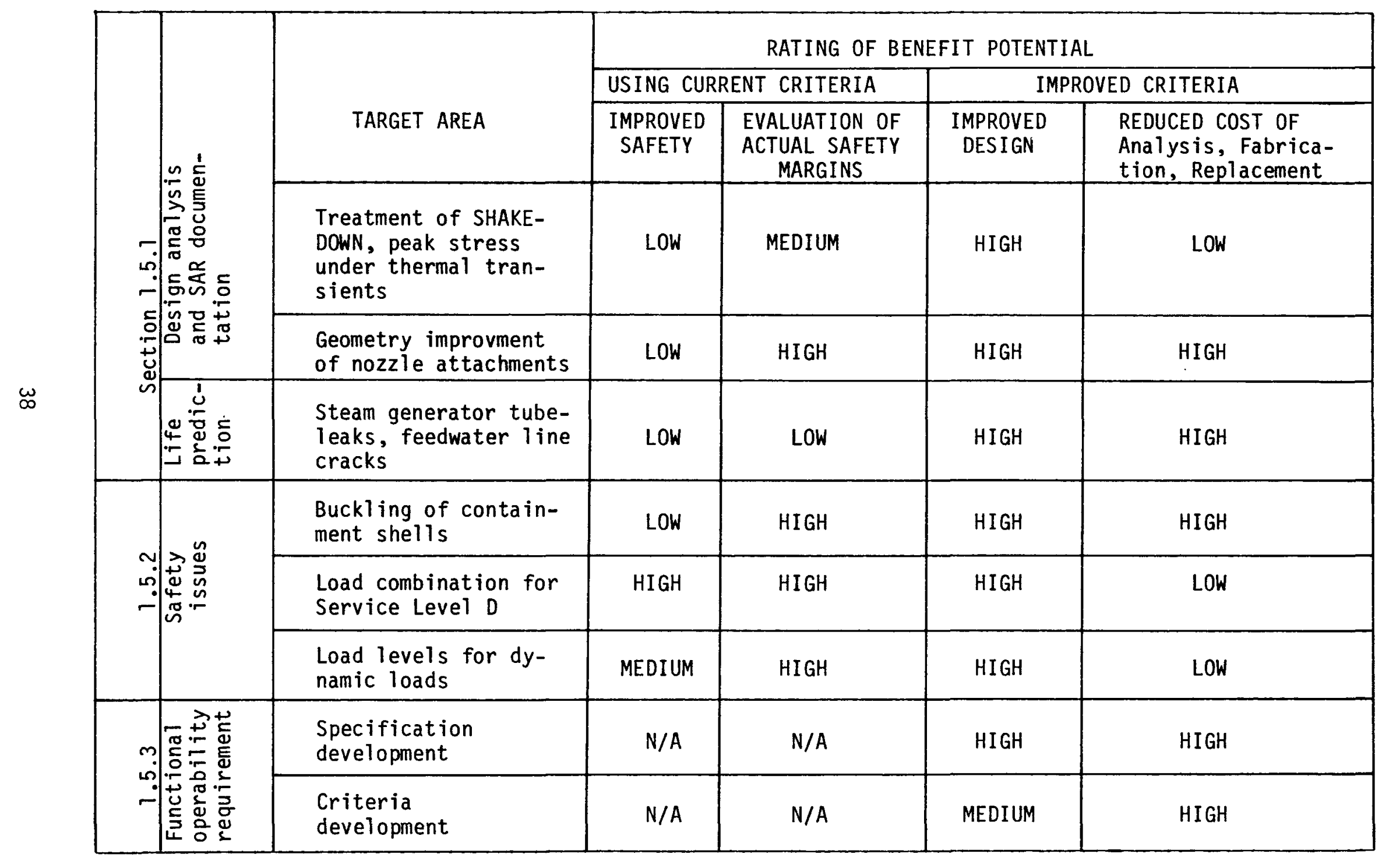




\section{NON-LINEAR ANALYSIS}

The utility of non-linear analyses in LWR design is examined from two aspects: First, the general practicality of performing such analyses is evaluated relative to material behavior, geometric modeling and cost. Secondly, the usefulness of non-linear analyses in quantifying true safety margins and improved design economy are assessed through actual examples.

Methods of non-linear analysis have in recent years attained various degrees of maturity depending upon the levels of understanding of material behavior and the types of non-linearities being considered. In the low temperature regimes (below $800^{\circ} \mathrm{F}$ ), which generally characterizes LWR applications (excluding fuel elements), quasi-static non-linear effects resulting from thermal and irradiation-induced creep are generally small and can be neglected. For similar reasons, the strain-rate sensitivity of tne material, which significantly influences the structure's response during trermal transients can be ignored. Having eliminated these two aspects of material behavior, namely, strain-rate sensitivity and creep, the only remaining material non-linearity one must consider is time-independent plasticity.

Although time-independent elastic-plastic analys is methodologies are well developed, many of their features still remain highly controversial. These include the choice of yield criterion and hardening rule, the distinction between loading surfaces and yield surfaces, radial vs. nonradial loading and the constitutive description under large plastic strains. Detailed examination of these aspects of plasticity falls outside the scope of this discussion; however, it is necessary for the present purposes to identify a state of acceptable level of current practice in elastic-plastic analysis of reactor components. Such a state of practice can be described as follows:

(a) Finite-element-based codes are utilized almost exclusively.

(b) Von Mises yield criterion and associated flow rule are adopted almost universally. No distinction is made oetween yield and loading surfaces. 
(c) The isotropic hardening rule and the kinematic hardening rule have been utilized with the latter being the more representative of cyclically-saturated material behavior.

(d) Although cyclic dependence of the stress-strain curve (i.e. combined isotropic-kinematic hardening) have been incorporated in analysis, design analyses generally utilize cyclic-independent (saturated) curves. This implies the use of kinematic-hardening rule.

(e) Although technical controversy surrounded the use of linear vs. non-linear kinematic hardening in earlier applications, non-linear kinematic hardening models have been incorporated in analysis and have become accepted methodologies.

(f) Initial strain vs, tangent stiffness approaches have received many pro and con arguments, the use of one or the other, given correct constitutive formulation, is generally a matter of economy and convenience. The tangent stiffness approach, however, has become more widely accepted as it offers improved convergence and better accuracy when the stressstrain curve becomes fairly flat.

(g) Although finite element spatial modeling can be independent of material modeling, the inter-relationship between the spatial behavior, such as for example the propagation of the plastic zone, and the material constitutive description requires a judicial choice of finite element type and mesh density. There is no general rule for selecting a given mesh density and the best guide is experience and good knowledge of non-linear material behavior. This area in general contributes the largest uncertainty in the analys is next to material data scatter.

(h) Interaction of material and geometric non-linearities is far less developed, but analys is tools for large strain 
plasticity are available. The three areas where such interaction might occur are plastic collapse, large deformations leading to loss of function, and plastic fracture.

Considering these general guidelines for the current state of elastic-plastic analysis, it is useful for the objectives of this work to give a mathematical description of material models and constitutive relations that would constitute a practical and accepted methodology.

\subsection{MATERIAL MODELS FOR LWR ELASTIC-PLASTIC ANALYSIS}

As was discussed earlier, adequate consideration must be given to the practical aspects of material modeling that would render non-linear analyses achievable on a routine basis consistently with the daily demands of the design process. Therefore, by necessity, the material models and the companion constitutive relations must be based on qualified proven theories for which ample experimental support exists. In this section, we present such models without derivations whereby relying on the literature to provide the necessary details.

In the early stages of elastic-plastic analysis, the material constitutive models were based on isotropic hardening and the Prandt1-Reuss Stress-Strain relations. The kinematic hardening rule, which was proposed by Prager [11] to better represent the hysteritic behavior of metals, did not find its way into computerized finite-element analyses until the early part of this decade when LMFBR program was launched. Even then, the LMFBR design-by-analysis methodology as described in RDT standard F9-5 restricted the use of kinematic hardening theory to Prager's original postulate of linear hardening, namely admitting only the use of bi-linear stress-strain curves. This presented a number of difficulties, since the materials used in LMFBR design, namely stainless steel types 304 and 316, exhibited strong hardening characteristics, and, therefore, artificial rules for bi-linear curves had to be devised [12]. Combined loadings that could result in non-radial loading situations, i.e., thermal and pressure, presented certain problems for which linear kinematic hardening theory was thougnt to be 
adequate. Cyclic-dependent bi-linear stress-strain curves were devised in which the yield stress depended on cycle and temperature [13]. Finite element computer codes which include these material models exist and are currently used in practice. This state of development, though somewhat deficient, is thought to present a reasonably reliable and generally practiced method of design-by-analysis.

Further developments in non-linear material modeling $[14,15]$ reinforced the use of general non-linear stress-strain curves in finite element analysis. Although the cyclic dependence of stress-strain curves can be handled within a non-linear kinematic hardening theory, the saturated curve constitutes the basis for elastic-plastic analysis. It is believed that the current state of practice permits elastic-plastic analyses utilizing general non-linear stress-strain curves, combined states of loading and unloadings, including incursion into reversed plasticity. The mathematical description of the model presented below includes such general features, but it can also be used under the restricted assumption of bi-linear stressstrain curve as in the case of LMFBR practice.

Prager's kinematic hardening rule [11], makes use of Von Mises yield potential in the following form:

$$
F=1 / 2 S_{i j} S_{i j}^{\prime}-K^{2}
$$

where

$$
\begin{aligned}
& S_{i j}^{\prime}=\sigma_{i j}^{\prime}-1 / 3 \sigma_{k k}^{\prime} \delta_{i j} \\
& \sigma_{i j}^{\prime}=\sigma_{i j}-\alpha_{i j}
\end{aligned}
$$

$\alpha_{i j}$ being the translations of the yield surface and $K$ is a material parameter which may depend on the material environment. By Prager's assumption, the yield surface translates in the direction of the plastic strains, namely,

$$
\alpha_{i j}=c \varepsilon_{i j}^{p}
$$


where $C$ is a constant, related to the slope of a bilinear stress plasticstrain curve, and $\varepsilon_{i j}^{p}$ are the plastic strains.

The above linear kinematic hardening theory can be extended to non-linear kinematic hardening (See for example Reference 15) by requiring that

$$
\alpha_{i j}=\int C d \varepsilon \stackrel{p}{i j}^{p}
$$

Note that in this equation, $C$ becomes a function of the plastic strains.

The integration in (5) is taken over the most recent plastic path. This derivation led to the following equation for $\mathrm{C}$ :

$$
C=2 / 3 E_{t} /\left(1-E_{t} / E\right)
$$

where $E$ and $E_{t}$ are the elastic modulus and tangent modulus respectively.

Consider the effective stress-effective strain curve shown in Figure 3 , which represents the uniaxial equivalence of three-dimensional state of stress. The points $x_{1}, x_{2}$ and $x$ represent the states of initial yielding, reversed yielding and post yielding, respectively. Now, the yield surface translations $\alpha_{i j}$ are represented on the curve uniaxially by $\alpha_{e}$ during the initial post yielding state and $\alpha^{*}$ e during reversed plasticity state. These two quantities are defined by

$$
\begin{aligned}
& \alpha_{e}=3 / 2\left(\alpha_{i j}-1 / 3 \alpha_{k k} \delta_{i j}\right)\left(\alpha_{i j}-1 / 3 \alpha_{k k} \delta_{i j}\right)^{1 / 2} \\
& \alpha_{e}^{*}=3 / 2\left(\alpha^{*}{ }_{i j}-1 / 3 \alpha_{k k}^{*} \delta_{i j}\right)\left(\alpha^{\star}{ }_{i j}-1 / 3 \alpha_{k k}^{*} \delta_{i j}\right)^{1 / 2}
\end{aligned}
$$

where

$$
\alpha_{i j}=\int_{x_{1}}^{x} d \alpha_{i j}=\int_{x}^{x} c d \varepsilon_{i j}^{p}
$$



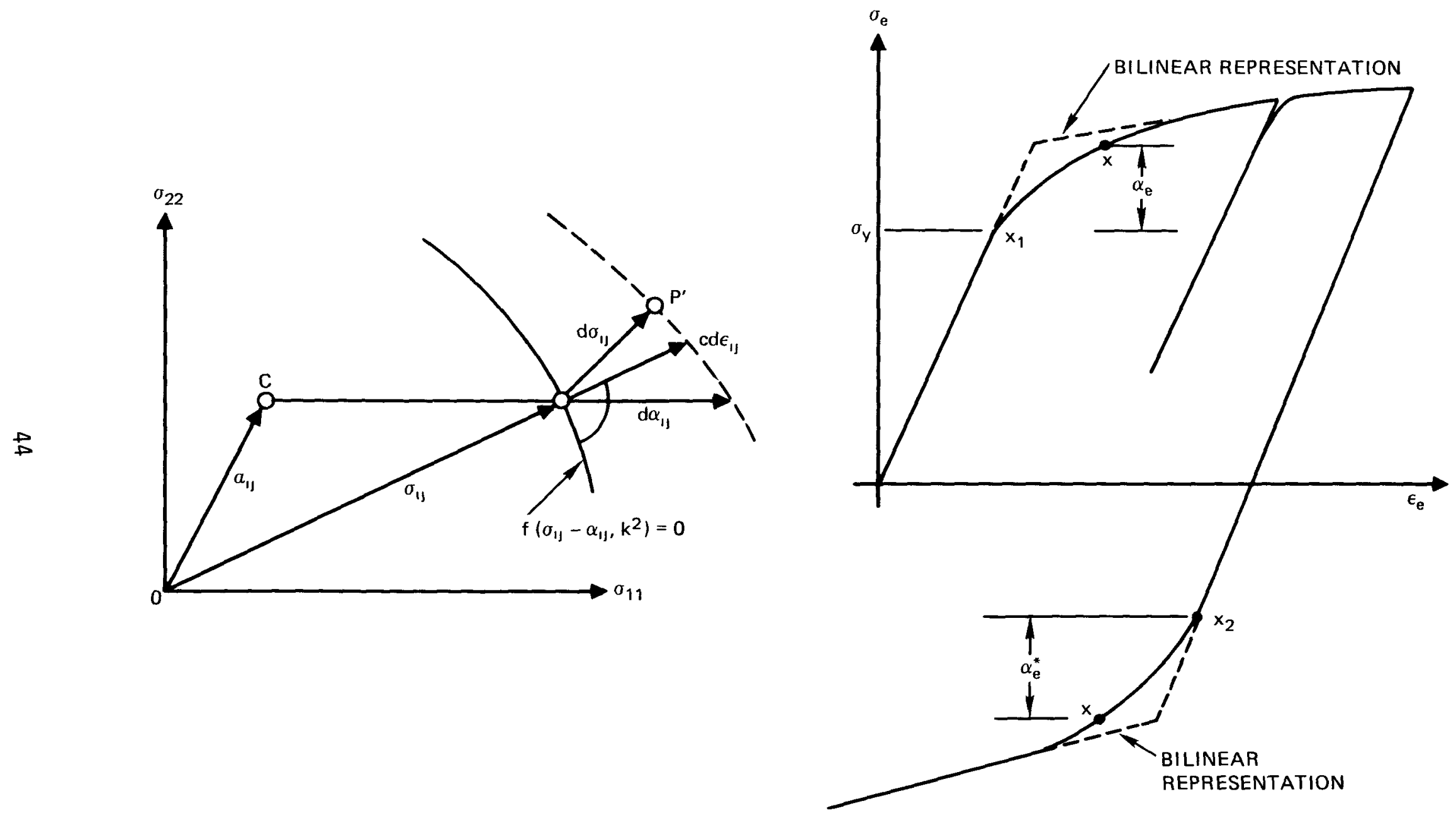

Figure 3 Stress-Strain and Yield Surface Representations 
and

$$
\alpha_{i j}^{*}=\int_{x_{2}}^{x} d \alpha^{*}{ }_{i j}=\int_{x_{2}}^{x} c d \varepsilon_{i j}^{p}
$$

Equations (9) and (10) simply mean that the integrations are taken over the plastic path just preceeding the current state $x$. Note that elastic unloading and reloading contribute nothing to the $\alpha_{i j}$ 's and $\alpha^{*}{ }_{i j}{ }^{\prime} s$. If, instead of plotting the stress vs. total strain as in Figure 3 , one plots the stress vs. plastic strain, the parameter $C$ becomes equal to $2 / 3$ the slope of such curve, namely,

$$
C=2 / 3 \frac{d \alpha e}{d \varepsilon_{e}^{p}} \text { or } 2 / 3 \frac{d \alpha^{*} e}{d \varepsilon_{e}^{p}}
$$

depending on which branch of the curve the current state $x$ is situated. Equation (11) is not a practical representation of the material data, and, therefore, the parameter $C$ is usually obtained from equation (6), which utilizes the usual stress-strain curve. In this equation

$$
E_{t}=\frac{d \sigma_{e}}{d \varepsilon_{e}}=\frac{d \sigma_{e}}{d \varepsilon_{e}} \text { or } \frac{d \sigma^{*} e}{d \varepsilon_{e}}
$$

depending upon the position of $x$ on the curve. In actual analysis, it is not necessary to distinguish between $\alpha_{i j}$ and $\alpha^{*}{ }_{i j}$ if the process of incremental accumulation of $\alpha_{i j}$ is re-initialized at each new state of yielding. This usually takes place whenever the inner product inequality

$$
\alpha^{\star}{ }_{i j} d \sigma_{i j}<0
$$

holds, which occurs only at the onset of reversed plasticity, as would exist at all elastic-plastic transition points in the hysterisis loop.

If the stress-strain curve in Figure 3 represents the saturated curve, i.e., it does not vary with subsequent cycles, then it would represent a bound on the material behavior. Another bound can be proposed in the form of bilinear representation as shown by the dotted line. For this bound, the 
analysis would be simpler, since the constant hardening modulus is independent of the history of deformation and the distinction between the $\alpha_{i j}$ and $\alpha^{*}{ }_{i j}$ becomes irrelevant in this case. This type of bilinear representation has been discussed earlier in this section; it can, however, be treated as a special case of the non-linear model.

Now, having defined the necessary features of a bounding material model, the derivation of incremental stress-strain relations follows routinely. The final results are given by the following equations. The stress incremental vector $\Delta \underset{\sim}{\sigma}$ is related to the total strain incremental vector $\Delta \underset{\sim}{\varepsilon}$ under non-isothermal conditions by the following equation:

$$
\Delta \sigma=\underset{\sim}{H}(\underset{\sim}{\varepsilon}-\Delta \underset{\sim}{\theta})+2 \eta \frac{K \Delta K}{Q} \underset{\sim}{D} \mathcal{\sim}^{\prime}
$$

where

$$
\begin{aligned}
& \underset{\sim}{H}=\underset{\sim}{D}-\underset{\sim}{D} S_{\sim}{ }_{\sim}^{S} \cdot{ }^{T} \underset{\sim}{D} / Q \\
& Q=\underset{\sim}{S^{-}}{ }_{\sim \sim} S_{\sim}{ }^{\prime}+C S_{\sim}^{-T} S_{\sim}{ }^{\prime}
\end{aligned}
$$

In the above equations, $\underset{\sim}{D}$ is the elastic material matrix, $\Delta \underset{\sim}{\sigma}$ is the thermal strain incremental vector, $S_{\sim}^{\prime}$ is the deviatoric stress vector whose elements $S_{i j}$ are defined in equation (2), $C$ is the hardening parameter defined in equation ( $\hat{\sigma}), n$ is zero or unity for elastic or plastic states, respectively, and $K$ is material parameter given in equation (1) and is equal to $\sigma_{y} / \sqrt{3}$ where $\sigma_{y}$ is the temperature dependent yield stress. The yield surface translations $d_{\alpha_{i j}}$ are given by

$$
d \alpha_{i j}=\sigma_{i j}^{\prime}\left(S_{m n}^{\prime} d \sigma_{m n}-2 K \Delta K\right) /\left(\sigma_{k 1}^{\prime} S_{k l}^{\prime}\right)
$$




\subsection{SOIL MODELING FOR NON-LINEAR SOIL-STRUCTURE INTERACTION SEISMIC ANALYSIS:}

The literature is quite extensive on the subject of the mechanical properties of soils, and the reader is referred to Reference [16] for discussion and bibliography. From an analytical modeling point of view, however, one requires the following information: A stress-strain curve for the soil encompassing the hysterisis loop obtained in a dynamic test, and a yield or a "failure" surface. Stress-strain curves can be obtained [17] in a variety of ways depending upon the type of soil and the ultimate utility of the test results. Such data is generally available to the analyst in the form of shear modulus as a function of strain and confining pressure. Sites composed of sandy soils generally exhibit insitu properties in the form

$$
G=A(\varepsilon) \sigma^{2 / 3}
$$

Where $G$ is the shear modulus, $\sigma$ is the confining pressure, and $A(\varepsilon)$ is strain dependent scalar function. The confining pressure $\sigma$ is usually taken to be equal to $2 / 3$ the overburden stress. The experimental parameter $A(\varepsilon)$ varies with the type of soil and the site. Figure 4 shows typical values for dense sand. The coefficient of lateral pressure, which is analogous to Poisson's ratio for solids, is typically .45.

The above properties are sufficient to conduct non-linear elastic Jynamic analysis (non-linear by virtue of the fact that the shear modulus depends on the strain and the confining pressure). However, the true nonlinearities of the soil are further mobilized through the failure surface of the material which can be adequately described by the Mohr-Coulumb criterion as follows:

$$
T=C+\sigma \tan \phi
$$

where $T$ is the ultimate shear capacity of the soil, $\sigma$ is the hydrostatic pressure, $\phi$ is the angle of internal friction and $C$ is the cohesion. Typical values for $\phi$ range from $30^{\circ}$ to $45^{\circ}$, and the cohesion varies from as small as 100 1b./sq.ft. to about 700 1b./sq.ft. for dense sand deposits. A more 


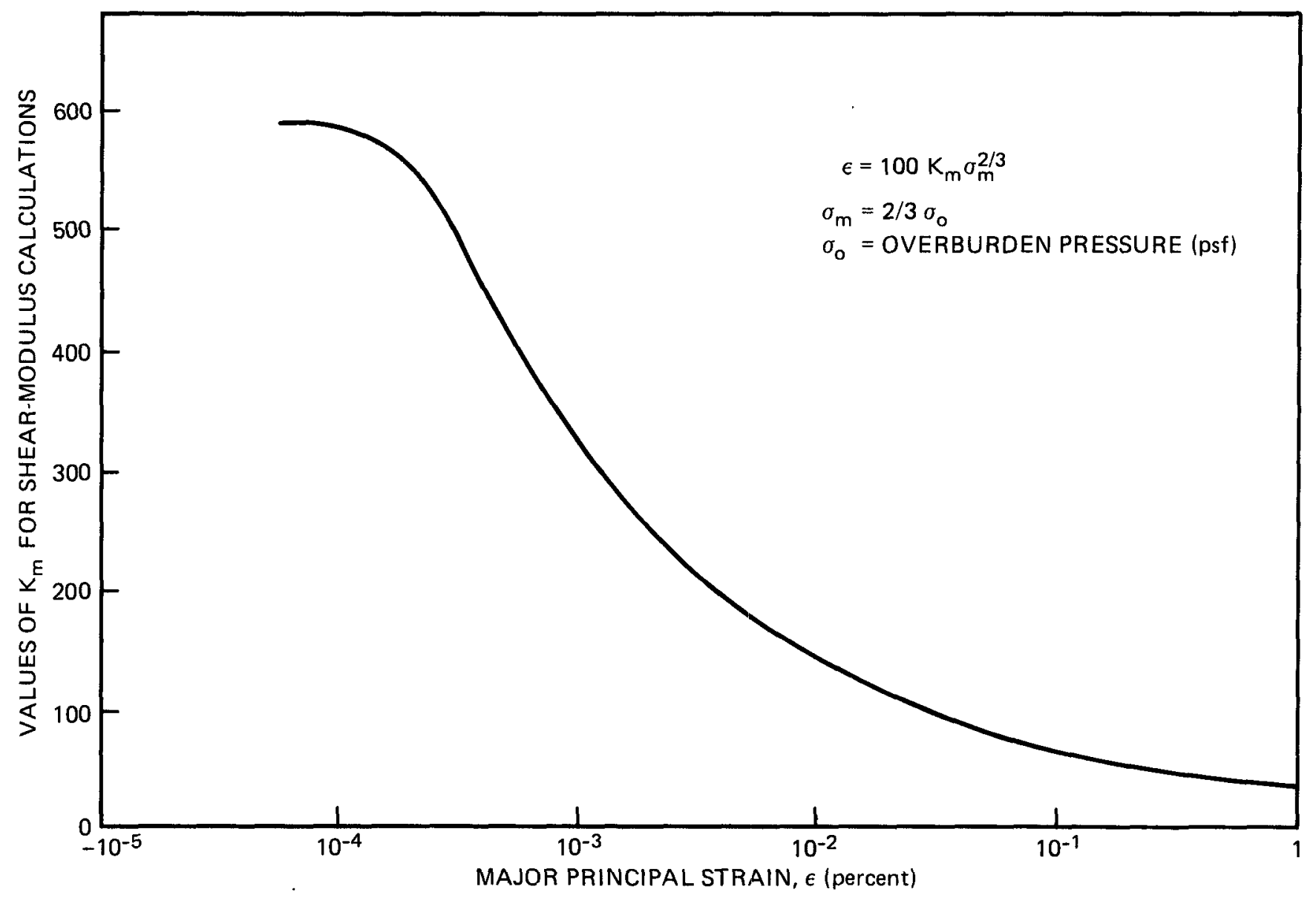

Figure 4 Dependence of the Shear Modulus of Dense Sands on Strain 
convenient, but equivalent, criterion used in finite element analysis is the Drucker-Prager criterion given in the form [18]:

$$
\mathrm{J}_{2}^{1 / 2}+\alpha \mathrm{J}_{1}-\mathrm{k}=0
$$

in which $\alpha$ and $K$ are material parameters related to the Mohr-Coulumb parameters by the following equation:

$$
\alpha=2 \sin \phi /[\sqrt{3}(3-\sin \phi)]
$$

and

$$
K=6 C \cos \phi /[\sqrt{3}(3-\sin \phi)]
$$

The stress invariants $\mathrm{J}_{1}$ and $\mathrm{J}_{2}$ are given by

$$
\mathrm{J}_{1}=\sigma_{\mathrm{kk}}
$$

and

$$
\mathrm{J}_{2}=1 / 2 \mathrm{~S}_{\mathrm{ij}} \mathrm{S}_{\mathrm{ij}}
$$

The stress-strain curve used in conjunction with this yield criterion is elastic-perfectly plastic in compression with usually zero tension cut-off.

The above set of equations describe an appropriate constitutive model for the soil, which can be incorporated in finite element dynamic codes with time integration algorithms. The development and usage of such codes, however, have not become part of the accepted practice in the industry, a)though one-dimensional linear wave-propagation codes, such as SHAKE [19], have become well known soil-structure interaction tools.

Current prevailing practice relies on linear analyses in which the soil is represented as linear springs. This permits modal superposition and the use of DBE (design basis earthquake) spectra, as specified in Regulation Guide 1.60, as input to lumped parameter dynamic models from which response spectra can be generated for various sub-components of the reactor plant. 
Non-linear analyses in which time-stepping replaces modal superposition can be alternatively carried out, utilizing artificial earthquake acceleration time histories generated form the design spectrum. This spectrum-matching technique of generating artificial acceleration records whose spectrum matches the NRC Regulatory Guide 1.60 spectrum is shown in Figure 5 for illustration.

It is clear from the above discussion that non-linear soilstructure interaction analysis, to be valid, must account for true soil properties and appropriate consitutive relations that account for MohrCoulumb, or equivalently, Drucker-Prager failure criterion, and straindependent shear modulus. Aside from these material considerations, however, one must further consider the spatial modeling of the soil medium and the kinematic representation of the governing equations of the soil-structure system. Two types of computer models have been utilized in the industry: the first represents the soil as a vibrating medium in which the seismic input is converted to equivalent inertia forces. The second type models the response of the soil as a shear wave propagating upward in the soil strata form the underlying bedrock [19]. Both methods can utilize non-linear constitutive relations, although the state of the art in this regard is not fully developed.

The spatial idealization and boundary conditions of the soil medium depends on the analyst's choice from the above two types of models. A one-dimensional infinite-extent layered system or a two-dimensional finiteelement grid with non-reflecting boundaries are two possible spatial representations for the wave-propagation analysis. However, the equivalent inertia vibration model generally utilizes either a non-linear spring or a finite-element representation of sufficient extent to minimize boundary effects.

\subsection{GEOMETRIC NON-LINEARITIES}

As in the case of material non-linearities based on small strain theory, large deformation analysis capabilitieis have become an accepted 


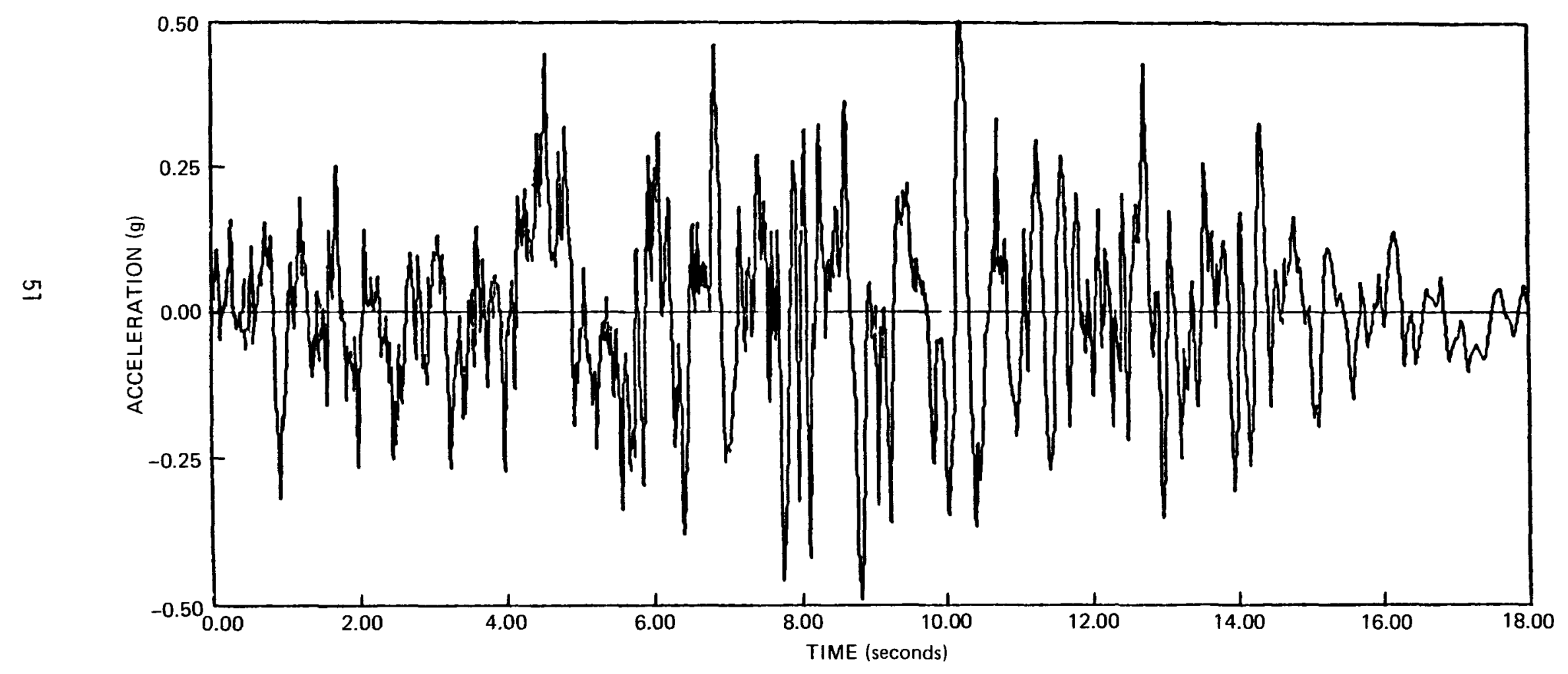

Figure 5 Artificial Earthquake Acceleration Time History 
practice in finite element analysis. The development of these capabilities followed a hierarchy of sophistication. The simpliest of these developments is based on elastic material behavior and the target of application of the resulting model is elastic instability and large deflection of long slender members.

The second level of sophistication of large deformation analysis combines infinitesimal elastic-plastic constitutive relations with smallstrain large rotation formulation. In this case the application extends to plastic buckling analysis of slender structures, such as, for example, reactor containments. The state of practice for this type of analysis is well developed and gives reliable results. The fact that the strains remain small in these analyses would not invalidate the material constitutive law being used and which is based on small strain theory.

The third level of sophistication of finite deformation models removes the limitation on the magnitude of the strain. However, in doing so the small strain constitutive law is assumed to apply to finite strains, not in total but incrementally. This is to say that the incremental constitutive relations that are developed for small strain theory are formulated for conjugate stress rate and strain rate measures that are materially objective, (i.e., produce no stress under rigid body rotation. Application of this type of model in LWR analysis practice would be limited to special types of problems, such as plastic fracture, where large highly localized strains can develop. Although it is outside the scope of this report, it would be worth mentioning that large strain, large displacement models of this type combined with inelastic strain-rate-sensitive constitutive law is required for accident analyses of LWR fuel rods. Such a model is currently under development [20].

Appropriate formulation of constitutive relations, regardless of the magnitudes of the strains, is an absolute requirement for the validity of elastic-plastic analysis. Most computer codes utilize the same classical theory, (e.g., Von Mises yield criterion and flow rule, kinematic hardening, etc.); however, the internal structures of these codes, which are not visible 
to the user, can vary considerably in their algorithms that in some cases incorrect treatment of the internal variables of the theory could result. This is not an uncommon occurance, and since the responsibility for the correctness of the analysis lies with the user, this could create serious quality assurance problems in non-linear computer code usage.

The nuclear industry is not unaware of these problems, but except for the simplest application of computer codes, namely, linear-elastic Code-type analyses, the Q.A. of computer codes still remains to be resolved. Therefore, any future applications of non-linear analysis in LWR systems will have to address this important issue.

\subsection{GEOMETRIC FEATURES AND COST CONSIDERATIONS}

It is discussed earlier in this report that the viability of non-linear analysis methods in LWR design practice depends very strongly on the practical aspects of these methods. These are generally judged by two considerations: cost (engineering and computer) and schedule. A third, but indirect, element of equal importance is the presence of the necessary technical skills for executing non-linear analyses successfully and interpreting the results appropriately.

Despite popular belief to the contrary, the largest cost element in 20 non-linear analyses is the cost of engineering, although computer cost has traditionally received the larger emphasis. This is so because the computer cost is ofter paid out of the analysis budget in cash, and is particularly painful if one uses out-of-house service bureaus. Therefore, the motivation for shorter running time is generally strong, and analys is economy is sometimes accomplished at the expense of accuracy or even the correctness of the results. Quite often the decision is made by the code developer, who might choose less sophisticated, and perhaps questionable, theory and internal algorithm, and thereby add to the Q.A. concerns discussed previousiy. 
Aside from theoretical considerations, one cannot ignore the fact that the computer cost of non-linear analyses has direct input to their becoming part of LWR design practice. Although, in theory, the extension of two dimensional analysis to three dimensions requires only the existence of three dimensional element framework, the state of practice discourages three dimensional analyses. The cost, both computer and engineering, can become prohibitive. Consider for example, the analysis of, say, the feedwater nozzle of a reactor pressure vessel which can be modeled both in 20 and 30 . If one is to maintain the same level of spatial accuracy in both models, the 20 finite element grid could consist of 700 to 800 unknowns, with a bandwidth of about 70. The 3D model, however, would be at least ten times the size and bandwidth. The computer time, assuming proportionate use of I.0., is generally proportional to the square of the bandwidth and linear with the number of equations. This gives a solution time factor of about 1,000 between the 30 and 20 models. Even a factor of 100 can be unacceptable, depending on the size of the problem. These cost ratios are borne out by the cost analysis of two actual cases: 3D linear and 2D non-linear analyses of a reactor vessel feedwater nozzle. The 3D linear elastic analys is was conducted to evaluate the crack growth characteristics in the nozzle and was done in 1971, see reference [21]; the non-linear analysis was carried out in the course of the present study, the first complete solution used 4.5 hours of UNIVAC - 1108 time. Crack release was accomplished in 8 steps, each of which took 1.5 hours, having made use of the initial matrix decomposition. If one is to make an analogy with time-stepped analysis, this 3D analysis may be regarded as a 9-step solution of a geometrically non-linear, materially linear problem, at a cost of 16.5 UNIVAC - 1108 hours. Although 3D finite element analysis has progressed considerably since then, the point can still be made that 30 solutions of practical size are very expensive. By contrast with the 30 analysis, a comparable grid of 8-node isoparametric elements was used for the two-dimensional elastic-plastic solution which used 0.5 system seconds of CDC-7600 time per step. The cost ratio for present day 1108 and 7600 is about $1 / 7$, and the $C P$ speed ratio between the two machines is about 25. This implies that if the $3 D$ analysis was to be repeated today on the 7600 , considering 9 steps, its' cost would amount to over $\$ 20,000$ compared to $y$ step 2D solution cost of under $\$ 50$. This is fairly consistent with the factor of 100 to 1,000 discussed previously. 
It is interesting to note that the engineering cost differential between the $3 \mathrm{D}$ and the $2 \mathrm{D}$ is very small by comparison, and could seldom exceed a factor of 2 . Therefore, the over-riding consideration against 3D non-linear analyses is the cost of computing time. However, with increased use of array processors, large scale 3D computations will become feasible. In the mean time, however, 3D non-linear analysis will have to be categorized as non-practical for general use in LWR component design. There will still be a place, however, for 3D non-linear analyses for special circumstances for which their omission far exceeds their cost. By contrast, two-dimensional non-linear analyses are well written within acceptable practical limitations and can be used to great advantages in LWR design practice.

\section{$2.5 \quad$ ANALYSIS EXAMPLES}

Qualitative arguments have been made in preceeding sections of this report to support the hypothesis that great benefits can be achieved from applying non-linear methodology to LWR component design and analysis. This hypothesis is quantitatively examined in this section through three examples, each of which emphasizes one important aspect of the general problem. The first deals with an elastic-plastic analysis of a pressure vessel nozzle which has been designed to meet the requirements of Section III of the ASME code. The point to be demonstrated by this analysis is that such nozzles which are costly to manufacture and weld can be unnecessarily overconservative in their design. Furthermore, considering that the real performance problem with feedwater nozzles is their propensity for cracking under thermal cycling, non-linear analysis can be used to optimize the nozzle geometry for this condition rather than maintain the current practice of replacement area method which is based on primary stress considerations.

The second example demonstrates the utility of non-linear analysis in determining the true safety margin of containment structures against buckling. The analysis presented here gives further demonstration that, given non-linear capapilities, special techniques can be devised to simplify elastic-plastic buckling analyses without sacrificing accuracy. 
The third example deals with an area that may have a large impact on the overall cost and licensing of the NSSS, and that is the definition of seismic loading on internal components. Since earthquake type loadings are determined by analysis, rather than direct physical data, the analysis assumptions dealing with the soil behavior as a medium for transmitting earthquake motion to the reactor structure becomes of critical importance. The analysis presented here will show that the inherent non-linearity of the soil, when accounted for in the analysis, can significantly mitigate ground motions. This particular area, however, is far less advanced than non-linear analysis of metal structures and would require further development before its potential in LWR design practice can be fully utilized.

\subsubsection{Shakedown Analysis of Pressure Vessel Nozzle}

Nozzle geometry is usually set by the ASME Code rules embodied in the area-replacement method and the Code stress limits. The area replacement method is based on the principle that the collapse load of the original vessel should be unaltered by the presence of the nozzle. The Code further gives specific rules for depositing the replaced material in the nozzle geometry. The purpose of the present analysis is to demonstrate that this method of design of pressure vessel nozzles can be overly conservative, and may even result in undesirable distribution of material.

The nozzle configuration selected for this analys is is shown in Figure $6 \mathrm{a}$, which is the same one used in the previous three-dimensional crack growth analysis [21] mentioned earlier. Since the pressure vessel is cylindrical and, therefore, would require three-dimensional modeling of the nozzle area, some geometric modification had to be introduced to permit an equivalent two-dimensional (axisymmetric) analysis. This was accomplished by requiring that the membrane stress in the original vessel be equal to the model, which meant that the vessel section in the model be given twice the radius of the original vessel. A finite element grid which models this equivalent configuration is shown in Fig. 6b. This grid contains 108 isoparametric 8 -node elements and 387 nodal points. 


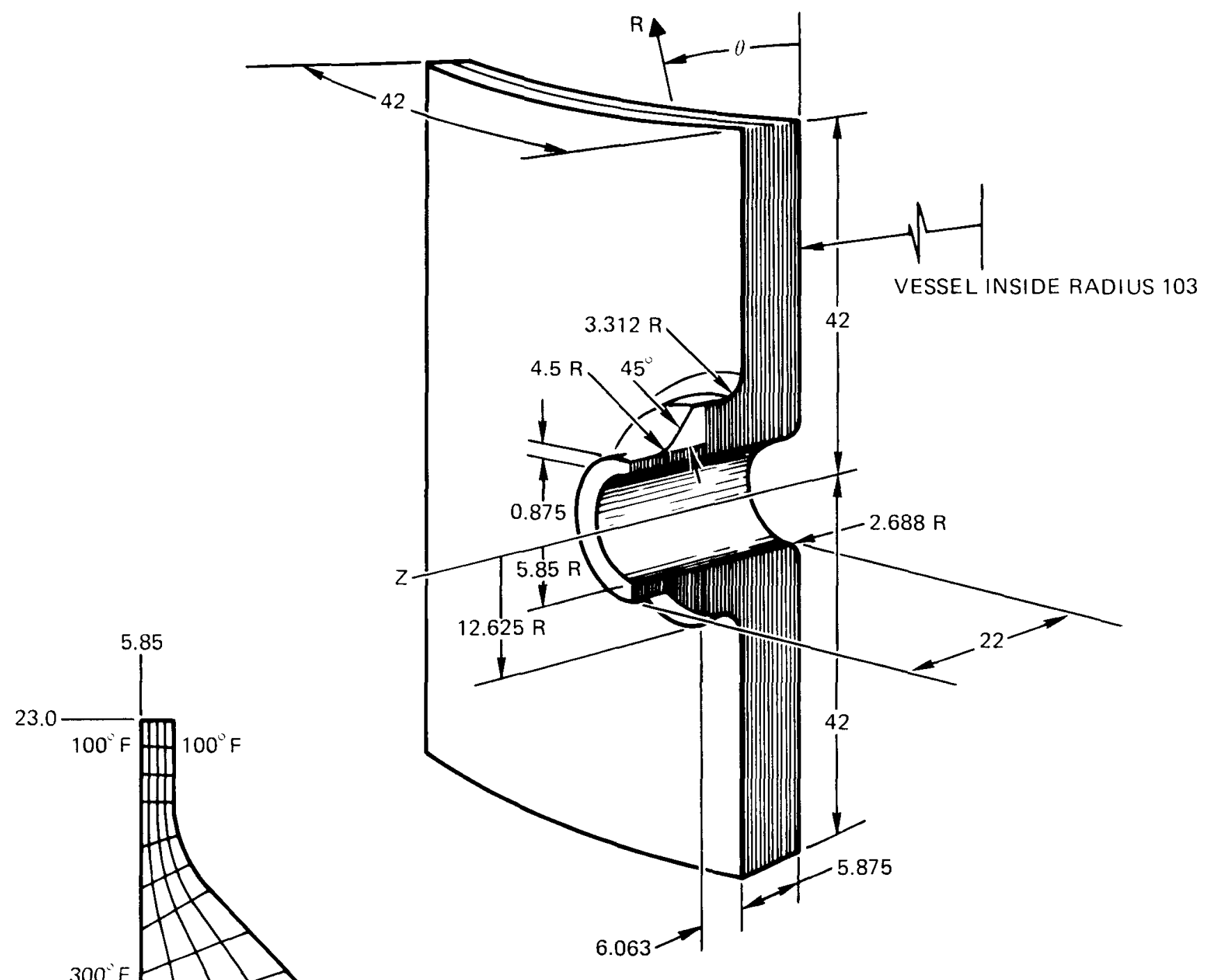

(a) Nozzle Geometry
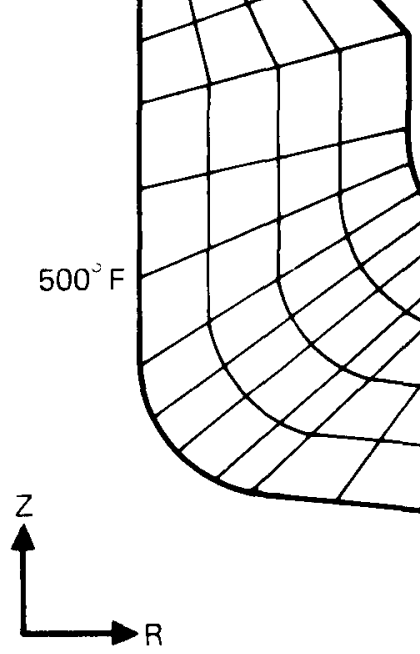
$500^{\circ}$

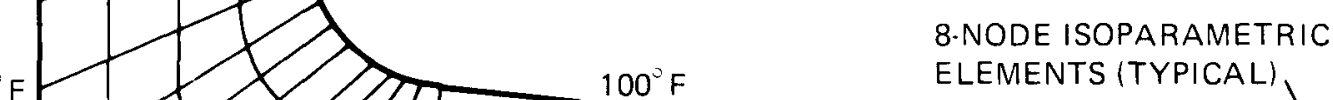

(b) Two-Dimensional Finite-Element Idealization

Figure 6 Finite Element Idealization of Axisymmetric Pressure Vessel Nozzle 
In addition to internal pressure, a steady state temperature distribution was imposed which consisted of $100^{\circ} \mathrm{F}$ on the outer surface and $500 \mathrm{~F}$ in the vessel and nozzle knee section decreasing linearly to $100^{\circ} \mathrm{F}$ at the thin section of the nozzle, as shown in Fig. 6b. This corresponds to a thermal gradient of $65^{\circ} \mathrm{F} /$ inch in the vessel section.

The material selected is stainless steel type 304 with an elastic modulus of $26.5 \times 10^{6} \mathrm{psi}$, a proportional limit of $11,000 \mathrm{psi}$ and $0.2 \%$ offset yield stress of $21,500 \mathrm{psi}$. The elastic-plastic portion of the stress-strain curve at $500^{\circ} \mathrm{F}$ is described by the formula $\varepsilon=\left(3 \times 10^{-6} \sigma-.0118\right)^{2}$.

The $S_{m}$ value for this material, according to the definition of the ASME Boiler and Pressure Vessel Code Criteria, is $19.0 \mathrm{Ksi}$. The magnitudes of the pressure and thermal loadings were selected consistently with this material data in order to ensure a Code-balanced design.

An elastic analysis was first carried out to select the design pressure and temperature in accordance with the code rules. This analys is gave a design pressure of $1,100 \mathrm{psi}$ and a temperature gradient of $57^{\circ} \mathrm{F}$ per inch of vessel thickness. The calculated stresses compared with the Code limits are shown below:

TYPE OF STRESS

General Primary Membrane

Local Primary Membrane

Primary Membrane Plus Bending

Primary Plus Secondary
CALCULATED

STRESS INTENSITY (Ksi)

$\mathrm{S}_{\mathrm{m}}$

$1.20 \mathrm{~S}_{\mathrm{m}}$

$1.42 \mathrm{~S}_{\mathrm{m}}$

$2.74 \mathrm{~S}_{\mathrm{m}}$
CODE LIMITS

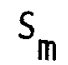

$1.5 \mathrm{~S}_{\mathrm{m}}$

$1.5 \mathrm{~S}_{\mathrm{m}}$

$3 S_{m}$

The next step in the analysis is to examine the reserve capacity of this nozzle by invoking the inelastic behavior of the material. In doing so, 
one must preserve the two basic design principles on which the design of the nozzle was originally based, and these are: first, the burst pressure of the vessel must not be reduced by the presence of the nozzle, and second, shakedown to elastic action within a few cycles must be demonstrated. Nonlinear analysis can be used to develop a physically more meaningful basis for the nozzle design and still satisfy these two criteria, namely, a sufficient safety margin against bursting and the assurance of shakedown. This can be accomplished in one of two ways: either maintain the same nozzle geometry but raise the design pressure and temperature, or alternatively reduce the nozzle geometry for the same design loads. The first alternative was selected for the present analysis.

Starting from the elastic state, the pressure and thermal loadings were increased proportionately in increments of $10 \%$ until an average value of $0.2 \%$ effective plastic strain was reached in the most critical section of the nozzle. This .2\% plastic strain limit was selected on the basis that, since the area-replacement rule resulted in operating stresses above the elastic limit, the $.2 \%$ offset strain constituted a physically more meaningful criterion. Fig. 7 shows a contour plot of the effective plastic strains in the nozzle at that condition. The corresponding pressure and thermal gradient were $1,250 \mathrm{psi}$ and $65^{\circ} \mathrm{F} /$ inch respectively. The elastic primary peak stress that corresponds to this pressure and temperature gradient, extrapolated from the elastic analysis, exceeds $100 \mathrm{Ksi}$. However, the true effective stress is calculated to be somewhat less than $24 \mathrm{ksi}$ as shown in Fig. 8. In order to examine the shakedown characteristics of the nozzle, the total loading was cycled between 1,250 -0- 125 for two cycles. The effective stress-effective strain and the hoop stress vs total hoop strain plots are shown in Fig.'s 8 and 9 respectively. As can be seen from these figures, elastic action is nearly restored after the second cycle. The analysis was terminated after it became clear that subsequent cycling would confirm the trend already established. From the standpoint of safety margin against failure, the total peak stress at $24 \mathrm{ksi}$ can be compared with the minimum tensile strength of this material, which is estimated to be $77 \mathrm{ksi}$, thus giving a factor of 3 . This value of $77 \mathrm{Ksi}$ also corresponds to $10 \%$ strain, which is about 30 times the peak strain (including strain concentration) reached at 1,250 psi. 


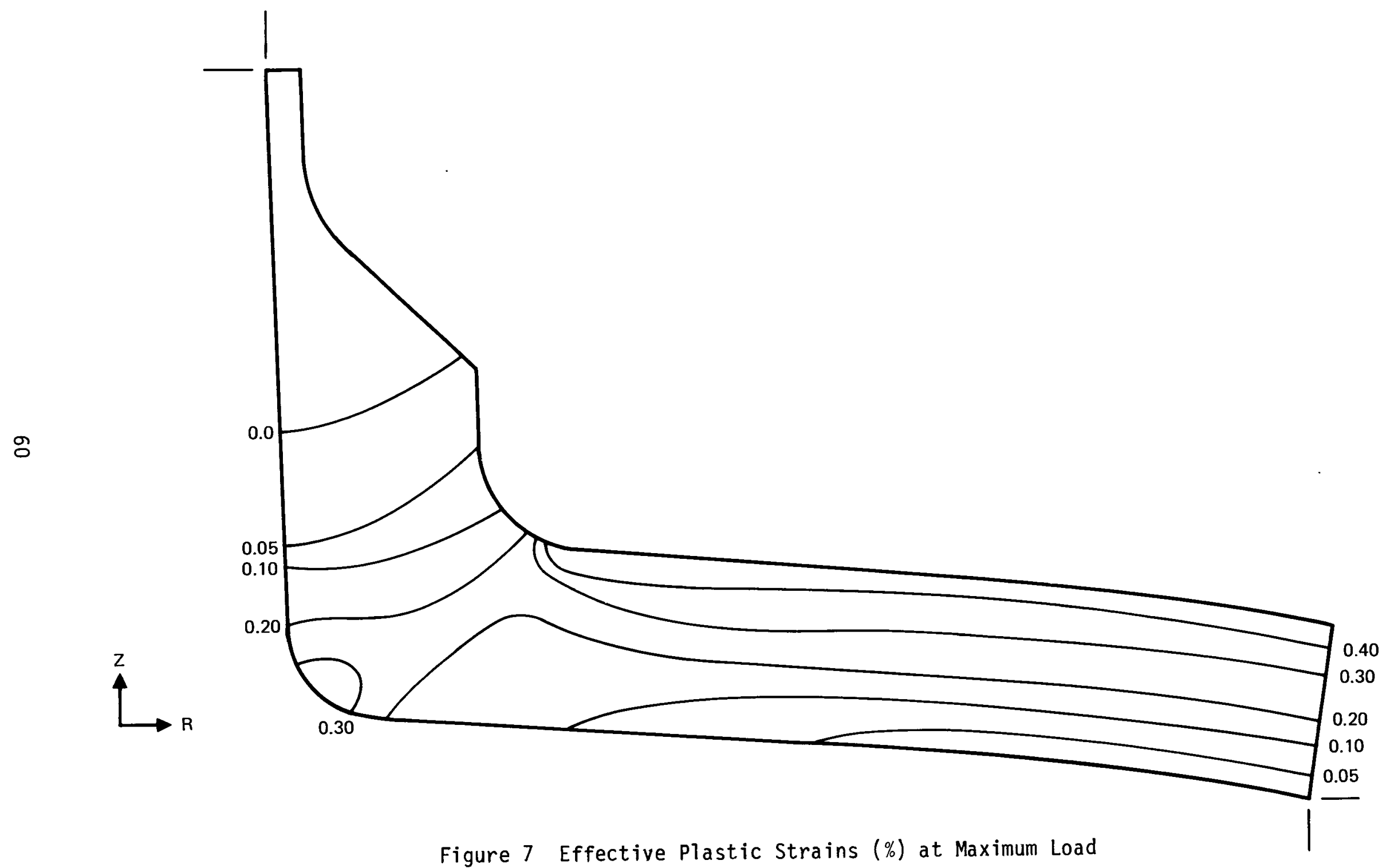




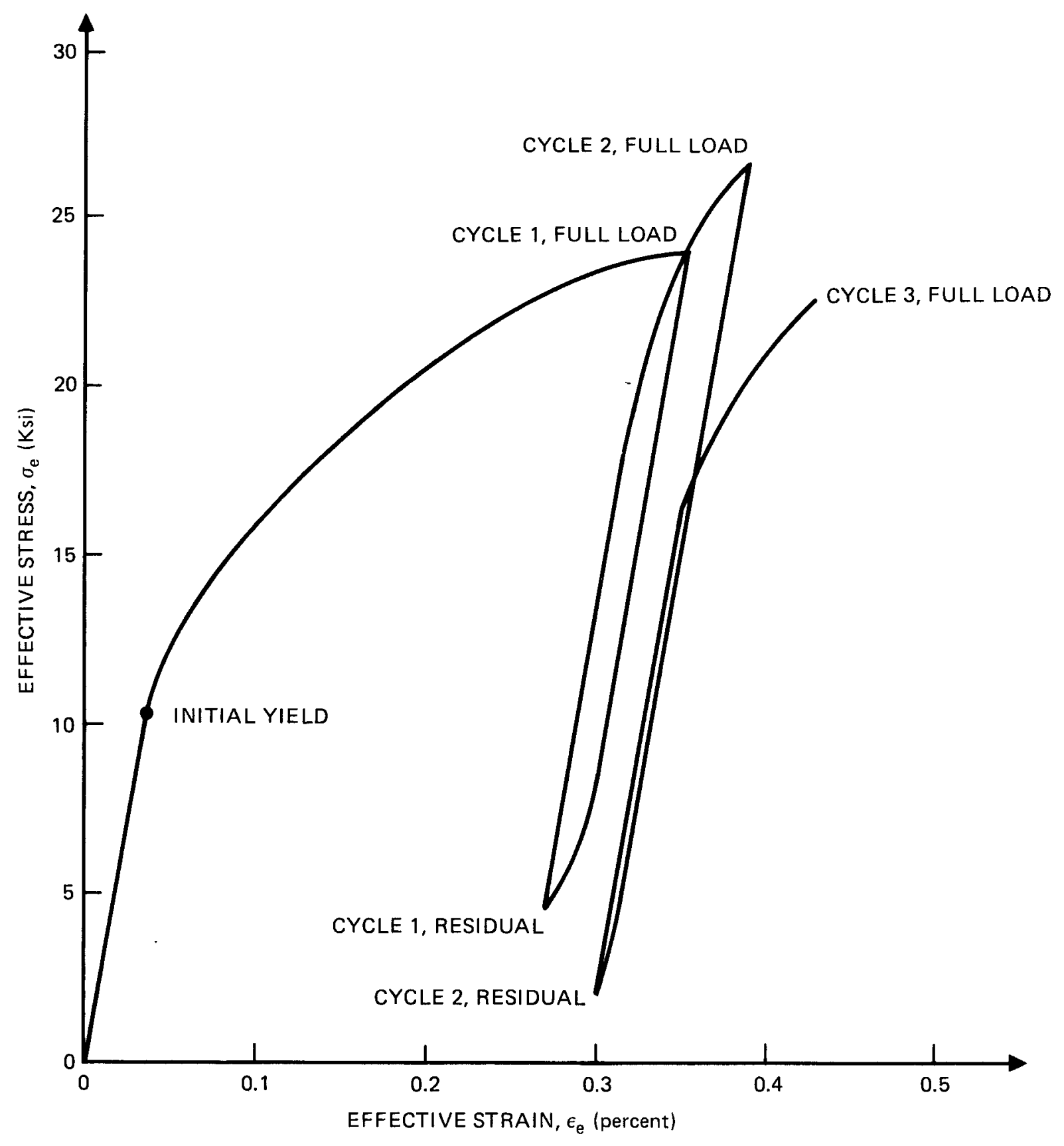

Figure 8 Effective Stress-Strain Curve at the Critical Point on the Inside Surface of the Nozzle 


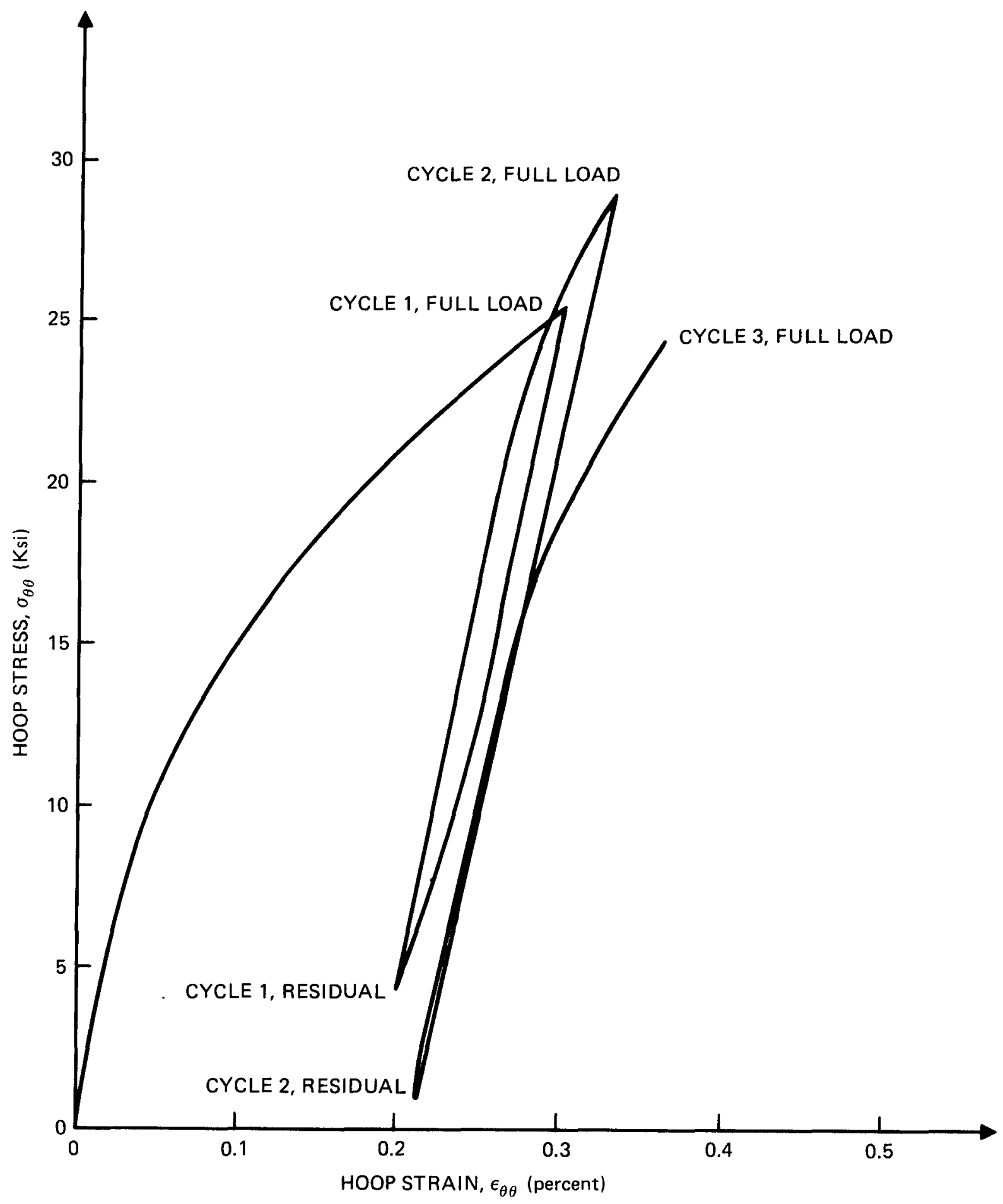

Figure 9 Hoop Stress-Strain Curve at the Critical Point on the Inside Surface of the Nozzle 
The above analysis then, although preliminary, indicates clearly that the nozzle could be designed to meet the primary criteria for structural adequacy for higher loading than can be permitted by the Code on the basis of elastic analysis. Conversely, for the reference loadings, the nozzle geometry can be adjusted to suit better manufacturability and more economical welding and inspection procedures. A third point which can be stressed also is that, since the reserve capacity of the nozzle has been demonstrated to exceed the structural adequacy criterion, the area replacement rule can be relaxed to allow the nozzle geometry to be optimized for minimum thermal stresses.

\subsubsection{Containment Buckling Analysis}

A coherent treatment of the non-linear buckling problem has been given in an obscure paper by Dupuis, et. al., [22]. This material is rephrased here, especially in terms of its comparison to the Koiter Method [23] for analyzing imperfection-sensitive structures. The Koiter Method has been adapted for finite element computations in its purest form by Haftka, et. al., [24]; however, a more recent treatment that attempts to use scaled linearized buckling modes for non-linear prebuckling deformation is more closely akin to this development [25].

We begin with the incremental equations of equilibrium, including small-strain, large displacement effects, for the finite element matrix displacement method:

$$
\left[\underset{\sim}{[\underset{\sim}{k}}{ }^{(0)}+\underset{\sim}{\underset{\sim}{k}}(1)(\underset{\sim}{)})+\underset{\sim}{\underset{\sim}{k}}(2)(\underset{\sim}{u})\right] \cdot \Delta \underset{\sim}{u}=\Delta \underset{\sim}{F}
$$

where $k^{(0)}$ is the linear elastic stiffness matrix, $k^{(1)}$ is the initial stress matrix (1inearly dependent upon the current state of stress), and $\underset{z}{\sim}(2)$ is the initial displacement matrix (quadratically dependent upon the current deflection). Since the stress and deflection at the end of the load increment, $\Delta F$, is unknown, iterative solutions are sought for the incremental displacements, $\Delta u$, using such techniques as the tangent stiffness method (Newton-Raphson) or the initial force method. 
In order to adapt this approach to the buckling problem, the analyst may choose to apply incremental loads until the tangent stiffness matrix becomes singular, indicating instability. Imperfection sensitivity can be accounted for by applying the loads to an initially imperfect structure. However, the failure to converge may be due to some other factor (e.g., numerical error), and the singularity misinterpreted. Also, such analysis can be very expensive, especially if small load steps are used to define the buckling load with precision. The analyst might otherwise choose to estimate the buckling load through eigenvalue analys is based upon linear extrapolation from the current state, and this current state may be quite removed from the buckled configuration. In order to do this, the current state is expanded in terms of a multiplier, $\lambda$, on the incremental force. Thus,

$$
[\underset{\sim}{\underline{\sim}}(0)+\underset{\sim}{\underset{\sim}{k}}(1)(\underset{\sim}{\sigma}+\lambda \Delta \underset{\sim}{\sigma})+\underset{\sim}{\underline{\sim}}(2)(\underset{\sim}{u}+\lambda \Delta \underset{\sim}{u})] \cdot \Delta \underset{\sim}{\underline{u}} \cong \lambda \Delta \underset{\sim}{F}
$$

Expanding, we obtain

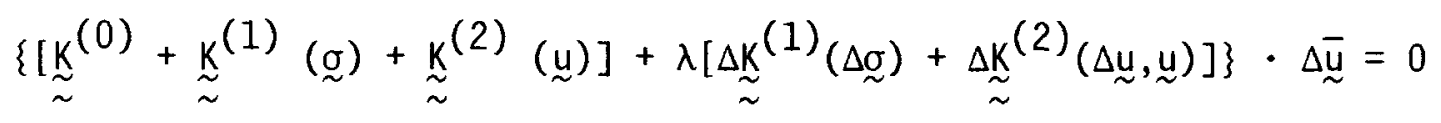

where $\Delta \bar{u}$ is the eigenvector.

This eigenvalue problem can be restated by noting that we seek the incremental displacement, $\lambda \Delta \underset{\sim}{u}$, and the incremental stress, $\lambda \Delta \underset{\sim}{\sigma}$, due to the incremental load, $\lambda \Delta F$, such that the tangent stiffness matrix is singular. Now, the multiplier, $\lambda$, may be quite large, indicating that the linearized extrapolation is a poor approximation to the critical stress and deformation state of the loaded structure. Also, it should be noted that there is a multiplicity of eigenvalues and eigenvectors for Eq. (27). 
Since $K^{(1)}$ is linear in stress, we observe that $\Delta K^{(1)}(\Delta \sigma)$ can be

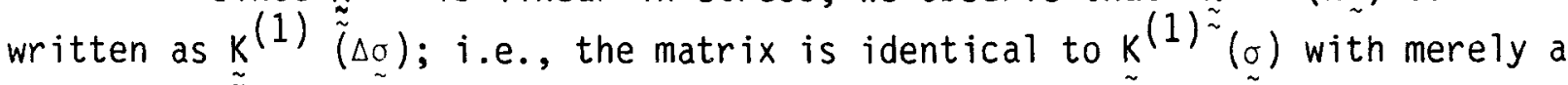
replacement $\tilde{\tilde{t}}$ of stress values. Then, the classical Eule $\tilde{\tilde{r}}$ buckiling problem can be written as:

$$
\left\{\left[\underset{\sim}{k}{ }^{(0)}+\underset{\sim}{k}(1)(\underset{\sim}{\sigma})\right]+\underset{\sim}{\lambda \underset{\sim}{(1)}}(\Delta \sigma)\right\} \cdot \Delta \underset{\sim}{\Delta u}=0
$$

where only the effect of initial stresses is accounted for. Since $\underset{\tilde{z}}{\underset{\gamma}{(2)}}$ is quadratic in displacement, no such simplification results unless the quadratic terms are neglected. We choose to retain these quadratic terms, since the matrix $\underset{\sim}{(2)}(\Delta \underset{\sim}{u}, \underset{\sim}{u})$ is essential to an improved treatment of initial imperfections.

Dupuis, et. a1. [22] compare the Koiter method with this method in the following sentence:

\footnotetext{
"The Koiter approach may be summarized briefly as a numerical procedure which expands nonlinearity about a linearized solution which neglects initial deflections while the current approach is one which linearizes the nonlinear problem ab initio and at every stage without neglect of any initial state."
}

It is our intent to demonstrate that this characterization of Koiter's method, and, in particular, a variant called the "reduced deflection" method can be accommodated within the preceding framework by suitable interpretation of $\underset{\approx}{\Delta K^{(2)}}$.

In order to motivate this development further, we cite some recent work by Kao [24] on the elastic-plastic buckling of spherical shells with initial imperfections. Figure 10 shows some of the more interesting and pertinent results from this work. The critical buckling load, as a function of the amplitude of a assumed imperfection shape, is shown for two different spnerical caps, with two different thicknesses, in order to illustrate the effect of plastic behavior. The first observation is that for elastic 


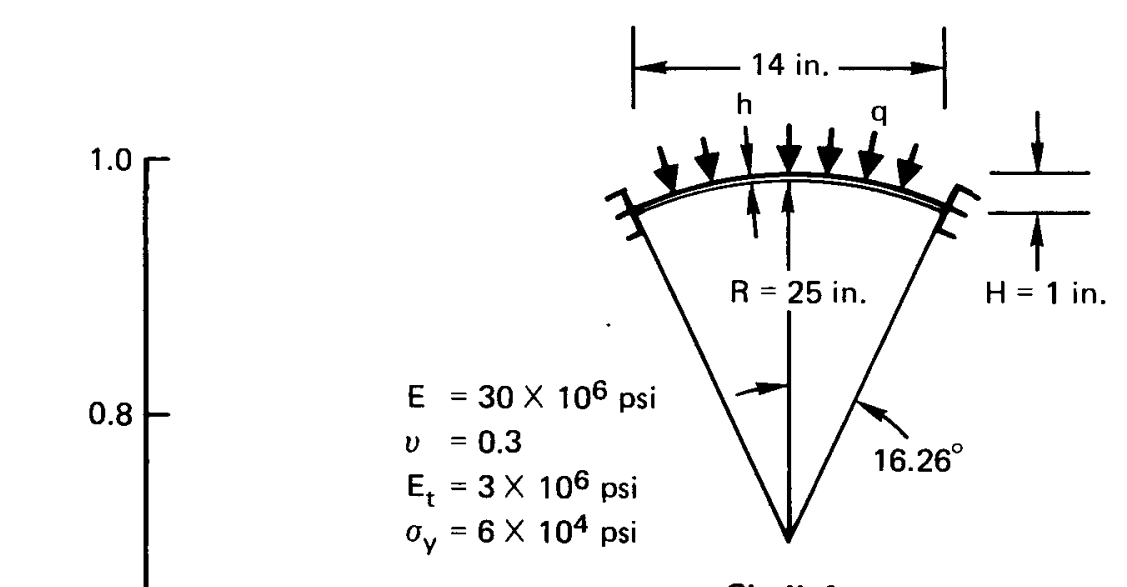

Shell A

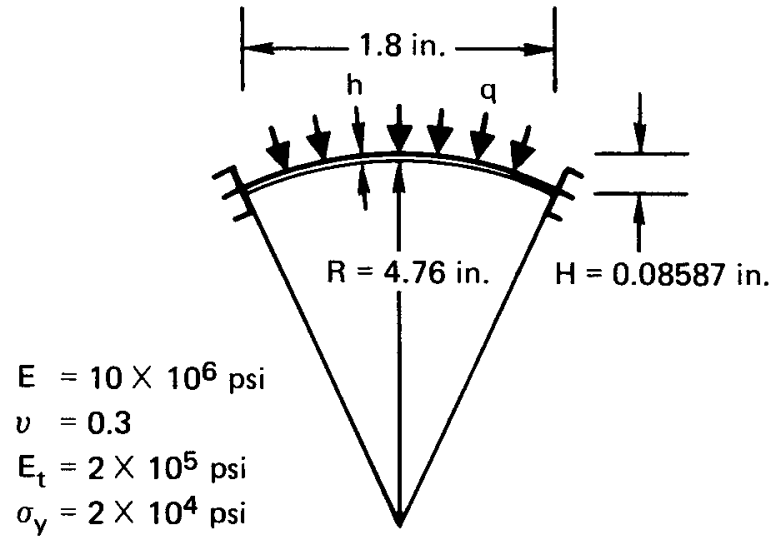

Shell B
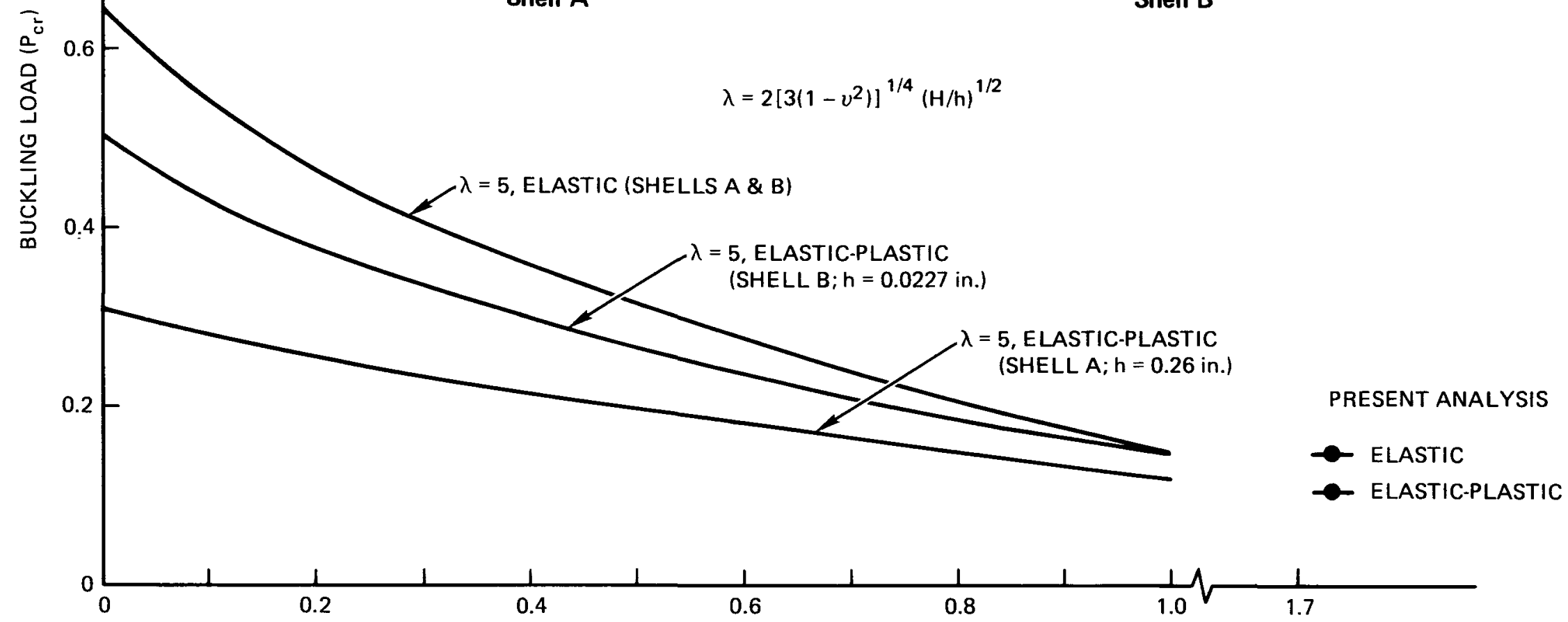

INITIAL IMPERFECTIONS $\left(W_{i o} / h\right)$

Figure 10 Buckling Load vs Initial Imperfection for Axisymmetric Spherical Caps 
behavior, the imperfection sensitivity does not saturate; that is, the buckling load continues to decrease with increasing imperfection amplitude and does not appear to be converging toward an asymptotic limit short of zero load. The second observation is that the well-known rule that structures which buckle as the result of elastic-plastic behavior tend not to be imperfection sensitive is correct. The first observation is a damaging blow to the concept of knockdown factors, since it seems impractical to specify a safety factor, or buckling reduction factor, that would conservatively account for imperfection sensitivity. The second observation would apparently lead to a different set of design criteria for structures that buckle inelastically.

The theoretical derivation of these results are useful for our purposes. The particular term in Kao's derivation that accounts for imperfection sensitivity is shown in the strain and curvature equations for axisymmetric deformation (See Figure 11 for sign convention):

$$
\begin{aligned}
& \varepsilon_{r}=u^{\prime}-\frac{w}{R}+\frac{1}{2}\left(w^{\prime}\right)^{2}+w^{\prime} w_{i}^{\prime} \\
& \varepsilon_{\theta}=\frac{u}{r}-\frac{w}{R}, \\
& x_{r}=-w^{\prime \prime}
\end{aligned}
$$

and

$$
x_{\theta}=-\frac{w^{\prime}}{r}
$$

where $u$ is the meridional displacement and $w$ the transverse displacement, a prime denotes the meridional derivative, and $w_{j}$ is the imperfection shape. Of interest here is the rotation-dominated part of the deformation, namely, that part of the transverse displacement that leads to significant $w^{\prime}$. 
Kao's analysis involved an assumption of the imperfection shape, $w_{j}$, such that

$$
w_{i}(s)=\left(\frac{\bar{w}_{i}}{h}\right)\left(1-s^{2}\right)^{2}
$$

where $s$ is the meridional coordinate, $h$ is the shell thickness, and $\bar{w}_{i}$ is the peak amplitude of the imperfection at the shell apex. For this particular she11, the sensitivity with respect to imperfection amplitude was investigated, but sensitivity with respect to imperfection shape was not studied.

The approach taken here is intended to overcome the current objections to design against structural instability failure. These objections fall into two categories. First, the use of "knockdown" factors in order to reduce buckling loads calculated by linear bifurcation theory and, thereby, take unknown imperfections into account is both unreasonable and uncertain. The major disadvantages are that no asymptotic limit on imperfection sensitivity has been observed (see Kao's results), which implies that the buckling load continues to decrease as the imperfection amplitude increases, and that the knockdown factors are apt to be so large (perhaps a factor of four or five) that many structures will be unnecessarily penalized.

The second objection pertains to design by nonlinear analys is, where the large deformation terms are retained and conservative estimates of existing or potential imperfection shapes and amplitudes are attempted. Such analysis, regardless of whether the method chosen is incremental up to and including singular behavior or uses linearized extrapolation from a nonlinear state, is quite expensive. Many designers feel that this expense is unwarranted, considering the uncertainty in the imperfection estimates. The situation with respect to nonlinear buckling analysis, in fact, has many of the same characteristics as nonlinear fracture mechanics; that is, these methods are more suited for Section XI of the ASME Code (Inservice Inspection) than for Section III (Construction). Nonlinear fracture mechanics is ideally suited for flaw evaluation, with proper conservatisms applied to the detected flaw, and nonlinear buckling analysis is well-suited 
for the evaluation of observed preservice or inservice imperfections, with appropriate applied conservatisms.

With these objections in mind, a method must be found that meets the following requirements:

1. The analysis must be able to detect the sensitivity of the structural design to fairly arbitrary imperfections and applied loadings;

2. The analysis method should readily accommodate conservatisms on the imperfections and/or the loadings;

3. The analysis should be relatively inexpensive, with the expense commensurate with the accuracy of the design data;

4. The results of the analysis should provide a clear indication to the designer of any structural weakness that should be remedied.

The objections stated previously and these four requirements all seem to be met by a technique referred to as the "reduced deflection method" by Ewing [26]. The basic principle follows the notions of Koiter that the Difurcation displacement field of a structure (the deformed shape of a loaded structure that is sufficiently "perfect" to have a dual equilibrium path at the bifurcation load) is not dominated by rotation, while the displacement field corresponding to a buckling mode shape is dominated by rotational components. Therefore, when loading is applied to the structure, the elastic or elastic-plastic or elastic-plastic-creep deformation will consist of two parts: a part called $\underline{\sim}_{0}$, that would yield the classical buckling load from the equation

$$
\left[{\underset{\sim}{k}}^{(0)}+\underset{\sim}{\underset{\sim}{k}}(1)\left({\underset{\sim}{0}}_{0}\right)\right]+\lambda \underset{\sim}{\underset{\sim}{k}}(1)\left({\underset{\sim}{\sigma} 0}_{0}\right) \cdot \Delta \bar{\sim}_{0}=0
$$


where $\underset{\sim}{\sigma}$, are the stresses calculated from $\underset{\sim}{u_{0}}, \underset{\approx}{\underset{\sim}{k}}(0)$ is the linear elastic stiffness matrix, and $\underset{z}{\mathrm{~K}}(1)$ is the initial stress matrix; and another part called ${\underset{\sim}{b}}_{b}$, that contains the rotations that identify the propensity of the structure to buckle.

The Koiter method can be thought of as consisting of the following steps:

a) compute the bifurcation buckling mode shapes from the classical buckling equation, neglecting the initial displacement (large rotation, small strain) matrix; this step has also been used in [25].

b) these buckling mode shapes can be used as initial imperfection shapes for subsequent buckling analysis, although the choice of amplitude is a troublesome issue; therefore,

c) choose a variety of multipliers on the bifurcation buckling modes (now imperfection modes) and calculate new buckling loads with a linearized approximation to the initial displacement matrix; e.g., form and

$$
{\underset{\sim}{\sim}}^{(2)}\left({\underset{\sim}{u}}_{b}\right)
$$

$$
\underset{\sim}{\Delta \underset{\sim}{K}}(2)(\Delta \underset{\sim}{\bar{u}}, \underset{\sim b}{u})
$$

where $u_{b}$ is the assumed imperfection shape from bifurcation buckling analysis with an assumed amplitude.

Note that, with Koiter's method interpreted in this manner, only linearized buckling analysis is needed, which is economical, but a number of these linearized buckling analyses must be performed in order to insure that the design is adequate. Also note that unsymetric imperfection shapes may emerge, even though the design loading is symmetric. A disadvantage of the 
method is that no guidance with repsect to imperfection amplitude is provided.

The reduced deflection method differs slightly from the Koiter method in that the shape ${\underset{\sim}{b}}_{b}$ is not found from a classical bifurcation buckling mode, but by subtracting a non-rotation-dominant deformation field from the pre-buckling deformation. For such a method, an unsymmetric imperfection shape could never be found from symmetric design loads. However, the advantage is that a classical bifurcation buckling calculation need not be performed. The analyst might use previous results (total deflection from applied service loads), estimate $u_{0}$ from a knowledge of classical buckling behavior, and use the remainder ${\underset{\sim}{b}}_{b}$ (or some multiple of ${\underset{\sim}{b}}_{b}$ ) as the imperfection shape for a buckling calculation that includes displacement terms.

In both cases (Koiter and reduced deflection), all of the requirements mentioned previously are met. The Koiter method is more arbitrary in terms of imperfection shape, but is perhaps a bit more expensive. Both methods accommodate conservatism with respect to imperfection amplitude, but neither can overcome the lack of saturation of imperfection effects. Both are relatively inexpensive, in comparison to complete nonlinear buckling analysis, and both can be extended naturally to inelastic material behavior. The last requirement is met best by the Koiter method, in terms of structural design weaknesses, and best by the reduced defection method, in terms of sensitivity with respect to actual loadings.

For our purposes, we have chosen to illustrate the approach by using the reduced deflection method on the spherical cap analyzed by Kao [27]. The geometry and sign convention are shown in Fig. 11. A "design" pressure considerably less than the buckling pressure for a perfect shell was applied to the shell "A" of Fig. 10. This pre-buckling deflection consisted virtually of a rotaion-dominated part only, since the extremities of the cap are fixed, permitting no pure membrane displacement. The deflected shape from this linear analysis is called $\underset{\sim}{u_{b}}$, and the shape is multiplied by a 


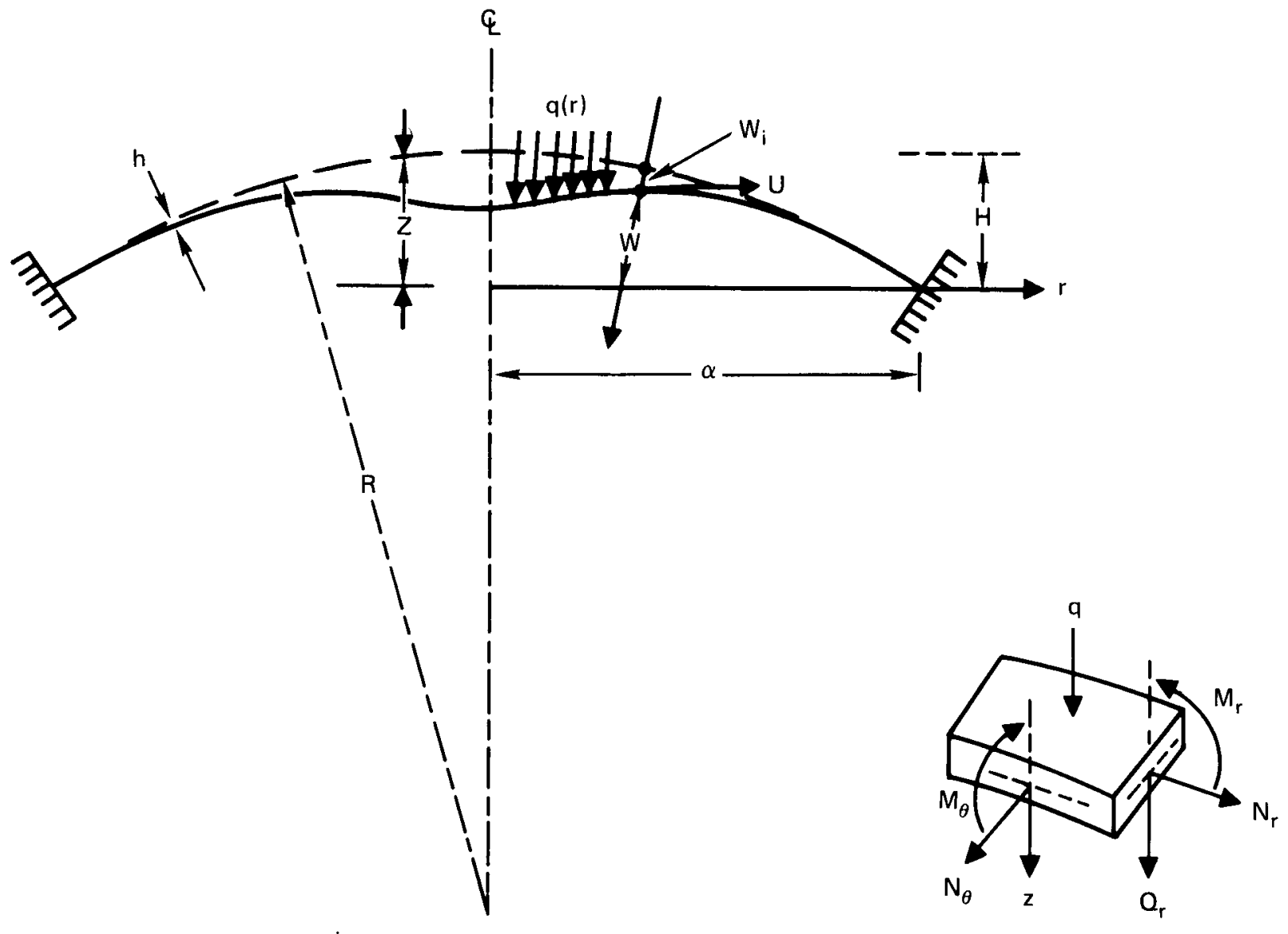

(a)

(b)

Figure 11 Geometry and Sign Convention for Spherical Cap 
factor $k$, in order to develop an initial imperfection with a margin. A variety of buckling mode shapes could have been calculated; however, only the deflected shape $u_{\sim}$ was used in this calculation in lieu of the first buckling mode.

The buckling mode for the nonlinear pre-buckling case (i.e., an initial imperfection sufficiently large to couple the geometrically nonlinear terms to the initial stress terms) is then approximated by a linearized extrapolation from the pre-buckling state ${ }_{\sim} \underset{\sim}{b}$ using the eigenvalue equation:



$$
\begin{aligned}
& +\lambda\left[\underset{\sim}{\underset{\sim}{k}}(1)\left({\underset{\sim}{b}}_{b}\right)+\underset{\sim}{\Delta \underset{\sim}{k}}{ }^{(2)}\left(\Delta{\underset{\sim}{b}}_{b}, k{\underset{\sim b}{b}}_{b}\right)\right] \cdot \Delta \bar{u}=0
\end{aligned}
$$

The results for the cases where the initial stress matrix is both elastic and elastic-plastic are shown in Fig. 10. The safety factor was chosen to be large so that the calculations are considerably to the right of results calculated by Kao. Extrapolation of Kao's data indicated the validity of the procedure.

The method needs further application in order to examine a number of buckling modes for the same pre-buckling design loading. Also, the factor $\kappa$ should be varied within realistic limits, as a way of determining whether current safety factors on initial imperfections and service-induced deformations are adequate.

\subsubsection{Effects of Soil Non-Linearity On Seismic Response}

In order to account for the numerous uncertainties encountered during the process of seismic analysis and design, the current US NRC seismic safety requirements result in an over-conservative structure with respect to seismic hazard.

The conservatisms introduced at each stage of the seismic design process, not only divert the analysis frum predicting a realistic benavior, but has the effect of compounding conservatism (i.e., at each stage of the 
analysis a safety factor is introduced with no account to the previous and subsequent stages of the design). Such analysis and design process currently involves the following stages: a) seismic input phase, where the earthquake hazard at nuclear power site is defined, b) soil structure interaction phase where the free-field ground motion is transformed to base-mat response, $c$ ) structural response phase, where the dynamic response at the structure is determined, and the final phase, d) component failure analysis and subsystem, pumps, valves, etc., response determination stage, where the structural response from stage (c) is used as input to determine stresses as criteria for failure.

The response of the base-mat calculated in the second stage has the critical nature of determining the magnitude of the dynamic loads for the overall system; and any undue conservatisms introduced at this stage contribute significantly to an over-designed structure.

In this section such significant effect will be addressed with the prime objective of estimating the conservatisms in the linear analysis approach currently practiced in seismic desing.

Due to uncertainties in our knowledge of the soil conditions under nuclear reactor site, the NRC Regulatory Guides require unwarranted conservatism in the form of criteria based on linear analysis approach. Such criteria, for example, define the seismic input by peak ground acceleration and the shape of the free-field site response spectrum. The known inelastic response of soil to seismic input, the interaction of soil with the massive structure and the structure to structure interaction should provide an energy absorbing mechanisms and a force redistribution effect, by which the instructure response will be significantly reduced.

Toward demonstrating this reverse capacity available beyond elastic assumptions level, the non-linear soil behavior aspect of the problem is chosen for study in this report. In order to estimate in a simple manner the influence of soil nonlinearities on reducing the dynamic loading conditions 
of the structure due to a seismic excitation, a typical two-degree-of-freedom system was developed and a comparison study between the elasto-dynamic response and the non-linear dynamic response is conducted. In the following, a detailed description of the model is given and the results of the analyses are discussed.

Structural Model: The structural system is idealized as a simple two-mode mode1. It consists of two masses and two springs as shown in Fig. 12 a. This model cannot represent adequately an actual problem, but it can he considered adequate for the purpose of this study. The first mass $M_{1}$ represents the base mass of a nuclear power plant. The supporting spring representing the soil has a stiffness $k_{1}$ that was allowed to vary, depending on deformation. This description of the spring stiffness which is the only source of non-linearities considered in this study represents the variation of the shear stress $\tau$ with the shear strain $\gamma$ for a typical medium soil. Detailed discussion of this material model is given later. It should be noted here that the first mass and its supporting spring could represent the first normal mode of the structure that has a frequency of approximately 2.5 $\mathrm{Hz}$. The second mass represents an internal structure mass with a linear spring that has a constant value $k_{2}$. Damping was introduced to the system by selecting a conservative damping ratio of $2 \%$ of the critical damping of the first mode of excitation.

Seismic Input: Earthquake motion can produce significant loading since the dominant frequencies of such motion are usually in the region of the natural frequencies of reactor vessels. In this model an excitation at the base is used as input, which consists of a combination of two singlefrequencies harmonics, namely, $2.5 \mathrm{~Hz}$ and $5 \mathrm{~Hz}$, with corresponding acceleration amplitude of $0.2 \mathrm{~g}$ and $0.5 \mathrm{~g}$ respectively. The combined excitation is shown in Fig. 13 a. This combination is chosen to excite the two response modes of the system.

Non-Linear Soil Model: The current state of the art in non-linear mechanics lacks constitutive equations to describe realistically the soil response under general loading conditions. Attempts to describe the cyclic 


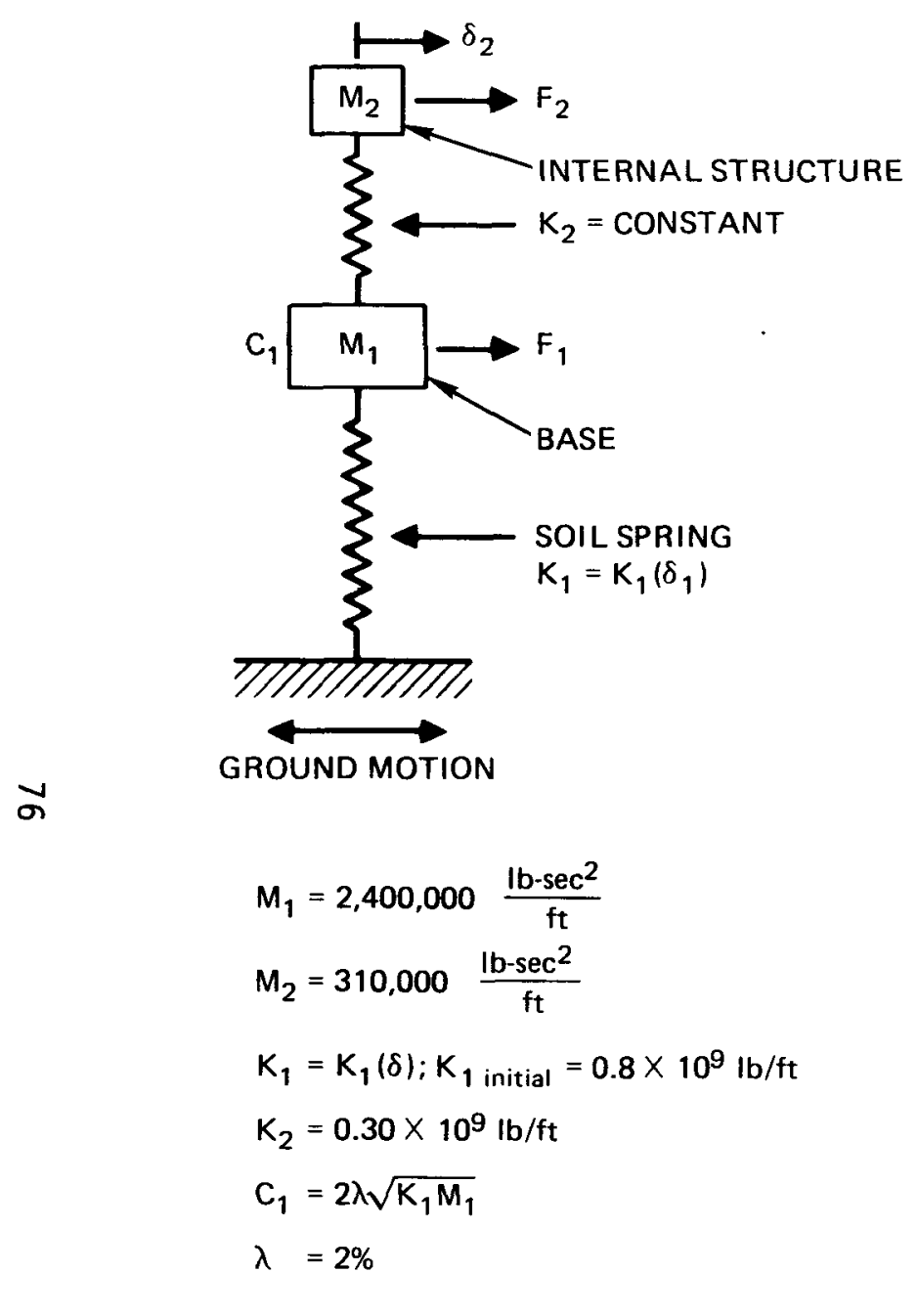

(a) Two-Degree-of-Freedom Model

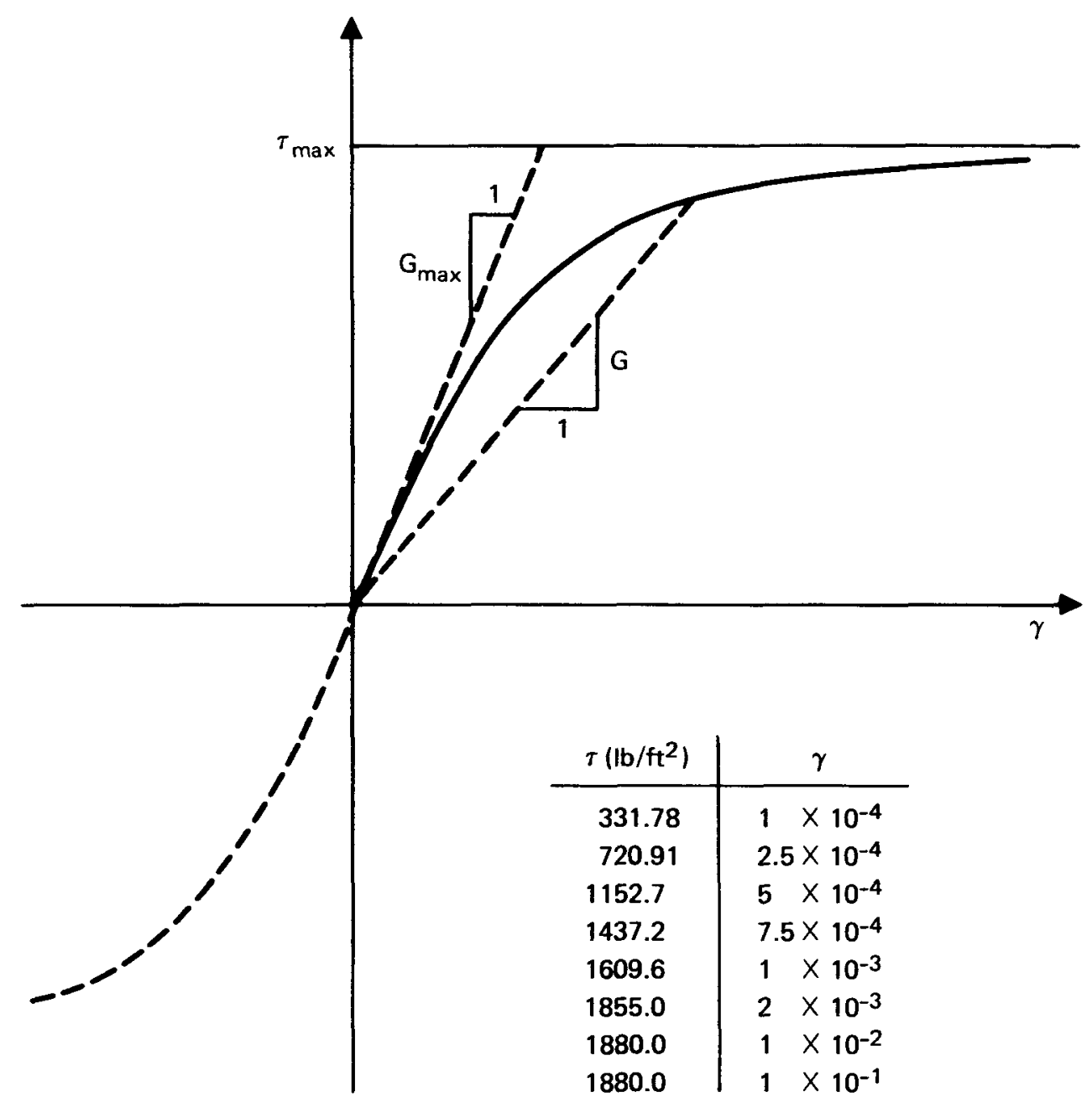

(b) Shear Stress-Strain Curve for the Soil

Figure 12 Dynamic Model and Soil Properties 
shear stress-shear strain behavior of soils under dynamic loading conditions has been done experimentally. It was found that cyclic behavior of soils is of hysteretic nature and strain-dependent. However, this information still needs to be described in a form that can be used in presently available analysis tools, such as finite element computer codes. In order to allow for the strain dependent nature of the non-linear soil characteristics in the present analysis the spring stiffness in the model were taken to vary according to a hyperbolic description in terms of deformation. This description to characterize the cyclic shear stress-shear strain behavior of soil was proposed by Hardin and Drnevich [41]. They arrived at this description by fitting an analytical stress-strain curve to the experimental spine curve. This relationship reflects the dependance of the shear stress on the shear strain throughout a wide range of amplitudes up to failure. Fig. 12 b shows such behavior together with some numerical values selected on the curve. This particular description is considered to be sufficient to demonstrate the purpose of this study, in addition, to be a typical non-linear behavior of medium stiff site.

Finite Element Model: A finite element program is used to model the system shown in Fig. 12. In this model a numerically equivalent system consisting of truss elements was chosen to represent the spring stiffness. The two masses were modeled as concentrated masses at the nodes. Damping was applied to the system in the form of a concentrated damper at node 1. Integration with respect to time was achieved using an implicit Newmark time integration operator (average constant acceleration scheme) with $\propto=1 / 4, \delta=$ $1 / 2$ constants. Loads were applied as inertia forces at the nodes. Two cycles of the ground acceleration function described above were applied. In the linear dynamic system calculations the material behavior of the soil element was assumed to be linear elastic in order to simulate the soil spring stiffness to have a constant value equal to the initial value. In the non-linear analysis, the material behavior of this element is modeled according to the non-linear curve shown in Fig. 12 b. In both analyses the element representing the supporting structure of mass two was assumed to have 
a linear elastic material behavior. For the non-linear analysis, the stiffness of the spring was updated at each time step and in addition, equilibrium was checked and satisfied within a tolerence at each time step.

Results and Conclusion: The response prediction obtained by linear analysis is plotted in Fig. $13 \mathrm{~b}$, where the linear acceleration response at the secondary mass, representing the internal structure response at node (2) is shown. The non-linear acceleration response for the same node is also plotted and shown in Fig. 13 b. By comparing the two responses, the analyses demonstrate that due to the effect of soil non-linearities the peak acceleration value was reduced by more than a factor of two as shown in Table 2. In addition, it is believed that non-linearities have the implicit effect of detuning the structure and internal structure interaction response.

It should be noted that these results were concluded during application of the first two cycles of the ground motion and for the low frequency range only. While it is believed that more significant reduction ratio will be acnieved through; first, incorporation of a true and more realistic soil behavior model, where the cyclic behavior and the related absorbing energy mechanism have been more accurately accounted for; second, application of a longer history cycle, since it is expected that non-linear effects are more dominant at later stages of the response (i.e., after application of few cycles of the time history input). Thus, based on the above results, the non-linear considerations in the seismic analys is and design process of nuclear plants will result in a more realistic modeling and consequently will reduce the unwarranted conservatism inherent in the current design level.

It should be pointed out that very little has been done in this area performing a 20 analysis, and much work is still needed to understand tnis particular problem. However, it is believed that the conclusions drawn from the above results should be generally valid with proper modification of the calculated reduction values.

Other Related Studies: It is worthwhile noting here, that a similar comparison study was performed by EPRI (Electric Power Research 
TABLE 2

\begin{tabular}{|c|c|c|c|c|}
\hline \multirow[t]{2}{*}{ Maximum Input, $\mathrm{g}$} & \multicolumn{2}{|c|}{ Peak Response, g } & \multicolumn{2}{|c|}{ Amplification Ratio } \\
\hline & Linear & Non-Linear & Linear & Non-Linear \\
\hline $\begin{array}{c}0.641 \\
2.5 \mathrm{~Hz}, 5 \mathrm{~Hz}\end{array}$ & 2.789 & 1.292 & 4.35 & 2.02 \\
\hline
\end{tabular}

TABLE 3 Maximum Surface Acceleration and Amplification Ratio for Aritificial Earthquake Excitation Applied to Variable Soil Profile

\begin{tabular}{|c|c|c|c|c|}
\hline MODEL & $\frac{\text { Surface Accel }}{\text { STEALTH }}$ & $\frac{\text { eration, } g}{\text { SHAKE }}$ & $\frac{\text { Ampl ificat }}{\text { STEALTH }}$ & $\frac{\text { on Ratio }}{\text { SHAKE }}$ \\
\hline $\begin{array}{c}\text { MD } \\
\text { HDD }\end{array}$ & $\begin{array}{l}0.421 \\
0.342\end{array}$ & $\begin{array}{l}7.093 \\
0.897\end{array}$ & $\begin{array}{l}0.84 \\
0.68\end{array}$ & $\begin{array}{l}2.19 \\
1.79\end{array}$ \\
\hline
\end{tabular}




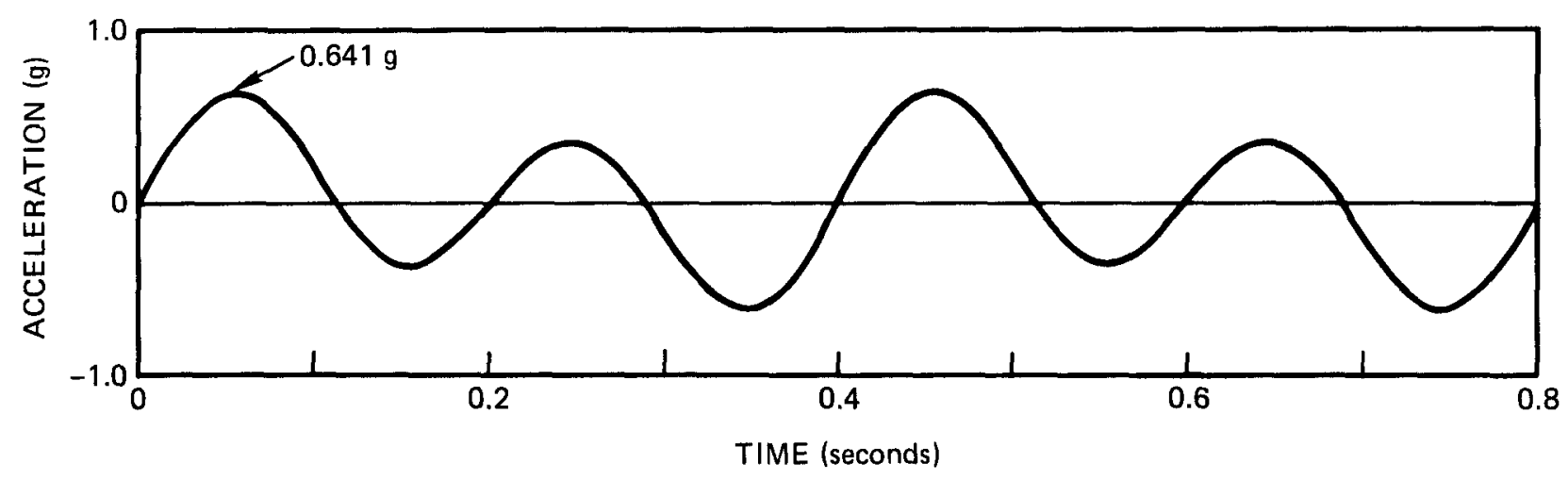

(a) Input Acceleration $(2.5 \mathrm{~Hz}+5 \mathrm{~Hz})$

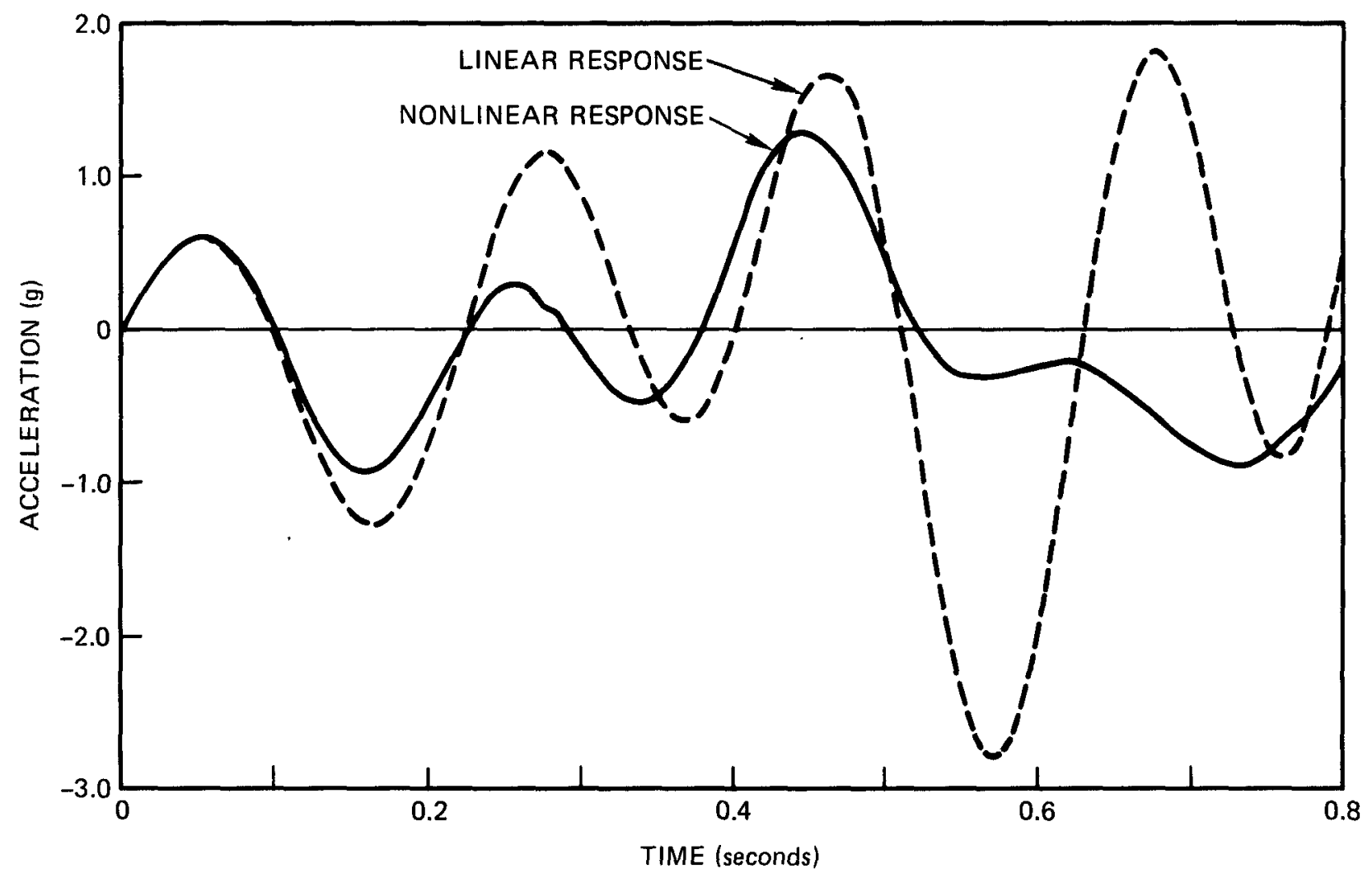

(b) Response Acceleration

Figure 13 Dynamic Response Curves 
Institute) to determine the basic effects of non-linear soil behavior on the seismic response near the surface of a soil deposit. The analytical study conducted consisted of a comparison of the surface response of a onedimensional soil layer as computed by the programs SHAKE and STEALTH. The program SHAKE is based on the continuous solution to the wave equation and the transient solution was obtained through the fast Fourier transformation algorithm. Soil properties were determined through the equivalent linear method [19] widely used in practice. As for the non-linear analysis, the program STEALTH [40] was used where the approximation is based on an explicit finite difference technique in Lagrangian framework. The non-linear constitutive soil models used were Martin-Davidenkov (MD) and the HardinDrnevich-Davidenkov (HDD) model, where strain dependency is considered (see reference [16]).

The soil profiles were subjected to several input motions, including an artificial earthquake acceleration time history shown in Fig. 5 . By comparing the seismic response, they found that the maximum values for surface acceleration computed by the linear analysis (SHAKE) were more than twice those calculated by the non-linear analysis (STEALTH). Their results are tabulated in Table 3. The ground response spectra computed from both programs are shown in Fig. 14. As indicated by the figure the response spectra computed from SHAKE shows much higher accelerations with in the more dominant lower frequency range of 1 to $5 \mathrm{~Hz}$. However, greater accelerations are given by the STEALTH results for higher frequency range. These results confirm the conclusions reached in our study.

\subsection{NON-LINEAR FRACTURE MECHANICS}

Current regulatory systems safety criteria and regulatory positions require that the level $D$ operating conditions for Safety Class 1 components of nuclear power plants include the simultaneous effects of the safe shutdown earthquake (SSE) and a loss-of-coolant event (LOCE). Probably no other single regulatory requirement has had the economic impact on plant design as this load simultaniety stipulation. Efforts have been underway for many 


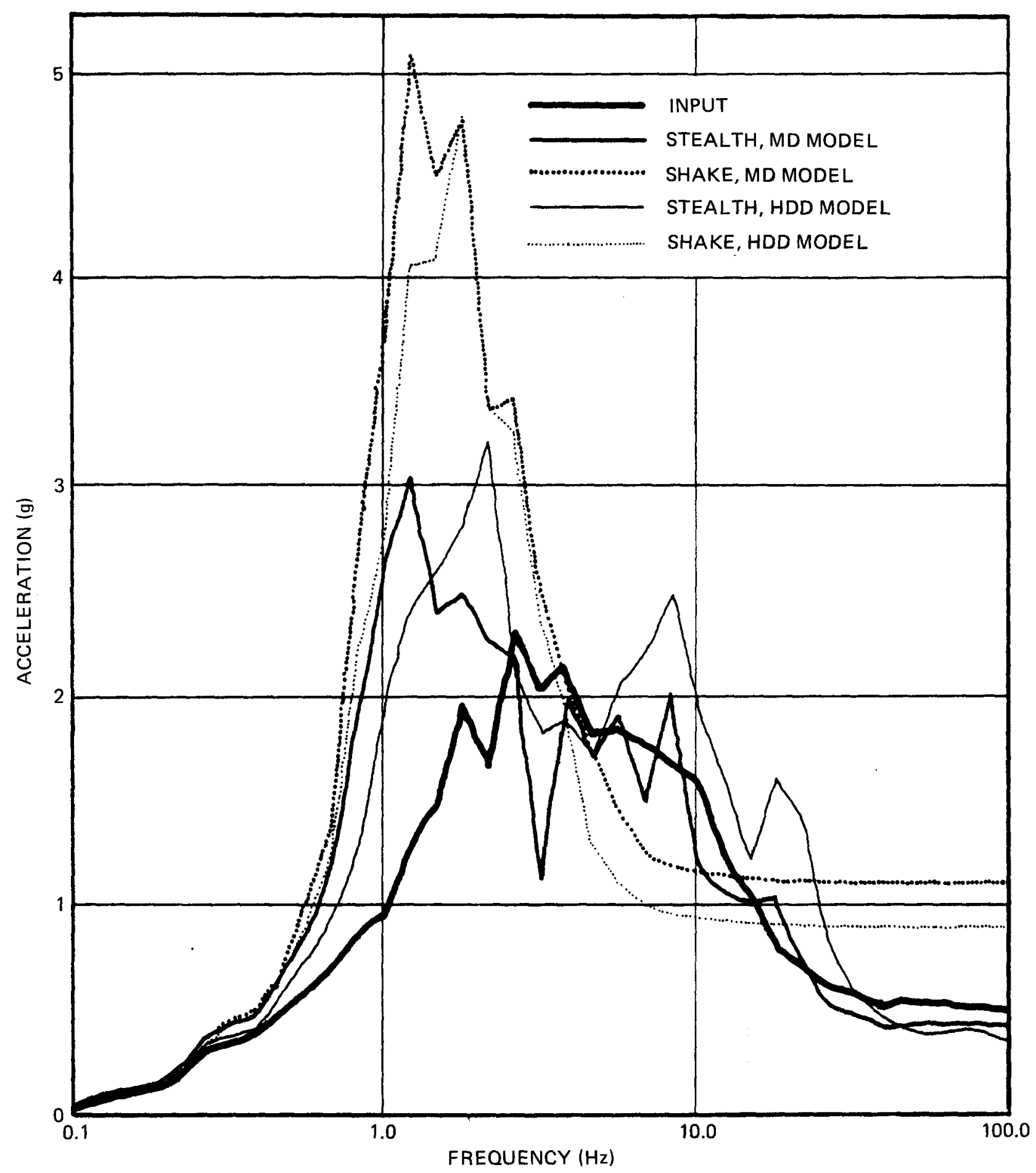

Figure 14 Surface Response Spectrum from Artificial Earthquake Excitation 
years, by both reactor steam system suppliers and by regulatory consultants, in an attempt to mitigate this load combination requirement, and the role of non-linear stress analysis, in general, and non-linear fracture mechanics, in particular, is central to these efforts.

The Advisory Committee on Reactor Safeguards has indicated to USNRC staff the willingness to entertain arguments for decoupling the loadins from the SSE and the LOCE, as a prelude to modification of Regulatory Guide 1.48; however, the ACRS has cautioned the USNRC staff that these arguments, dependent as they are upon non-linear fracture mechanics concepts, should be complete and convincing. For example, some reasonable evidence should be produced that justifies the position that while the SSE cannot. promote rapid crack propagation sufficient to initiate a LOCE, considerably lower cyclic loads are able to cause significant failures in Class 2 equipment.

To understand how the design of nuclear power plant equipment became subject to the principles of fracture mechanics one has to review the current procedures for historical emphasis. For instance, it is recognized that pressure vessel materials, such as SA-533 and SA-508, are characterized by a transition between orittle and ductile behavior at approximately room temperature. At temperatures below about $-40^{\circ} \mathrm{F}\left(-40^{\circ} \mathrm{C}\right)$, the fracture toughness is so low that pressure vessel design (with relatively large membrane stresses) should not be attempted with these materials [28]. Even the most optimistic estimates of potential crack size (and Appendix $G$ of the ASME Code, Section III [29], provides conservative values) yield localized stress intensities around crack tips that are a factor of two above the lower-sheif toughness. On the other hand, at reactor operating temperatures, the upper-shelf toughness is applicable and is many multiples of the crack tip stress intensity.

Based upon these considerations, the only material parameter of interest for design of vessels should be the nilductility transition temperature. This was, in fact, the case until approximately a decade ago, when inservice inspection of operating power plants revealed flaw indications, especially in vessel nozzles, that called the supposed fracture 
toughness into question. Two modifications of design procedure resulted. One of these - the procedure adopted in Appendix G -- appears to be justified only if the material is intentionally to be used in the transition range (e.g., at $120 \mathrm{~F}(50 \mathrm{c})$ ) and at stress levels approaching yield. The second modification was more realistic, and was based upon the recognition that the more likely source of flaw propagation was the cyclic stresses due to reactor startups and shutdowns, not the operating stresses.

Emphasis was then diverted from linear elastic fracture mechanics (LEFM) where it had been mistakenly placed, to fatigue crack growth. The nuclear power industry grasped eagerly an extension of LEFM, widely referred to as the Paris Crack Growth Mode I, [30].

$$
\frac{d a}{d N}=C(\Delta K)^{m}
$$

where $d a / d N$ is the crack growth rate (in/cycle), $\Delta K$ is the range of the stress intensity factor ( $k s i \sqrt{i n}$ ), and $C$ and $m$ are factors to be determined by experiment. For example, $m$ is the slope of the $\log (d a / d N)$ versus $\log (\Delta K)$ curve drawn through experimental points.

Cyclic crack growth data for nuclear power component materials tend to follow a tripartite, or sigmoidal, pattern. At very small values of $\Delta K$, the data follow a virtually non-propagating rate of crack growth which corresponds roughly to the fatigue endurance limit. The highest level of safety would be assured by maintaining stress levels at or below this range. The Paris model is used to fit the data in the intermediate range, a region that encompasses much of the crack growth observed in nozzles during startup and shutdown transients. This region should not be considered necessarily to be unsafe, but the scientific basis for permitting crack growth during operation should be well developed. The third region, which should be completely avoided in design, is that of rapid unstable crack growth.

Procedures that are adopted form the Paris crack growth model have been incorporated into flaw evaluation procedures (in order to detarinine need for component repair or replacement) in Section XI of the ASME Code, Appendix 
A. These procedures are well known and have been described elsewhere [31]; we merely note here that the intent of these rules is to permit operation of components at normal and upset service levels of loading (Levels A and B) such that measurable crack growth may occur during each event.

Such measurable crack growth during a sufficiently intense seisinic event, such as a safe shutdown earthquake, could be a more serious matter, and the treatment of this contingency is the crux of the load combination controversy now before the ACRS. The arguments separating SSE loads from LOCE loads rest on the available proof that cyclic seismic loading will not propagate an existing flaw so rapidly that virtually instantaneous pipe rupture would occcur. The methodology for developing this proof has been sumnarized in a recent paper [32] that is an outgrowth of the concern of the Electric Power Research Institute with ductile failure under gross yielding conditions. The paper describes and compares two of the four competing theories for prediction stable crack growth under these conditions -- the tearing modulus associated with the slope, $d J / d a$, of the J-integral crack growth resistance curve and the tearing modulus associated with the crack opening angle, $d \delta / d a$, where $\delta$ is the crack tip opening displacement.

Unfortunately, the remaining competing theories -- one based upon a fully plastic uncracked ligament (gross plastic instability) and one based upon extension of the Paris crack growth model into the $\Delta K$ range involving significant plasticity -- are not compared. Both this EPRI work and similar work sponsored by USNRC seem to be preoccupied with test results from the Heavy Section Steel Technology (HSST) program, which tend to empinasize single application of overload, rather than low-cycle fatigue, which is more directly relevant.

A more pertinent study has been provided by the Westinghouse Electric Coporation's safety analysis report on the Diablo Canyon plants, and the review of this SAR by USNRC staff and consultants [33]. In this report, a review of three of the four competing methodologies were applied and compared -- plastic instability, Paris crack growth law, and d.J/da. In many cases, the experimental data supporting the applications was used well beyond 
their range of validity, but the work represents the cutting edge of the state of the art. Non-linear and quasi-linear analysis were used to establish the strain and stress intensity ranges for postulated flaws, and limit capacity was calculated for some flawed cross sections. Shakedown has since been demonstrated for the nominal stress states in order to justify the use of simplied quasi-linear methods.

In effect, these calculations are the principal evidence that the ACRS has heard to date. The only major shortcoming in the methodology is the crack growth data itsolf, not the analytical procedures. Unfortunately, the analysis is only useful when exercised in a confirmatory manner with respect to a valid crack growth theory, and comparing analyical predictions with numbers obtained from Extrapolated data does not constitute confirmation.

A more meaningful approach would involve a postulated failure thoery valid for both monotonically increasing and cyclic loading. The theory should be valid for both computationally testing against notched bar, Charpy V-Notch, and other tests that produce a damaged volume ahead of a strain concentration. Examples of theories that at least partially satisfy these requirements are plentifut, with one of the most promising being the ductile void nucleation, growth, and coalescence model of McClintock [34], Rice and Tracy [35], Hancock and McKenzie [36], Norris, et. a). [37], and most recently Curran, et. a1. [38]. When adapted for cyclic loading and for possible time dependant effects (e.g., corrosion-assisted fatigue crack growth), the model may be able to account for all of the ACRS concerns -namely, the intergranular craci growth acceleration, due to corrosion, that plagues many class 2 components, and the cyclic crack growth, due to large scale yielding that tends to be of concern for Class 1 components under SSE loading.

\subsection{SUMMARY OF NON-LINEAR ANALYSIS APPLICATIONS IN LWR DESIGN}

The impact of non-linear analysis on LWR design practice has been quantitatively demonstrated on a selective basis in the course of this study. Conclusions drawn from the specific cases presented in this report and 
extended to other areas of application are judged to be valid at least qualitatively. A summary of these conclusions and the general state of applicability of non-linear analyses in LWR systems and components design is contained in Table 4. Four major categories are considered in this summary, namely, analytical modeling, computational requirements, state of development and potential benefits. This summary table provides a matrix of self explanatory abbreviated descriptions of each category and each target area. For ease of reference, the target areas identified in Table 4 are the same as in Table 1, the summary table for Part 1 of this report.

The analytical modeling category of Table 4 deals with the basic material properties presently available for analysis, the constitutive models which utilize these properties, and the kinematic (strain-displacement) relations employed in the governing equations.

The computational requirenents category deals with the spatial (two- and three-dimensional) idealization and the time-dependent aspects of the solution - whether the analysis is dynamic as in vibration and seismic analyses, or quasi-static as in incremental loading analyses.

The state of development category describes currently acceptable practice and points out areas of needed new developments and improvements.

The fourth category in Table 4 deals with the potential benefits that could be gained from introducing non-linear methodology in LWR design practice. Some of these benefits have already been demonstrated in the course of the present study. 
TABLE 4 - SUMMARY OF NON-LINEAR ANALYSIS APPLICATION

\begin{tabular}{|c|c|c|c|c|c|c|c|c|c|}
\hline \multirow[b]{2}{*}{ TARGET AREA } & \multicolumn{2}{|c|}{ Modeling Requirements } & \multicolumn{2}{|c|}{ Computational Requirements } & \multicolumn{2}{|c|}{ State of Development } & \multicolumn{3}{|c|}{ Potential Benefits } \\
\hline & MAT. DATA & ANALYT. MODELS & SPATIAL IDEALIZ. & TIME SOLUTION & CURRENT STATUS & NEEDED DEVELOPMENT & IMPACT & $\begin{array}{c}\text { GURRENT } \\
\text { TOOLS } \\
\end{array}$ & $\begin{array}{l}\text { IMPROVED } \\
\text { TOOLS }\end{array}$ \\
\hline $\begin{array}{l}\text { Treatment of } \\
\text { Shakedown, } \\
\text { peak stress } \\
\text { under thermal } \\
\text { transients }\end{array}$ & $\mid \begin{array}{l}\text { piece-wise } \\
\text { linear stress } \\
\text { strain curve }\end{array}$ & $\begin{array}{l}\text { elastic-plastic, } \\
\text { von-Mises yield } \\
\text { criterion and } \\
\text { flow rule, kine- } \\
\text { matic hardening, } \\
\text { infintesimal de- } \\
\text { formations } \\
\end{array}$ & $\begin{array}{l}\text { two-dimensional } \\
\text { (plane and axisy- } \\
\text { mmetric), higher } \\
\text { order el ements }\end{array}$ & \begin{tabular}{|} 
incremental load- \\
ing, tangent stif- \\
fness approach \\
with Newton-Raph- \\
son interation, \\
transient heat \\
conduction
\end{tabular} & $\begin{array}{l}\text { widely available } \\
\text { reliable codes }\end{array}$ & $\begin{array}{l}\text { plastic fracture } \\
\text { methodology (2D \& } \\
\text { 3D) to predict cr- } \\
\text { ack propagation in } \\
\text { global plasticity } \\
\text { non-radial loading }\end{array}$ & $\begin{array}{l}\text { improved SAR } \\
\text { documenta- } \\
\text { tion, enhan- } \\
\text { ced licens- } \\
\text { ability }\end{array}$ & $\begin{array}{l}\text { medium } \\
\text { to } \\
\text { high }\end{array}$ & high \\
\hline $\begin{array}{l}\text { Geometry im- } \\
\text { provements of } \\
\text { nozzles and } \\
\text { penetration } \\
\text { reinforcement }\end{array}$ & same as above & same as above & $\begin{array}{l}\text { mainly } 2 D \text {, same } \\
\text { as above, with } \\
\text { some } 3 D \text { analysis }\end{array}$ & same as above & same as above & $\begin{array}{l}\text { non-radial loading } \\
\text { plasticity, but cur- } \\
\text { rent state of the } \\
\text { art is adequate for } \\
\text { this analysis } \\
\end{array}$ & $\begin{array}{l}\text { improved SAR } \\
\text { documenta- } \\
\text { tion and noz- } \\
\text { zle manufac- } \\
\text { turability, } \\
\text { easier weld- } \\
\text { ing, more re- } \\
\text { liable inser- } \\
\text { vice inspec- } \\
\text { tion }\end{array}$ & high & high \\
\hline $\begin{array}{l}\text { Steam genera- } \\
\text { tor tube- } \\
\text { leaks, feed- } \\
\text { water } 1 \text { ine } \\
\text { cracks, crack } \\
\text { in heat sen- } \\
\text { sitized zones }\end{array}$ & $\begin{array}{l}\text { parent and } \\
\text { weld material } \\
\text { stress-strain } \\
\text { curves, str- } \\
\text { ain- rate } \\
\text { sensitivity }\end{array}$ & $\begin{array}{l}\text { same as above, } \\
\text { plus strain-rate } \\
\text { dependence of } \\
\text { stress-strain re- } \\
\text { lations }\end{array}$ & $\begin{array}{l}\text { 2D, special 3D } \\
\text { for thermal tran- } \\
\text { sient weld depo- } \\
\text { sition coupled } \\
\text { with stress } \\
\text { analysis }\end{array}$ & $\begin{array}{l}\text { transient heat } \\
\text { conduction with } \\
\text { incremental load- } \\
\text { ing, Newton-Raph- } \\
\text { son interation, } \\
\text { special treatment } \\
\text { of liquidus sol- } \\
\text { idus transition } \\
\text { states }\end{array}$ & $\begin{array}{l}\text { use of present } \\
\text { codes requires sp- } \\
\text { ecial care - may } \\
\text { be inadequate for } \\
\text { weld deposition } \\
\text { analyses }\end{array}$ & \begin{tabular}{|l|} 
plastic fracture, \\
effects of sensiti- \\
zation \& residual \\
stresses, improved \\
30 transient con- \\
duction-stress ana- \\
lysis tools for \\
weld deposition, \\
strain-rate sensiti \\
tive constitutive \\
relations
\end{tabular} & $\begin{array}{l}\text { improved } \\
\text { life predic- } \\
\text { tion, reduc- } \\
\text { ed down time } \\
\text { reduced field } \\
\text { repairs, im- } \\
\text { proved safe- } \\
\text { ty and licen- } \\
- \text { sability }\end{array}$ & medium & high \\
\hline $\begin{array}{l}\text { Buckling of } \\
\text { containment } \\
\text { shells }\end{array}$ & $\begin{array}{l}\text { piece-wise } \\
\text { linear stress } \\
\text { strain curves }\end{array}$ & $\begin{array}{l}\text { elastic-plastic } \\
\text { formulation as } \\
\text { above, finite de- } \\
\text { formation with } \\
\text { small strain } \\
\text { large displace- } \\
\text { ment formulation }\end{array}$ & $\begin{array}{l}\text { mainly 2D and } \\
\text { selected 3D } \\
\text { analyses }\end{array}$ & $\begin{array}{l}\text { elastic buckling } \\
\text { (eigenvalue so- } \\
\text { lution), elastic } \\
\text { plastic buckling }\end{array}$ & $\begin{array}{l}\text { buckling eigenval- } \\
\text { ue capabilities in } \\
\text { some codes, elas- } \\
\text { tic plastic buck- } \\
\text { ling codes gener- } \\
\text { ally available }\end{array}$ & $\begin{array}{l}\text { simplified proced- } \\
\text { ures to reduce cost } \\
\text { as is described in } \\
\text { section } 2.5 .2 \text { of } \\
\text { this report }\end{array}$ & $\begin{array}{l}\text { enhanced } \\
\text { safety and } \\
\text { licensabili- } \\
\text { ty, more re- } \\
\text { liable safe- } \\
\text { ty margins }\end{array}$ & high & high \\
\hline $\begin{array}{l}\text { Load combina- } \\
\text { tions for } \\
\text { Service level } \\
\text { D }\end{array}$ & same as above & $\begin{array}{l}\text { same as above, } \\
\text { including strain- } \\
\text { rate sensitivity } \\
\text { for LoCA type tr- } \\
\text { ansients, large } \\
\text { strain formula- } \\
\text { tion }\end{array}$ & $\begin{array}{l}\text { mainly } 20 \text { and } \\
\text { selected } 30 \\
\text { analyses }\end{array}$ & $\begin{array}{l}\text { quasi-static in- } \\
\text { cremental loading } \\
\text { dynamic, transient } \\
\text { heat conduction }\end{array}$ & $\begin{array}{l}\text { adequate state of } \\
\text { the art for most } \\
\text { applications, l im- } \\
\text { itations mentioned } \\
\text { above apply }\end{array}$ & $\mid \begin{array}{l}\text { all a bove mentioned } \\
\text { improvements are } \\
\text { needed depending on } \\
\text { type of event, also } \\
\text { constitutive rela- } \\
\text { tions valid in the } \\
\text { large strain }(20- \\
50 \%) \text { range } \\
\end{array}$ & $\begin{array}{l}\text { enhanced } \\
\text { safety, im- } \\
\text { proved post } \\
\text { accident an- } \\
\text { alyses }\end{array}$ & $\begin{array}{l}\text { medium } \\
\text { to } \\
\text { high }\end{array}$ & high \\
\hline $\begin{array}{l}\text { Load levels } \\
\text { for dynamic } \\
\text { loads \& seis- } \\
\text { mic events }\end{array}$ & $\begin{array}{l}\text { stress-strain } \\
\text { curves for } \\
\text { steels, con- } \\
\text { crete and } \\
\text { soils }\end{array}$ & $\begin{array}{l}\text { Drucker-Prager } \\
\text { yield potential } \\
\text { based on Mohr- } \\
\text { Coulumb failure } \\
\text { envelope for } \\
\text { soils, elastic } \\
\text { plastic formula- } \\
\text { tion for metals, } \\
\text { cracking models } \\
\text { for concrete } \\
\end{array}$ & $\begin{array}{l}20-30 \text { analyses } \\
\text { are very costly }\end{array}$ & $\begin{array}{l}\text { dynamic time in- } \\
\text { tegration }\end{array}$ & $\begin{array}{l}\text { soil-structure in- } \\
\text { teraction inade- } \\
\text { quate, mostly } \\
\text { based on non-l in- } \\
\text { ear springs, equi- } \\
\text { valent linear me- } \\
\text { thods or linear } \\
\text { wave propagation } \\
\text { (ID) codes }\end{array}$ & $\begin{array}{l}20 \text { finite el ement } \\
\text { based, large strain } \\
\text { soil-structure in- } \\
\text { teraction codes }\end{array}$ & $\begin{array}{l}\text { improved } \\
\text { safety, more } \\
\text { reliable } \\
\text { seismic si- } \\
\text { ting }\end{array}$ & high & $\begin{array}{l}\text { very } \\
\text { high }\end{array}$ \\
\hline $\begin{array}{l}\text { Criteria De- } \\
\text { velopment }\end{array}$ & $\begin{array}{l}\text { as noted } \\
\text { above }\end{array}$ & $\begin{array}{l}\text { all of the above } \\
\text { as needed }\end{array}$ & 2D only & $\begin{array}{l}\text { quasi-static in- } \\
\text { cremental loading } \\
\text { dynamic and tran- } \\
\text { sient heat con- } \\
\text { duction as needed }\end{array}$ & $\begin{array}{l}\text { all of the above } \\
\text { comments apply }\end{array}$ & $\begin{array}{l}\text { as noted above ac- } \\
\text { cording to need }\end{array}$ & $\begin{array}{l}\text { all of the } \\
\text { above }\end{array}$ & high & $\begin{array}{l}\text { very } \\
\text { high }\end{array}$ \\
\hline
\end{tabular}




\section{ATTACHMENT I}

San Onofre $2 \& 3$ FSAR

3.9 MECHANICAL SYSTEMS AND COMPONENTS

3.9.1 SPECIAL TOPICS FOR MECHANICAL COMPONENTS

\subsubsection{Design Transients}

The following information identifies the transients used in the design and fatigue analysis of ASME Code Class 1 components, reactor internals and component supports. Cyclic data for the design of ASME Code Class 2 and 3 components, as applicable, are discussed in subsection 3.9.3. All transients are classified with respect to the component operating condition categories identified as normal, upset, emergency, faulted, and testing as defined in the ASME Boiler and Pressure Vessel Code, Section III, Division 1. The transients specified below represent conservative estimates for design purposes only and do not purport to be accurate representations of actual transients, or necessarily reflect actual operating procedures; nevertheless, all envisaged actual transients are accounted for, and the number and severity of the design transients, exceeds those which may be anticipated during the life of the plant.

Pressure and temperature fluctuations resulting from the normal, upset, emergency and faulted transients are computed by means of computer simulations of the reactor coolant system, pressurizer, and steam generators. Design transients are detailed in the equipment specifications. The component designer then uses the specification transient curves as the basis for design and fatigue analysis.

In support of the design of each Code Class 1 component, a fatigue analysis of the combined effects of mechanical and thermal loads is performed in accordance with the requirements of Section III of the ASME Boiler \& Pressure Vessel Code. The purpose of the analysis is to demonstrate that fatigue failure will not occur when the components are subjected to typical dynamic events which may occur in the power plant.

The fatigue analysis is based upon a series of dynamic events depicted in the respective component specifications. Associated with each dynamic event is a mechanical, thermal-hydraulic transient presentation along with an assumed number of occurrences for the event. The presentation is 
MECHANICAL SYSTEMS AND COMPONENTS

generally simple and straightforward, since it is meant to envelop the actual plant response. The intent is to present material for purposes of design. A best-estimate representation of the expected plant dynamic response is neither intended nor appropriate.

Similarly, the characterization of a given dynamic event with a specific name is unimportant. Any plant dynamic occurrence with consequences which fall within the envelop associated with one of these dynamic events is by definition represented by that dynamic event. The fundamental concept is to ensure that the consequences of the normal and upset conditions which are expected to occur in the power plant are enveloped by one or more of the dynamic event portrayals in the component specifications. The number of occurrences selected for each dynamic event is considered to be conservative, so that in the aggregate, a 40 year useful life will be provided by this design process.

Design load combinations for ASME Code Class 1,2 , and 3 components are given in subsection 3.9.3 (tables 3.9-8 and 3.9-10). Design loading combinations for reactor internal structures are presented in paragraph 3.9.5.2.

The principal design bases of the reactor coolant system (RCS) and reactor internal structures are given in section 5.2 and subsection 3.9.5, respectively.

Table 3.9-1 summarizes the transients to be used in the stress analysis of Code Class 1 components. Additional specific component transients for the reactor coolant pumps, steam generators, reactor coolant piping, and the pressurizer are provided in subsections 5.4.1, 5.4.2, 5.4.3, and 5.4.10, respectively. The basis for the transients is indicated, and the number of occurrences specified is to provide a system/component design that will not be limited by expected cyclic operation over the life of the plant. The number of occurrences is generally based on a once/day, once/week, once/month, etc., type of evaluation. It is expected that the frequency of cyclic transients will be greater than design at the beginning of plant life and significantly less than design after the first year of operation with cumulative occurrences 


\section{MECHANICAL SYSTEMS AND COMPONENTS}

less than design values. System integrity is further assured by using conservative methods of predicting the range of pressure and temperature for the transients. The list of transients is intended to include startup and shutdown operations, inservice hydrostatic tests, emergency and recovery operations, switching operations, and seismic events. An explanatory discussion of each transient is also given. The applicable operating condition category as designated by the ASME Code Section III is also indicated in each case.

The transients listed include allowance for less severe transients, such as rod withdrawal incident or boron dilution incident. The number of transients listed are believed to be far in excess of any number and severity that can be anticipated to occur during the life of the facility.

Pressure and thermal stress variations associated with the above design transients are considered in the design of supports, valves, and piping within the reactor coolant pressure boundary (RCPB).

In addition to the design transients listed above and included in the fatigue analysis, the loadings produced by the OBE and DBE were also applied in the design of components and support structures of the RCS. The $O B E$ and DBE are classified as upset and faulted condition events, respectively. For the number of cycles pertaining to the $O B E$, refer to paragraph 3.7.3.2. 
It is concluded that the seismic loadings specified for the design of the reactor coolant system components and supports are adequate.

\subsubsection{SEISMIC SUBSYSTEM ANALYSIS}

\subsubsection{Seismic Analysis Methods}

The seismic analysis methods used for Seismic Category I subsystems are discussed in Sections 3.0 through 6.0 of Bechtel Topical Report BC-TOP$4 A(5)$ and paragraph 3.7.3.14. Appendix 3.7B describes the methods used for seismic analysis of piping systems.

\subsubsection{Determination of Number of Earthquake Cycles}

3.7.3.2.1 Subsystems Other than the NSSS (Systems, Equipment and Components)

Procedures to determine the number of earthquake cycles for piping during seismic events are discussed in appendix 3.7B. Structures and equipment are designed on the basis of analytical results. In general, the design of structures and the majority of the equipment is not fatigue controlled, since most stress and strain reversals occur only a small number of times. The occurrence of earthquake and design basis accident ful1-design strains occurs too infrequently and with too few cycles to generally require fatigue design of structures.

The number of earthquake cycles to be used in the design of subsystems is dependent upon three parameters:

A. The significant frequency characteristics of the subsystem and/or supporting media.

B. The duration of the postulated seismic event.

C. The number of seismic events to which the plant might be subjected. 
A conservative estimate of the number of design cycles can be established by multiplying the numerical value of each of these three parameters together.

$$
N=n \cdot f \cdot d
$$

where:

$$
\begin{aligned}
N= & \text { number of earthquake cycles } \\
n= & \text { number of seismic events to be considered } \\
f= & \text { significant frequency characteristic of the subsystem and/or } \\
& \text { supporting media } \\
d= & \text { duration of the postulated seismic event }
\end{aligned}
$$

Further conservatism is introduced by applying the resulting number of design cycles to the maximum stress range even though most of the actual stress cycles are well below the maximum stress range.

In the application of equation (11) two occurrences of the OBE are assumed to occur over the life of the plant. The resulting number of design cycles is specified in the Design Specifications for the various subsystems.

\subsection{NSSS}

The procedure used to account for the fatigue effect of cyclic motion associated with the OBE recognizes that the actual motion experienced during a seismic, event consists of a single maximum or peak motion, and some number of cycles of lesser magnitude. The total or cumulative fatigue effect of all cycles of different magnitude will result in an equivalent cumulative usage factor. The equivalent cumulative usage factor can also be specified in terms of a finite number of cycles of the maximum or peak motion. Based on this consideration, Seismic Category I subsystems, components, and equipment are designed for a total of 200 full-load cycles about a mean value of zero and with an amplitude equal to the maximum response produced during the entire OBE event. 


\subsubsection{Procedure Used for Modeling}

General modeling techniques used for the remainder of the Seismic Category I subsystems are in accordance with the criteria specified in Section 3 of reference 5 . Such modeling incorporates either a multi-degree of freedom lumped-parameter technique or a finite-element modeling approach. The degree of complexity of the individual models is sufficient to define the dynamic behavior characteristics of the specific subsystem. Modeling of the attachment interface is consistent with the method of mounting the subsystem in its installed condition.

Modeling of internals, fuel assemblies and CEDMs is described in paragraph 3.7 .3 .14 .

\subsubsection{Basis for Selection of Frequencies}

Structural fundamental frequencies ("forcing frequencies") are not selected, but are calculated in accordance with Section 4.2 .1 of reference 5 and paragraph 3.7.3.14. 
Table 3.9-1

TRANSIENTS USED IN STRESS ANALYSIS OF CODE CLASS 1 COMPONENTS (Sheet 1 of 3)

\begin{tabular}{|c|c|}
\hline \multicolumn{2}{|r|}{ Normal Conditions } \\
\hline Occurrence & Conditions \\
\hline $\begin{array}{l}\text { Heatup and } \\
\text { cooldown cycles }\end{array}$ & $\begin{array}{l}500 \text { heatup and cooldown cycles during the design } \\
1 \text { ife of the components in the system. The rate } \\
\text { of heating and cooling is } 100 \mathrm{~F} / \mathrm{h} \text { between } 70 \mathrm{~F} \text { and } \\
545 \mathrm{~F} \text { except for the pressurizer which has a rate } \\
\text { of } 200 \mathrm{~F} / \mathrm{h} \text { between } 70 \mathrm{~F} \text { and } 653 \mathrm{~F} \text {. The heatup and } \\
\text { cooldown rate of the system is administratively } \\
\text { limited to assure that these limits will not be } \\
\text { exceeded. This condition is based on a normal } \\
\text { plant cycle of one heatup and cooldown per month } \\
\text { rounded up to the next highest hundred. }\end{array}$ \\
\hline Power changes & $\begin{array}{l}15,000 \text { power change cycles over the range of } 15 \% \\
\text { to } 100 \% \text { of ful1 } 10 \text { ad at a rate of } 5 \% \text { of full load } \\
\text { per minute either increasing or decreasing. }\end{array}$ \\
\hline $\begin{array}{l}\text { Normal cyclic } \\
\text { variations }\end{array}$ & $\begin{array}{l}10^{6} \text { step changes of } \pm 100 \mathrm{lb} / \mathrm{in} .^{2} \text { and }+10 \mathrm{~F}( \pm 20 \mathrm{~F} \\
\text { for surge line) when at operating conditions. } \\
\text { This condition is selected based on } 1 \text { million- } \\
\text { cycles approximating an infinite number of cycles } \\
\text { so that the limiting stress is the endurance } \\
\text { limit. Grouped together in these cycles are: } \\
\text { pressure variations associated with fluctuation } \\
\text { in pressurizer pressure between the setpoint for } \\
\text { actuation of the backup heaters and the opening } \\
\text { of the spray valves; temperature variations } \\
\text { associated with the CEA controller deadband; } \\
2,000 \text { step power changes of }+10 \% \text { of full load } \\
\text { assuming } 1 \text { cycle per week for } 50 \text { weeks of the } \\
\text { year. (Two weeks of the year are assumed } \\
\text { required for refueling.) }\end{array}$ \\
\hline
\end{tabular}


Table 3.9-1

TRANSIENTS USED IN STRESS ANALYSIS OF

CODE CLASS 1 COMPONENTS (Sheet 3 of 3 )

\begin{tabular}{|c|c|}
\hline \multicolumn{2}{|r|}{ Normal Conditions } \\
\hline Occurrence & Conditions \\
\hline $\begin{array}{l}\text { Primary system } \\
\text { hydrostatic }\end{array}$ & $\begin{array}{l}10 \text { primary side cycles from } 151 \mathrm{~b} / \mathrm{in}^{2} \text { to } \\
3,125 \text { 1b/in. } 2 \text { at a temperature between } 100 \mathrm{~F} \text { to } \\
400 \mathrm{~F} \text {. These cycles are based on one initial } \\
\text { hydrostatic test plus a major repair every } 4 \\
\text { years for } 36 \text { years which includes equipment } \\
\text { failure and normal plant cycles. The secondary } \\
\text { side of the steam generator is at atmospheric } \\
\text { pressure during this test. }\end{array}$ \\
\hline $\begin{array}{l}\text { Primary system } \\
\text { leak }\end{array}$ & $\begin{array}{l}200 \text { cycles from } 15 \mathrm{lb} / \mathrm{in}^{2} \text { a to } 2,250 \mathrm{lb} / \mathrm{in} .^{2} \mathrm{a} \text { at } \\
\text { a temperature between } 100 \mathrm{~F} \text { to } 400 \mathrm{~F} \text {. These cycles } \\
\text { are based on a normal plant maintenance operation } \\
\text { involving } 5 \text { shutdowns per year for } 40 \text { years. }\end{array}$ \\
\hline
\end{tabular}




\section{REFERENCES}

1 ASME Boiler and Pressure Vessel Code, 1977 Edition.

$\therefore$ Anon., "Criteria of the ASME Boiler and Pressure Vessel Code for Dasign by Analysis in Section III and VIII, Division L", ASME, NY, 1953.

3 Geraeen, T.C., "A Critical Evaluation of Plastic Behavior DAta dnj a Unified Definition of Plastic Loads for Pressure Components", PVRC Report (Draft), Apri1 9, 1979.

4 Edmunds, H.G., and F.J., Beer, "Notes on Incremental Collapse in Pressure Vessils", Jn1. Mech. Engineering Sci., Vol. 3, No. 3, 1961, pp. 187-199.

5 Leckie, F.A. and Penny, R.K., "Shakedown as a Guide to the Design of Prassure Vesse1s", ASME Paper No. 68-WA/PVP-8, Trans. ASME, JnT. of Engrg. for Ind.

6 Leckie, F.A. and R.K. Penny, "Shakedown Loads for Radidl Nozzles in Spherical Pressure Vessles", Int. J. Solids Structures, Vol. 3, 1907, pp. $743-75$ s.

7 Procter, E., and J.T. Strong, "Pressure Tests on Flush Cylinder/Cylinder Intersections. Elastic and Elastic/Plastic Benavior", Central Electricity Generating Board, Research Dept., Berkeley Nuclear Lab., Report RD/B/N2244, Feb. 1972.

3 Lewis, D.J. and R.H. Price, "A Shakedown Approach to the Reinforcement of Flusi Brancines in Cylindrical Pressure Vessels Below tne Creep Range", Ceritral Electricity Generating Board, Research Dept., Berikeley Nuclear Lab., Report RD/B/N2569, Fed. 1974.

9 Procter, E. and R.F. Flanders, "Experimental Investigation into the Elastic/Plastic Benavior of Isolated Nozzles in Spherical Shells, Part Il, Snakedown and Plasic Analysis", Central Electricity Generating Board, Research Dept., Berkeley Nuclear Lai., 1375.

10 Save, M.A. and C.E. Massonnet, "Plastic Analys is and Design of Plates, Siells and Disks", North Holland, Ty72, pp. 48-57.

11 W. Prager, "The Theory of Plasticity; A Survey of Recent Achievements", Proc. Inst. Mecn. Eng. 169, 1955, pp. 41.

12 Corum, J.M. et al., "Interim Guidelines for Detailed Inelastic Analysis of High Temperature React) s System Components", ORNL-5014, Dec. 1974, Jak Ridge National Lab., Oak Ridge, Tenn. 
13 Corum, J.M., "Appendix Material Property Data for Elastic-Plastic Creep Analyses of Benchmark Problems, Pressure Vessels and Piping", Verification and Qualification of Inelastic Analysis Computer Prograns. Second National Congress on Pressure Vessels and Piping, San Francisco, California, June 1975.

14 M.A. Eisenserg and A. Phillips, "On Non-Linear Kinematic Hardening", AcTA MECH. $\underline{5}, 1968$, pp. 1-13.

15 Y.R. Rasnid, "On Non-Linear Kinematic Hardening Plasticity Theory", Nuclear Engineering and Design, Vol. 29, No. 1, Nov. 1974.

1u Dames, Moore, and Science Applications, Inc., "Study of Non-Linear Effects on One-Dimensional Earthquake Response", EPRI NP-865, Aug. 1978.

i7 Sead, H.B. and Idriss, I.M., "Soil Moduli and Damping Factors for Dynamic Response Analyses", Report No. EERC 70-10, Earthquake Engineering Researci Center, University of California, Berkeley, Dec. 1970.

18 Drucker, D.C., and Prager, W., "Soil Mechanics and Plastic Analysis or Limit Design", Quart. App1. Math., Vol. 10, No. 2, 1952, pp. 157-ib5.

Iy Schnade 1, P.B., Lysmer, I., and Seed, H.B., "SHAKE--A Computer Program for Earthquake Response Analys is of Horizontally Layered Sites", Report No. EERC 72-12, Earthquake Engineering Research Center, University of California, Berkeley, Dec. 1972.

20 Rashid, Y.R., and Sharabi, M.N., "Analytical Methods for Transient Fuel Behavior-FREY Code Architecture", EPRI, Palo Alto, California, 1979.

21 Rasinid, Y.R., and Gilman, J.D., "Three Dimensional Analys is of Reactor Pressure Vessel Nozzles", - First International Conference on "Structural Mechanics in Reactor Tecnnology", Berlin, Germany, Sept. 1972.

22 Dupuis, G.A., Pfaffinger, D.D. and Marcal, P.V., "Effective Use of the Incremental Stiffness Matrices in Non-Linear Geometric Andlys is", Proceadings, IUTAM Symposium on High Speed Computing of Elastic Structures, Liege, Belgium, 1970.

23 Koiter, W.T., "Elastic Stability and Post-Buckling Behavior", Proceedings, Symposium on Nonlinear Prostems, Ed., R.E. Langer, liss.

24 Haftka, R.T., Mallett, R.H., and Nachbar, W., "Adaptation of Koiter's Method to Finite Element Analysis of Snap-Through Buckling Benavior", Int. J. Solius Struc., Vo1. 7, pp. 1427-1445, 1971.

25 Nagy, D.A., and Konig, M., "Geometrically Nonlinear Finite Element Benavior Using Buckling Mode Superposition", Comp. Meth. Appl. Mech. Engr., Vol. 19, pp. 447-484, 1979. 
Lo Ewing, D.J.F., "The Reduced Deflection Method' for Calculating Structural Buckling Loads", in: Non-Linear Problems in Stress Analysis, ed. by P. Stanley, Applied Science Publications Ltd., London, 1978, pp. 345-372.

Ll Kà, R., "Large Deformarion Elastic-Plastic Bucklling Analys is of Spherical Caps with Initial Imperfections", George Wasnington University Repori, Office of Naval Research Contract N0014-75-C-0946, May 1979.

28 Harvey, J.F., "Theory and Design of Modern Pressure Vessels, Second Edition, Van Nostrand Reininold Company, New York, 1974.

29 Appendix G, "Protection Against Nonductile Failure", ASME Boiler and Pressure Vessel Code, Section III, ASME, New York, 1977.

30 Paris, P.C., "The Fracture Mechanics Approach to Fatigue", Syracuse University Press, 1964.

31 "Flaw' Evaluation Procedures in ASME Section XI", T. Marston, Ed., EPRI NP-719 SR, Aug. 1978.

32 Snin, C.F., Anarews, W.R., Wilkinson, J.P.D., and Kumar, V., "Crack Initiation and Growth Under Fully Plastic Conditions with Applications to Pressure Vessel Staels", Paper No. G 5/2, Smirt V, Berlin 1979.

33 Witt, F.J., Bamford, W.H., and Esselman, T.C., "Integrity of the Primary Piping Systems of Westinghouse Nuclear Power Plants During PJstulated Seismic Events", Report No. WCAP-9283, Westinghouse Electric Corporation, Pittsiurgn, March 1978.

34 McClintock, F.A., "A Criterion for Ductile Fracture sy Growth oí Holes", J. Appl, Mecn., Jine 1908, pp. 30̈3-37i.

35 Rice, J.R., and Tracey, D.M., "On the ductile Enlargement of Voids i:l Triaxial Stress Fields", J. Mech. Phys. Solids, pp. 201-217, June 1907.

31 Hancock, J.W., and Mackenzie, A.C., "Dn the Mechanism of Ductile Failurs in High-Strangth Steels Subjected to Multi-Axial Stress States", J. Mech. Phys. Solids, Vol. 24, pp. 147-169, 1976.

37 Norris, D.M., Jr., et al., "A Plastic-Strdin, Mean-Stress Criterion for Ductile Fracture", Paper No. 78-Mat-13, ASME, New York, 1978.

38 Curran, D.R., Seaman, L., Snockey, D.A., Das, D.C., and Burback, R.L., "Computational Modeling of Microstructural Ductile Fracture Processes in a 533B Pressure Vessel Steel", Paper No. G 6/4, Smirt V, Berlin, 1979.

39 Seide, P., Weingarten, V.I., and Masri, S.F., "Buckling Criteria and Application of Criteria to Design of Steel Containment She 11", Report to the U.S. Nuclear Regulatory Commission by International Structural Engineers, Glendale, California, March 1979. 
40 Hofmann, R., STEALTH, A Lagrange Explicit Finite-Difference Code for Solids, Structural, and Tnermohydraulic Analysis", EPRI NP-176, EPRI, Palo Alto, California, June 1976.

41 Hardin, B.D. and Drnevich, V.P., "Shear Modulus and Damping in Soils; 1. Measurement and Parameter Effects", J. of Soil Mech. and Foundations

Div., ASCE, Vol. 98, No. SM6, pp. 603-624, June 1972; "Design Equations and Curves", J. of the Soil Mesil. and Foundations Div., ASCE, Vol. 98, No. SM7, pp. 007-092, JuTy 1972. 
DISTRIBUTION :

TID-4500 Distribution UC-78 (197 copies)

M. P. Norin, Actg. Chief (5)

Safety and Quality Assurance Branch

Division of Nuclear Power Development

U. S. Department of Energy

B-107

Washington, DC 20545

J. Carlson

$\mathrm{B}-107$

U. S. Department of Energy

Washington, DC 20545

R. DiSalvo

Probabilistic Safety Analysis Staff

Mail Stop 3106

U. S. Nuclear Regulatory Commission

Washington, DC 20555

Arthur D. Little, Inc.

Acorn Park

Cambridge, MA 02140

Attn: P. D. Hilton

O'Donnell \& Associates, Inc.

241 Curry Hollow Road

Pittsburgh, PA 15236

Attn: Samuel Brown

ANATECH International Corp.

3344 North Torrey Pines Court

Suite 220

Lia T, IIa, CA 32037

Attn: Y. R. Rashid

T. L $\rightarrow$ dyre Engineering Services

303 Bear Hill Road

Waltham, MA 02154

Attn: P. P. Rajn

BDM Corporation

¿600 Yale Blvd., S. E.

Albuquerque, NM 87106

At ${ }^{+} n_{l}:$ R. C. Butler

URS/BLUME Engineers

130 Jessie Street

San Francisco, CA 94105

Attn: R. E. Scholl 
Distribution (cont'd):

EDS Nuclear Inc. (2)

220 Montgomery Street

San Francisco, CA 94104

Attn: R. J. Stuart

J. B. Mc Carthy

Center of Energy Studies

Bldg. 19, Lehigh University

Bethlehem, PA 18015

Attn: E. K. Levy

Southwest Research Institute

P. O. Drawer 28510

San Antonio, TX 78284

Attn: H. N. Abramson

Shelltech Associates

809 Tolman Drive

Stanford, CA 94305

Attn: G. V. Ranjan

Pressure Vessel Research Committee

345 East 47 th Street

New York, NY 10017

Attn: C. R. Felmley, Jr.

Aptech Engineering Services

745 Distel Drive

Los Altos, CA 94022

Attn: G. R. Egan

Robert L. Cloud Associates, Inc.

2972 Adeline Street

Berkeley, CA 94703

C-E Power Systems

Combustion Engineering, Inc.

1000 Prospect Hill Road

Windsor, CT 06095

Attn: D. W. Stuteville

Nuclear Division (3)

ORNL

P. O. BOX Y

Oak Ridge, TN 37830

Attn: G. D. Whitman

W. L. Greenstreet

S. E. Moore

Structural Mechanics Associates, Inc.

4740 Von Karman

Newport Beach, CA 92660

Attn: R. P. Kennedy 
Distribution (cont'd):

General Electric Co.

Nuclear Energy Engineering Division

175 Curtner Avenue

San Jose, CA 95125

Attn: Edward Kiss

Engineering Decision Analysis Co., Inc.

2400 Michelson Drive

Irvine, CA 92715

Attn: R. D. Campbell

Ebasco Services, Inc.

2 Rector Street

New York, NY 10006

Attn: W. S. Mott

Hibbitt \& Karlsson, Inc.

132 George M. Cohan Blvd.

Providence, RI 02903

Attn: H. D. Hibbitt

Stone \& Webster Engineering Corp.

245 Summer Street

Boston, MA 02107

Attn: G. H. East, Jr.

Electric Power Research Institute

P. O. Box 10412

Palo Alto, CA 94304

Attn: Conway Chan

Argonne National Laboratory

9700 South Cass Avenue

Argonne, IL 60439

Attn: S. H. Fistedis

Westinghouse Electric Corp.

Nuclear Equipment Division

P. O. Box 355

Pittsburgh, PA 15230

Attn: G. J. Bohm

Westinghouse Nuclear Technical Division

Penn Ctr, Bldg. 2

P. O. Box 355

Pittsburgh, PA 15230

Attn: S. Palusamy

Foster Wheeler Energy Corp.

110 South Orange Avenue

Livingston, NJ 07039

Attn: D. H. Pai 
Distribution (cont'd):

Babcock \& Wilcox Co.

P. O. Box 1260

Lynchburg, VA 24505

Attn: James Galford

Babcock \& Wilcox Co.

Route 69

Nt. Vernon, IN 47620

Attn: C. W. Bruny

Bechtel Power Corp.

P. O. Box 3965

San Francisco, CA 94119

Attn: Randy Broman

Nuclear Services Corp.

1700 Dell Avenue

Campbell, CA 95008

Attn: Douglas Munson

Burns \& Roe, Inc.

305 Route 17

Paramus, NJ 07652

Attn: J. B. Mahoney

Babcock \& Wilcox Co.

Barberton, OH 44203

Attn: J.R. Farr

Battelle-Columbus Laboratories

506 King Avenue

Columbus, OH 43201

Attn: E. C. Rodabaugh

4400 A. W. Snyder

4440 G. R. Otey

4442 W. A. Von Riesemann

4442 E-P Chen

4443 H. Jones (50)

5520 T. B. Lane

8266 E. A. Aas

3141 T. L. Werner (5)

3151 W. L. Garner (3)

For DOE/TIC (Unlimited Release) 